\title{
Effects of macrophage activation and galectin-3 expression in hypertension-induced cardiac dysfunction
}

Citation for published version (APA):

Sharma, U. C. (2005). Effects of macrophage activation and galectin-3 expression in hypertensioninduced cardiac dysfunction. [Doctoral Thesis, Maastricht University]. Universiteit Maastricht. https://doi.org/10.26481/dis.20051221us

Document status and date:

Published: 01/01/2005

DOI:

10.26481/dis.20051221us

Document Version:

Publisher's PDF, also known as Version of record

Please check the document version of this publication:

- A submitted manuscript is the version of the article upon submission and before peer-review. There can be important differences between the submitted version and the official published version of record.

People interested in the research are advised to contact the author for the final version of the publication, or visit the DOI to the publisher's website.

- The final author version and the galley proof are versions of the publication after peer review.

- The final published version features the final layout of the paper including the volume, issue and page numbers.

Link to publication

\footnotetext{
General rights rights.

- You may freely distribute the URL identifying the publication in the public portal. please follow below link for the End User Agreement:

www.umlib.nl/taverne-license

Take down policy

If you believe that this document breaches copyright please contact us at:

repository@maastrichtuniversity.nl

providing details and we will investigate your claim.
}

Copyright and moral rights for the publications made accessible in the public portal are retained by the authors and/or other copyright owners and it is a condition of accessing publications that users recognise and abide by the legal requirements associated with these

- Users may download and print one copy of any publication from the public portal for the purpose of private study or research.

- You may not further distribute the material or use it for any profit-making activity or commercial gain

If the publication is distributed under the terms of Article $25 \mathrm{fa}$ of the Dutch Copyright Act, indicated by the "Taverne" license above, 


\section{Effects of Macrophage Activation and}

Galectin-3 Expression in Hypertension-

\section{Induced Cardiac Dysfunction}

Umesh C Sharma 
The studies presented in this thesis were performed at the Experimental and Molecular Cardiology Laboratory. Department of Cardiology, Cardiovascular Research Institute Maastricht (CARIM) and Hypertension and Vascular Research Division, Henry Ford Hospital, Detroit, Michigan, USA.

Copyright Umesh C Sharma, Maastricht 2005

No part of this book may be reproduced in any form without the prior written permission from the author. 


\section{Effects of Macrophage Activation and}

\section{Galectin-3 Expression in Hypertension-}

\section{Induced Cardiac Dysfunction}

\section{PROEFSCHRIFT}

ter verkrijging van de graad van doctor aan de Universiteit Maastricht, op gezag van de Rector Magnificus,

Prof. mr. G.P.M.F. Mols

volgens het besluit van het College van Decanen,

in het openbaar te verdedigen

op woensdag 21 December 2005 om 12.00 uur

door

Umesh Chandra Sharma

Geboren te Okhatari, Nepal 
Promotor:

Prof J.G. Maessen

Co-Promotons.

Dr. YM, Pinto

Prof O.A. Carretero (Case Western Reserve University/Henry Ford Hospital, USA)

Beoondelingscommissie:

Prof. M.H.J. Brouwer (Academic Hospital Nijmegen, The Netherlands)

Prol. H.J.G.M. Crijns (Voorzitter)

Prof. M.J.A.P. Daemen

Prof. Hans-J Gabius (Ludwig-Maximilians University, Munich, Germany)

Prof. J.F. Smits

financial support by the Netherlands Heart foundation for the publication of this thesis is gratefully acknowledged. Additional support to print this thesis was granted by RESCAR foundation. 


\section{Contents}

Chapter 1

General introduction and aims of the thesis

Chapter 2

A systematic review of large scale and heterogeneous gene array data in heart failure

Chapter 3

Identification of novel immunological and matrix-related genes in heart failure and effects of early Angiotensin-II receptor blockade

Chapter 4

Galectin-3 marks activated macrophages in failure-prone hypertrophied hearts and contributes to cardiac dysfunction

Chapter 5

Real-time in vivo imaging of apoptotic cell membrane changes in monocytes and macrophages

Chapter 6

Presence of cardiomyopathy and anti-heat shock protein- 47 autoantibodies afer macrophage depletion in hypertensive rats

Chapter 7

Mice lacking Galectin-3 exhibit preserved cardiac function and decreaged fibrosis following Angiotensin_II infusion

Chapter 8

General discussion and future directions

Summary

Samenvatting

Acknowledgements

Curriculum Vitae

List of Publications 
To my family and friends 


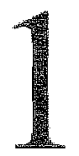

Introduction and aims of the thesis 


\section{Introduction}

Although the pathophysiological importance of myocardial inflammation was reported as early as in $1669^{\prime}$, the formal recognition that inflammatory mediators were activated in the setting of HF did not occur for another three centuries. Since the sentinel description of inflammatory cytokines in patients with HF in $1990^{2}$, there has been a growing interest in the role that these molecules play in regulating cardiac structure and function, particularly regarding their potential role in disease progression in $\mathrm{HF}^{3,4}$. A failing myocardium is often accompanied by infitration of inflammatory cells, local and systemic cytokine production and expression of genes that encode extracellular matrix (ECM) and embryonic proteins ${ }^{5-8}$. Consequently, myocardial damage and fibrosis are the uniform accompaniments when a chronically overloaded myocardium has progressed to failure. Despite the advances in the understanding of cellular biology of myocyte hypertrophy, the same for cardiac fibrosis remains to be defined.

\section{Renin-transgenic rats as the model of hypertension-induced heart failure}

Hypertension is a polygenic condition in which blood pressure is enigmatically elevated; it remains a leading cause of cardiovascular disease and death due to stroke, heart failure and kidney disease. Angiotensin II is one of the important triggers for macrophage infiltration, both in experimental animals and humans. In addition to its long-known blood pressure regulatory and fluid hemostatic effects, an active renin-angiotensin system (RAS) can induce a potent tissue inflammatory response 9,10 . The effectiveness of pharmacological antagonists of RAS in cardiovascular diseases has been attributed primarily to inhibition of inflammation and matricellular growth ${ }^{5,1,12}$. Angiotensin II, acting through ATl receptors, is reported to stimulate the production of inflammatory mediators such as TNF $-\alpha$, TGF $-\beta$ and MCP- $-\rrbracket^{12,13}$.

The genes for several of the proteins involved in blood pressure homeostasis have been cloned and characterized, including those of the renin-angiotensin system, which plays a central part in blood pressure control. In 1990, Mullins and colleagues described the introduction of the mouse Ren-2 renin gene into the genome of the rat and demonstrated that expression of this gene causes severe hypertension ${ }^{14}$. These transgenic animals then proved to be unique model for hypertension. In 1995 , Villarreal and colleagues also reported that Ren-2 transgenic rats develop fulminant lhypertension as a consequence of the overexpression of the mouse renin gene ${ }^{15}$. The authors suggested that these animals also develop cardiac hypertrophy and perivascular fibrosis. Given the broad functionality of renün-angiotensin-system activation in hypertension, cardiac hypertrophy and HF, we chose 
Introduction and aims

TGR(mRen2)27 (Ren-2) rats as the most suitable experimental model to profile the myocardial gene expression and investigate the mechanisms of hypertension-induced cardiac failure. In our experience, these rats rapidly develop $\mathrm{HF}$ and nearly $50 \%$ succumb to death by 3 months of age ${ }^{16}$. Nevertheless, the survival goes significantly up following the administration of either angiotensin converting enzyme (ACE) inhibitors ${ }^{17}$ or transforming growth factor $\beta$ antagonists ${ }^{18}$.

\section{Microarray technology to identify HF susceptibility genes in hypertensive Ren-2 rats}

Year 2005 marks the $10^{\text {th }}$ anniversary of the discovery of microarray technology. The number of publications employing microarray has undergone an exponential growth since its inception in 1995. The first article by Schena et al. that described the techniques of quantitative monitoring of gene expression patterns with cDNA microarray has been cited over 1200 times ${ }^{19}$. Furthermore, a search for the published literature using the keywords "microarray(s)" or "DNA/gene chip" yields over 13000 articles. Currently, there are over a dozen studies that investigated the gene expression profile in failing hearts ${ }^{20}$.

Heart failure is not a single disease entity, but a syndrome with various causes, including hypertension, ischemic, valvular and congenital heart diseases, cardiomyopathy, and myocarditis. Because of the multiple etiologies and secondary adaptations contributing to heart failure, the study of the cellular and molecular mechanisms underlying the development and progression of this syndrome has been rather challenging ${ }^{21}$. Much has been learned about the remodeling processes in heart failure, which involve complex interactions among numerous mediators in signaling and regulatory pathways ${ }^{22}$. The Human Genome Project and related projects have provided a preliminary database for a genone-wide analysis of complex polygenic disorders such as heart failure. With the aid of expressed sequence tag technology and microarray applications, both known and previously uncharacterized genes involved in the induction or regression of cardiac hypertrophy and its progression to heart failure can be analyzed simultaneously ${ }^{20}$. Deciphering the complexity of sequence-structure-function relationships in heart failure is a goal for the future, and will require advances in structural biology, proteomics, and computational technology.

Traditional gene expression studies typically focus on one or a few genes of interest. An important limitation of single-gene studies is that they present a portrait of disease that is essentially static. However, disease is a dynamic process, driven by a combination of genetic, epigenetic and environmental factors. Recently, genomic technologies have permitted better characterization of the 
dynamic aspect of disease progression. The microarray technology makes it possible to simultaneously study the expression of thousands of HF-related genes during a single experiment. The striking question of how to get the concerted expression so many genes in one picture, has been pondering for years. Traditional methods work on one gene at a time, which is time consuming and costly. The ingenuous idea of microarrays created a solution to this problem ${ }^{19}$.

This thesis focuses on the gene expression pattern observed in a Ren- 2 rats that constitute unique model of hypertension, left ventricular hypertrophy and varying propensity to develop acute HF. The Ren-2 rats are severely hypertensive, unless treated with angiotensin converting enzyme (ACE) inhibitors or angiotensin II receptor blockers (ARB). Consequently, all the transgenic rats develop left ventricular hypertrophy. However, these rats then diverge to yield two entirely different pathological states: HF or compensated hypertrophy. We employed microarray strategies to discern the differentially expressed genes involved in HF development in this model.

\section{Role of macrophages in the regulation of immune response in the hearts}

The mechanisms that explain the progressive dysfunction of the failing myocardium remain largely unknown. An imbalance of immune mediators together with inappropriate enhancement of proinflammatory cytokines or even reduction of anti-inflammatory mediators have recently been recognized to play an important role in the pathophysiology of cardiac diseases, not only in acute disorders like viral myocarditis but also in chronic conditions such as congestive $\mathrm{HF}^{23}$. Macrophages play an important role in innate and adaptive immunity by internalizing and degrading pathogens. They recognize pathogens that are opsonized by specific antibodies, through specific receptors, such as Fey receptors (FcyR's) or complement receptor-3 (CR3). Ligation of these receptors is accompanied by activation of specific signaling pathways and cytoskeletal changes, such as filamentous actin redistribution, as well as production of superoxide anion, proinflammatory cytokines, and chemokines such as TNF- $\alpha$, interleukin 1 (IL-1), and IL- $8^{24}$. Activated macrophages are known to produce galectin-3 (Mac-2), a $30 \mathrm{kDa}$ carbohydrate-binding protein that has proinflammatory, chemotactic and pro-fibrotic activity ${ }^{25-27}$.

The development of HF includes phenotypic changes in a host of homeostatic systems so that, as the disease advances, HF may be seen as a multi-system disorder with its origins in the heart but embracing many extra-cardiac manifestations ${ }^{28,29}$. Immunological abnormalities are recognized in this context, in particular, changes in the expression of mediators of the innate immune response. 
Higher llevels of various macrophage-derived pro-inflanmatory cytokines like interleukin-6 and tumor necrosis factor (TNF) are found in the circulation and in the myocardium of patients with HF than in controls, and these cytokines have been implicated in a number of pathophysiological processes that are thought important to the progression of $\mathrm{HF}^{28}$. Therapies directed against these cytokines therefore represent a novel approach to heart failure management. Anti-TNF strategies in CHF may target the mechanisms of immune activation, the intracellular pathways regulating cytokine production, or the fate of these cytokines once they have been released into the circulation ${ }^{4}$. Several established pharmacological therapies for patients with $\mathrm{HF}_{\text {, including }}$ angiotensin converting enzyme inhibitors, beta-blockers, and phosphodiesterase inhibitors may modify the cytokine milieu locally in the heart and in circulation ${ }^{30}$.

\section{Galectin-3 is a macrophage derived cytokine with diverse biological functions}

Galectins are a family of animal lectins with affinity for beta-galactosides. They are differentially expressed by various immune cells and their expression levels appear to be dependent on cell differentiation and activation. They can interact with cell-surface and extracellular matrix glycoconjugates (glycoproteins and glycolipids), through lectin-carbohydrate interactions ${ }^{3 !}$. Through this action, they can promote cell growth, affect cell survival, modulate cell adhesions, and induce cell migration ${ }^{32}$. They appear to do so by binding to different glycoconjugates decorated by suitable saccharides, rather than through specific receptors ${ }^{33}$. Galectins do not have a classical signal peptide and are often localized in intracellular compartments, including the nucleus ${ }^{34}$. Intracellularly, they can regulate cell growth and surwival by interacting with cytoplasmic and nuclear proteins, through protein-protein interactions, thereby affecting intracellular signaling pathways $^{33}$. Current research indicates that galectins play important roles in the immune response through regulating the homeostasis and functions of the immune cells.

Galectin-3 is secreted by various cell types, mainly monocytes and activated macrophages ${ }^{27}$. This is a $30 \mathrm{kDa}$ protein and a member of the galectin family, a group of carbohydrate-binding proteins with a specific amino-acid sequence able to recognize beta-galactose. Within this family, galectin-3 is unique in structure; rather than consisting of merely one or two carbohydrate-recognition domains (CRD), galectin-3 consists of tandem repeats of short amino-acid stretches fused onto the CRD. After macrophage activation, cytosolic galectin-3 shifts to the plasma membrane and integrates in vesicles extruding from the plasma membrane ${ }^{33,35}$. 
The released galectin 3 can function as an extracellular molecule to activate cells, mediate cell-cell and cell-ECM interactions, and induce migration of monocytes, macrophages, and endothelial cells, probably by binding to pertinent receptors through lectin-carbohydrate interactions ${ }^{33,35}$. More recently, cell surface galectin-3 was implicated in restricting $T$ cell receptor clustering and thus negatively regulating $\mathrm{T}$ cell activation ${ }^{36}$. This protein is also abundant inside cells and has been shown to play important roles in some biological responses tlarough its intracellular actions. For example, it has been identified as a factor in pre-mRNA splicing and as a regulator of the cell cycle and apoptosis, although the precise mechanisms of action are still undetermined ${ }^{33,35,37}$. Extracellularly, galectin-3 regulates cell adhesion with homo- and heterotypic cell-to-cell interaction $^{38}$, whereas it down-regulates cell adhesion to the $\mathrm{ECM}^{39}$. Extracellular galectin-3 also binds with $\operatorname{lgE}$ receptors facilitating mast cell activation ${ }^{40}$. Galectin-3 is also involved in a highaffinity binding, internalization and degradation of advanced glycosylation end-products ${ }^{41}$.

\section{Fibrosis, a common pathway to organ failure: angiotensin II and tissue repair}

Collagen type $I$ is the major fibrillar collagen produced by fibroblasts and myofibroblasts in the adult heart. Fibrillar collagen of the heart provides the structural scaffolding for cardiomyocytes and coronary vessels and imparts cardiac tissue with physical properties that include stiffness and resistance to deformation ${ }^{5}$. In addition, fibrillar collagen may also act as a link between contractile element of adjacent cardiomyocytes and as a conduit of information that is necessary for cell function. As in other organs, the fibrillar collagen turnover of normal adult heart results from the equilibrium between the synthesis and degradation of collagen $\mathrm{I}^{7}$. A number of factors have been described that may alter the balance in favor of either the synthesis (e.g., angiotensin II) or the degradation ${ }^{7}$. Predominance of synthesis over degradation leads to increased collagen I deposition or fibrosis that accompanies cardiac diseases such as hypertensive heart disease. Fibrosis alters myocardial structure and function and adversely affects the clinical outcome of hypertensive patients ${ }^{5}$.

For heart, kidneys, lungs and liver alike, fibrosis represents a common pathway to their failure. Understanding pathophysiologic mechanisms involved in organ fibrosis are therefore of considerable interest, particularly given the potential for protective pharmacological strategies. Tissue repair involves inflammatory cells, including members of the monocyte/macrophage lineage, integral to initiating the repair process; and myofibroblasts, phenotypically transformed interstitial tibroblasts, responsible for collagen turnover and fibrous tissue formation. Each of these cellular 
events in the microemironment of repair is often associated with molecular events that letad to the de novo generation of angiotensin $\mathbf{I}^{5}$. In an autocrine/paracrine/endocrine manner; angiotensin II regulates expression of TGF-beta 1 via angiotensin (ATI) receptor-ligand binding?. In addition, angiotensin II contributes to phenotypic conversion of fibroblasts to myofibroblasts and regulates myofibroblast turnower of collagen. Angiotensin-converting enzyme (ACE) inhibition or ATI receptor antagonism each prevent many of these molecular and cellular responses that eventuate in fibrosis and therefore have been found to be protective interventions ${ }^{42}$.

\section{Early growth regulator-1 is a transcription factor for collagen I}

The early growth response gene, Egr-1 is a nuclear transcription factor known to serve as an intermediary in a broad range of signal transduction processes. A recent study showed that angiotensin II and other growth factors implicated in ventricular hypertrophy and cardiac fibrosis are associated with the induction of $E g r-1$ gene ${ }^{43}$. Other studies have assigned $E g r-1$ a new role as an amplifier of gene expression ${ }^{44}$. Egr-l mRNA is expressed in the myocardium and is rapidly induced in response to hypertrophic stimuli. $E g r-l$ gene expression is rapidly induced by mitogens or mechanical injury to fibroblasts via mitogen- and stress-activated protein kinases ${ }^{45}$.

The biosynthesis of the zinc finger transcription factor $E g r-l$ is stimulated by many extracellular signaling molecules including hormones, neurotransmitters, growth and differentiation factors, and cytotoxic metabolites. The 5 -flanking region of the Egr-1 gene contains elements that are essential in connecting stimulation of the cells with enhanced transcription of the $E g^{-} / g^{\prime} e^{4}$ and subsequently, transcription of Egr-l-responsive genes. Thus, Egr-l links cellular signaling cascades with changes in the gene expression pattern ${ }^{44}$.

In human fibrosarcoma cells, $E g r-I$ directly transactivates the genes encoding fubronectin and transforming growth factor- $\beta 1$. In a recent study, Alexander and associates transfected synowial fibroblasts with 2 different $E g r-1$ expression vectors and showed that $E g r-1$ can contribute to fibrosis by activating the genes encoding the $\alpha 1$ and $\alpha 2$ chains of type $I$ collagen. In addition, $E g r-I$ caused a pronounced increase in platelet-derived growth factor $\beta 1$ expression ${ }^{46}$. However, other studies have shown that Egr-1 represses the transcription of collagen type $11^{47}$.

\section{Conclusions}




\section{Chapter 1}

It is known that macrophages are attracted to failing hypertensive hearts and there is a systenic surge of various cytokines in $\mathrm{HF}$. However, the underlying mechanisms how the activated macrophages contribute to the development of cardiac dysfunction are not known. Equally, the question whether macrophages are causative to or protective against the development of cardiac: dysfunction still remains to be answered. The current thesis, we tested the general hypothesis that macrophages (and its mediators like galectin-3 and Egr-l) participate in the progression from hypertrophy to HF. 


\section{The aims of this thesis}

1. To investigate the molecular mechanisms of cardiac fibrosis and failure

2. To identify novel immunological mediators that can yield clinically useful markers for the early recognition of faillure-prone hearts

3. To suggest the new pathways that can be therapeutically targeted in hypertension-induced cardiac hypertrophy and heart failure (HF)

\section{The rationale for the aims}

Despite state-of-the art treatment, high blood pressure-induced HF is still a progressive disease characterized by high morbidity and mortality, suggesting that important disease causing mechanisms remain active and unmodified by current treatment. A growing body of evidencelinks uncontrolled inflammatory response followed by reparative or replacement cardiac fibrosis to the development and progression of HF. Until recently, we did not have adequate knowledge on how the macrophage-derived factors participate in progressive deterioration of cardiac function and how we could combat cardiac fibrosis. The picture looked more blurred when some reports suggested that macrophages produce both pro- as well as anti-inflammatory cytokines. Similarly, many studies suggested that only fibrillar collagens contribute to the stiffening of the myocardium, whereas elastic forms are protective. It is very critical at this stage to figure out why high blood pressure damages the heart, how the scar formation starts, what underlying mechanisms participate during the transition from compensated hypertrophy to heart failure and more importantly, how it can be prevented. The central theme of this thesis is to identify the novel and previously unraveled HF-causative mechanisms that are activated in hypertrophied hearts, before HF can be clinically detected. This will aid us in the early detection of failure-prone hearts and initiation of appropriate treatment. 


\section{Refluteneses}

1. Lower R. Tractatus de Corde: De Motu Colore Sagnumus et Chyli in Eum Tranfiu. London. UK: Jacobi Allefiry. 1669 .

2. Levine B, Kalman J, Mayer L, Fillit HM, Packer M. Elevated circulaning levels of tumor necrosis factor in severe chronic theart fallure. N Engl Med 1990;323:236-41.

3. Diwan A, Trun T, Misra A, Mann DL. Inflammatory meduators and the failing heart: a translational approach. Cum Mol Med. 2003;3:161-82

4. Mann DL. Inflammatory mediators and the failing heart: past, present, and the foreseeable future. Cinc Res. $2002,91: 988-98$

5. Schnee MM, Hsueh WA. Angiotensin 11, adthesion, and cardiac fibrosis. Cardiovasc Res. 2000;46:264-8.

6. Weber KT. Extracellular matrix remodeling in heart failure: a role for de novo angiotensin II generation. Circularion. 1997;96:4065-82.

7. Weber KT, Sun Y, Guarda E. Structural remodeling in hypertensive heart disease and the role of hormones. Hyperension. 1994;23:869-77.

8. Pennica D, King KL, Shaw KJ, Luis E, Rullamas J, Luoh SM, Darbonne WC, Knutzon DS, Yon: $\mathbb{R}$, Chien KR, et al. Expression cloning of cardiotrophin 1, a cytokine that induces cardiac myocyte hypertrophy. Proc Natl Acad Sci U S A. 1995,92:1142-6.

9. Griendling KK, Lassegue B, Alexander RW. Angiotensin receptots and their therapeutic implications. Anms Rev Pharmacol Toxicol. 1996;36:281-306.

10. Timmermans PB, Wong PC, Chiu AT, Herblin WF Benteld P, Carini DJ, Lee RJ, Wexler RR, Saye IA, Smith RD. Angitotensin II receptors and angioterusin II receptor antagonists. Pharmacol Rey. 1993;45:205-51.

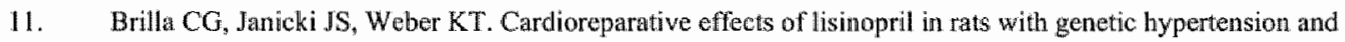
left ventricular hypertrophy. Circulation. 1991;83:1771-9.

12. Natarai C, Oliverio MI, Mannon RB, Mannon PJ, Audolly LP, Amuchastegui CS, Ruiz P, Smithies O, Coffman TM. Angiotensin II regulates cellalar immune responses through a calcineurin-dependent pathway. $J$ Clin Inwest, 1999:104:1693-701.

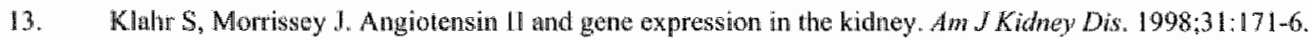

14. Mullins JJ, Peters J, Ganten D. Fulminant lypertension in transgenic rats hatbouring the mouse Ren-2 gene. Nature. $1990 ; 344: 541-4$.

15. Villarreal F. Mackenna DA, Onens HH, Dillmann WH. Myocardial remodeling in hypertensive Ren-2 transgentic mats. Hypertension. 1995;25:98-104,

16. Pinto $\mathrm{YM}_{n}$ Pinto-Sietsma SJ, Philipp T, Engler S, Kossamehl P, Hocher B, Marquardt H, Sethmann S, Lauster R, Merker HI, Paul M. Reduction in left ventricular messenger RNA for transforming growth factor beta( 1 ) attenuates len wentricular fibrosis and improves survivall without lowering blood pressure in the bypertensive TGR(mRen2)27 Rat. Mypertension. 2000:36:747-54.

17. Schroen B, Heymans S, Sharma U, Blankesteijn WM, Pokharel S, Cleutjens JP, Porter JG, Evelo CT, Duisters

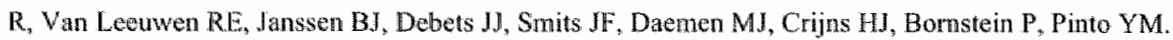

Thrombospondin-2 Is Essential for Myocardal Matrix Integrity. Increased Expression Identifies Failure-Prone Cardiac Hypertrophy. Circ Res. 2004 
18. Boer RA, Pokharel S, Flesch M, van Kamien DA, Sumrmeijer AJ, Boomsma F, van Gilst WH, van Veldhuisen DJ, Punto YM. Extracellular signal regulated kinase and SMAD signaling both mediate the angionangin II driven progression towards overt heart fahate in homozygons TGR(mRen2)27, J Mol Mad. 2004:82:678-87.

49. Schena $M$, Shaton $D$, Davis $R$ W, Brown PO. Quantitative monitoring of gene expression pattems with a complementary DNA microarray. Science. $1995 ; 270 ; 467-70$.

20. Sharma UC, Pokharel S, Evelo CT, Maessen IG. A systematic review of large scale and heterogeneous gene array data in heart fallure. J Mol Cell Cardiol. 2005;38:425-32.

21. Ruppert V, Maisch B. Genetics of human hypertension. Herz. 2003;28:655 62.

22. Waber KT. Fibrosis, a common pathway to organ failure: angiotensin II and tissue repair. Semin Nephrol. $1997: 17: 467-91$.

23. Devaux B, Scholz D, Hirche A, Klovekorn WP, Schaper J. Upregulation of cell adhesion molecules and the presence of low grade inflammation in human chronic heart failure. Eir Hear $\mathcal{1}$. 1997;18:470-9.

24. Ezekowitz RA, Gordon S. Interaction and regulation of macrophage receptors. Ciba Found Symp. $1986: 118: 127-36$

25. Sano H, $\mathbb{H}$ su DK, Apgar JR, Yu L, Sharma BB, Kuwabara I, Izai $S$, Liu FT. Critical role of galectin-3 in phagocytosis by mactophages. I Clin Irnest. $2003 ; 112: 389-97$.

26. Sharma UC, Pokharel S, van Brakel TJ, van Berlo JH, Cleutjens JP, Schroen $\mathrm{B}$, Andre $\mathrm{S}_{\mathrm{n}}$ Crijns HJ, Gabius HI, Maessen J, Pinto YM. Galectin-3 marks activated macrophages in failure-prone hypetrophied hearts and contributes to cardiac dysfumction. Circulation. $2004,110 \% 3121.8$.

27. Sato S, Hughes RC. Regulation of secretion and surface expression of Mac-2, a galactoside-binding protein of macrophages. I Biol Chem. $\| 994 ; 269: 4424-30$.

28. Seta $\mathrm{Y}$, Shan $\mathrm{K}$, Bozkurt B, Oral H, Mann DL. Basic mechanisms in heart failure: the cylokine hypothesis. $J$ Card Fail. 1996:2:243-9.

29. Mann DL, McMurray J, Packer M, Swedberg K, Borer JS, Colucei WS, Djan J, Drexler H, Feldman A. Kober L, Krum H, Liu P, Nieminen M, Tavazi L, vam Veldhuisen DJ, Waldenstrom A, Warren M, Westheim A. Zanmad $\mathbb{F}$, Fleming T. Targeted anticytokine therapy in patients with eluronic heart failure: results of the Randomized Etanercept Worldwide Evaluation (RENEWAL). Circulation. 2004;109:1594-602.

30. Gullestad L, Aakrust P. The cyokine network in heart fathe: pathogenetic importance and potential therapeutic targets. Heart Foil Monit. 20011:2:8-13,

31. Sasaki S, Bao Q, Hughes RC. Galectin-3 modulates rat mesangial cell proliferation and matrix synthesis during experimental glomerulonephritis induced by anti-Thyl i antibodies. J Pathol. 1999;187:481-9.

32. Yang RY, Liu FT. Galectins in cell growth and apoptosis. Cell Mol Life Sci, 2003;60:267-76.

33. Lit FT, Patterson RJ, Wang JL. Intracellular functions of galectins. Biochim Biophys Acra. 2002;1572:263-73.

34. Cherayil BJ, Weiner SJ, Pillai S. The Mac-2 antigen is a galactose specific lectin that binds lgE, I Exp Med. $1989 ; 170: 1959-72$.

35. Ochieng $\mathbb{~}$, Furtak V. Lukyanov P. Extracellular functions of galectin-3. Glycocorj J. 2004;19:527-35.

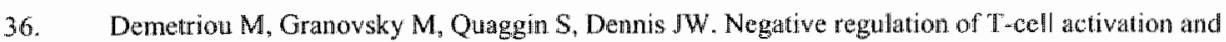
autoimmunity by Mgat5 N-glycosylation. Nanre. 2001;409:733-9. 
37. Dagher Sif: Wang JL, Patterson NU. Identification of galectin-3 as a factor in pre-mRNA splicing. Proc Nor Acad Sid US, $1995,92: 1213-7$.

38. Inohar $\mathrm{G}, \mathrm{Raz} \mathrm{A}$. Functional evidence that cell surface galectin-3 mediates homotypic cell adhesion. Cancer Res. $1995,55,3267.71$.

39. Ochieng $\mathrm{J}$, Leite Browning ML, Warfield $\mathrm{P}$. Regulation of celluhar adhesion to extracellular matrix proteins by gallectu-3, Biochem Biophys Rer Commun. 1998,246:788-91.

40. Friger LC, Zuberi LU, LW ET. Epsilon BP, a beta-galactoside-binding animal lectin, recognizes IgE receptor (Fe epsiton Rl) and activates mast cells. Biochemistry. 1993,32.7644-9.

41. Vlassara H, LI YM, Imani $\mathrm{F}$, Wojciechowicz D, Yang Z, Liu FT, Cerami A. Identification of galectir-3 as a high-afunity binding protein for advanced glycation end products (AGE): a new member of the AGE-receptor complex. Mol Med. 1995;1:634-46.

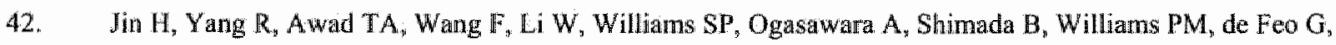
Paoni NF. Effects of early angiotensin-converting enzyme inhibition on cardiac gene expression after acute myocardial infarction. Crrowation. 2001;103:736-42.

43. Iwam K, Ashizawa N, Do YS, Graf K, Hsueh WA Comparison of ANG II with other growth factors on Egr-1 and matrix gene expression in cardiac fibroblasts. Aw J Physiol. 1996;270:142100m.

44. Yan SE, Fujita $T$, Lu J, Okada K, Shan Zou Y, Mackman N, Pinsky DJ, Stern DM. Egr-1, a master switch coordinating upregulation of diyergent gene families underlying ischemic stress. Nat Med. 2000;6; $1355-61$.

45. Adamson ED, Mercola D. Egrl transcription fartor: multiple roles in prostate tumor cell growth and survival. Tumour Biol, 2002;23:93-102.

46. Alexander D, Judex M, Meyringer R, Weis-Klemm M, Gay S, Muller-Ladner U, Aicher WK. Transcription factor Egr-1 activates collagen expression in immortalized fibroblasts or fibrosarcoma cells. Bial Chem. $2002 ; 383: 1845-53$

47. Tan L, Peng H, Osakj M, Choy BK, Auron PE, Sandel. LJ, Goldring MB. Egr-1 mediates transcriptional repression of COL2A I promoter activity by interleukin-I bett. J Biol Chem. 2003;278:17688-700. 


\section{2}

\section{A Systematic Review of Large Scale and Heterogeneous Gene Array Data in Heart Failure}

Umesh C Sharma ${ }^{1,2}$, Saraswati Pokharel ${ }^{2}$, Chris TA Evelo ${ }^{3}$ and Jos G Maessen ${ }^{1}$

"Pump Failure Investigation Group, Department of Cardio-thoracic Surgery, Academic Hospital Maastricht, Maastricht, The Netherlands

${ }^{2}$ Hypertension and Vascullar Research Division, Henry Ford Hospital, Detroit, Michigan, USA

${ }^{3}$ Bio-informatics Division, University of Maastricht, Maastricht, The Netherlands

Journal of Molecular and Cellular Cardiology 2005;38:425-32

Listed as one of the HITS 25 and wost frequently downloaded articles in Cardiovascular Science Category of Jownal of Molecular and Cellular Cardiology 


\begin{abstract}
Mictoarray analysis has become a widely available tool for the generation of gene expression data on a genomic scale. Since the studies with similar protocols are growing, it has become necessary to systematically revise the large body of literature to decipher the gene expression data. In this review, we analyzed and critically discussed the database presented from 14 published studies that showed the gene expression profile in heart fature (HF) using microarray as a primary tool. After comparing the diverse database from these studies, we explain the protein translational, matricellular, immunological and fibrosis-related mechanisms in HF. In addition to previously annotated genes; we analyzed two differentially expressed Expressed Sequence Tags (ESTs) (KIAA0152 and SGT1) in HF and showed how bio-informatic analysis of ESTs can lead to the identification of novel pathways active in HF. We have also discussed the new publicly accessible tools that link the gene expression data to gene ontogeny and functionality. Finally, we have systematically revised the chromosomal localization of the genes that are specifically up-regulated in HF. We have thus spotted chronosome $1,2,11$ and 12 as the chromosomal hotspots of HF. This methodical approach will simplify the existing concepts on the evolution and progression of HF and lead us toward the development of newer diagnostic and therapeutic tools. Although modeled to HF, this approach should be of broader scientific interest to elaborate multiple genes and complex pathways.
\end{abstract}




\section{Introduction}

The evolution of new methods that enable large-scale expression analyses, like serial analysis of gene expression (SAGE), in silico analysis of expressed sequence tag (EST) databases, cDNA and oligonucleotide microarrays allows researchers to investigate organ-or pathology-specific transcriptional profiles ${ }^{1,2}$. Understanding the genetic basis of complex cardiovascular diseases has been a challenging task for many years and this notion of complexity is being gradually expounded. with the advent and use of microarray technology in human cardiowascular diseases ${ }^{3,4}$.

Although, study of individual signaling pathways at the genetic level has provided significant insight into the development of HF, approaches such as gene knockout are limited by the interdependence of the cellular systems. A closer look on the functional genomics data shows a dynamic interaction within and across several cellular signaling and metabolic pathways. Therefore, with the exception of hypothesis-driven efforts to detect predictors, markers and modifiers of HF, the expression data should be more meaningful in the context of a detailed description of the conditions under which they are generated, with regard to the particular etiology and state of the failling hearts. Finally, the reported microarray data in HF are on varied platforms and experimental designs, thus making an integration of these data an error-prone exercise.

We believe that it is necessary to develop a new strategy to synthesize the microarray results obtained from diverse cases and models. Different arrays need to be systematically compared and most consistent observations defining the same or simillar biological phenomenon need to be translated to putative mechanisms contributory to the disease pathogenesis. Using the evidence gathered from such a cathartic approach, we reveal how the conventional method of reporting the gene array data are often 'stripped' of an adequate interpretation and how the information, which otherwise could be crucial to explain the mechanisms contributory to HF, is not discussed. To this end, we have revised 14 recent study reports pertaining to gene array analysis in $\mathrm{HF}^{\text {s-18 }}$. Expressed sequence tags (ESTs) constitute the essential tools for rapid gene discovery but are often omitted from the primary analyses. Therefore, we chose two differentially expressed ESTS in HF as model nucleotide probes in order to predict their molecular architecture and function ${ }^{8.19}$.

Gene expression data can be analyzed on at least three levels of increasing complexity ${ }^{20}$. First, the level of single genes, where one seeks to establish whether each gene in isolation behaves differently in a control versus a treatment situation. The second level considers gene combinations, 
where clusters of genes are analyzed in terms of common functionalities, interactions, coregulations and so forth. The third level attempts to infer the underlying regulatory regions and gene/protein networks that wltimately are responsible for the patterns observed ${ }^{2-23}$. Inherent to the large database and diverse nature of the expression profile, scientists often resort to an in silico approach for the data analysis. No matter at what level the information is drawn out of the gene chips, the most important step is adequate data interpretation where the precis made from all levels of dati analysis is re-evaluated, summarized and integrated to biological pathways immediately rellevant to a particular disease process.

\section{Heterogeneity of the study selection criteria and array design}

Although the microarray studies we revised are highly heterogeneous in terms of study subjects, etiology and stage of $\mathrm{HF}$ and data analysis and validation procedure, the investigators centered to a common research question i.e., the profile of differentially expressed genes in failing compared to functionally preserved hearts (Table 1 ). The spotlight of the researcher mainly dictates the technological description and fulfillment of the pre-requisites of a microarray experiment. It is unlikely; however, that such a system would be effective or scalable. It is recommended that the mictoarray data need to be standardized based on Minimum Information About a Microarray Experiment (MLAME) criteria developed by the Microarray Gene Expression Database Group (MGED; inttp: //www.mged org), a grass-root to develop standards for microarray data ${ }^{24,25}$. In this review, it was still difficult to grade the evidence based on MIAME criteria because of the following reasons- 1 . The six components of MIAME including, experimental design, array design, samples, hybridizations, measurements and normalization controls were not designed for an objective scoring, but designated as an informal specification on which microarray experimentannotation tools may be based. 2. Some components of MIAME did not reach consensus among the MGED working group. Therefore, the peer-reviewed publications together with the information. that was necessary to verify and reproduce the experimental results were considered to be eligible to be included in our data discussion.

\section{Gene expression fingerprint of extracellular matrix: a common lesson from diverse arrays}

In this section, we discuss how the different studies can provide a common and more convincing evidence to explain the matrix changes undergoing in failing hearts. A robust increase in the expression of ECM-related genes in most of the microarray analyses underscored the importance of myocardial matrix remodeling in failing hearts ${ }^{26,27}$. These genes included connective tissue growth 
factor (CTGF), both fibrillar and reticular collagens, along with the genes involved in controlling the deposition and orientation of collagens, and binding of cells to ECM. Recently, snall Ieucinerich repeat proteoglycans (SLRP) have emerged as a significant multimember group, expressed in high levels in many tissues including heart and are capable of binding and regulating collagen fibril assembly and growth ${ }^{28}$. The four SLRP members- lumican, fibromodulin, decorin and biglycans have recently been the focus of gene targeting studies to understand their role in connective tissue biology. For example, lumican-deficient mice had collagen fibrils of increased diameters forming a disorganized matrix in the cornea and skin, with subsequent decrease in corneal clarity and increased skin laxity. Similarly, fibromodulin-deficient mice contained more immature collagens with small diameter ${ }^{29}$. Excluding the natriuretic factors, SLRPs constituted the most reproducible group of genes with increased expression in failing hearts. A recent microarray study by Boheler and associates showed lumican as one of the only two finally passed genes overexpressed in HF after neutralizing the possible confounding effects of age, sex and data normalization procedure ${ }^{14}$.

Fibronectin, a widely investigated glycoprotein in myocardial matrix, was anong the consistently overexpressed genes, regardless of cause and severity of HF. In addition to the individual role of fibronectin in regulating the growth and organization of myocardial matrix, it possesses an Arginine-Glycine-Aspartate (RGD) domain that can bind to the special group of integrin molecules expressed in the heart ${ }^{19}$. After a broader search for the molecules sharing the RGD domain, we noticed that more genes encoding the proteins of this family e.g., thrombospondin- $1,2,3,4$, osteopontin and activin were also reported to be overexpressed in HF. Integrins are heterodimeric cell-surface adhesiwe receptors which bind to ECM proteins. Upon stimulation, integrins interact with signal transducing molecules like Phospho-FAK, c-src and shc ${ }^{30}$. Activation of these tyrosinerich proteins leads to the phosphorylation and activation of mitogen-activated protein kinases (MAPKs) signaling cascade, finally leading to myocardial matrix growth ${ }^{3 !}$. Interestingly, MAPK was the second gene exclusively overexpressed in HF out of 10,176 clones tested by Boheler and associates. The meaning for the transcriptomal increase of matri-cellular gene expression in the context of HF can be two-fold. Firstly, an increased expression of the genes involved in matrix organization can be beneficial by offering an additional structural support and resilience to failing hearts. Secondly, however, an aberrant activation of signaling cascades that are contributory to cardiac fibroblast activation and excess fibrillar collagen production can induce myocardial stiffness, lead to electromechanical uncoupling and increase myocardial ischemia, thus turning the virtuous intentions to malign consequences. Taken together, it can be concluded that, despite 
apparenty large differences in the design of the arrays and individual experiments, the results are often complementary and converge to a common gene expression profile of failing hearts.

\section{Cell-cycle regulators and protein elongation factors in failing hearts: the unusual suspects}

The role of cell cycle activation and increased mitotic activity in failing ventricles is currently a subject of interest. The active remodeling of myocardial matrix is invariably accompanied by an increased tumover of t' cellular counterpart. We have observed a 10-fold increase in cyclin DI expression in the failing hearts of Ren-2 rats compared to the littermates that had normal cardiac function $^{32}$. A recent study by Yung and associates also showed a 4.3-fold increase in cyclin G2 in failing hearts ${ }^{18}$. A second interesting point raised by most of the microarray studies discussed in this review is the increased expression of protein ellongation factors (elF) in $\mathrm{HF}^{6,7,10,33,34}$. Increased elF activity can lead to an increase in bulk protein synthesis and therefore enhance cell replication because cell division requires sufficient protein production to fulfill the metabolic requirements of the daughter cells. It was found that elF-2 is one of the most prominently phosphorylated proteins in mammalian tissue extracts ${ }^{35}$. Phosphorylation of elF-2 results in its inactivation, thus suggesting a mechanism for global protein synthesis regulation ${ }^{36}$. Of note, elF-null mice develop severe cachexia and succumb to death within a month ${ }^{37}$. In the absence of mechanistic insight, it is probably too early to postulate that HF is a malignant form of cardiac remodeling. However, it could be argued that an unchecked cell division and protein synthesis machinery could still be the hidden suspects in failing hearts. The therapeutic translation of this concept could lead to the testing of new cell-cycle activation inhibitors or specific inhibitors of elF for HF therapy.

\section{New publicly accessible tools to link the functionality of the genes}

Since the differentially expressed genes in HF or any other disease process have either shared ontogeny, domain or function, there was a need for an array-clustering tool, which can map the differentially expressed genes in individual database to known biological pathways. Identifying groups of biologically related genes that are showing a large number of gene-expression changes will create an informative description of the biology that is occurring in a particular dataset, making it possible to generate new hypotheses and identify those specific areas of biology that warrant more detailed investigation. One tool that assists in the identification of important biological processes is GenMAPP (Gene MicroArray Pathway Profiler) ${ }^{38}$, a program for viewing and 
analyzing microarray data on microarray pathway profiles (MAPPs) representing biological pathways or any other functional grouping of genes. The second and more recently developed tool is MAPPFinder that dynamically links gene-expression data to the gene ontogeny (GO) hierarchy ${ }^{39}$. MAPPFinder therefore generates a gene-expression profile at the level of biological processes, cellular components and molecular functions, rapidly identifying those areas of biology that warrant further study. Similarly, Zeeberg and associates developed GoMiner as a new tool to interpret genomic as well as proteomic data in the context of gene ontology. Using this fieely downloadable tool, one can input a list of up- or downregulated genes and a list of total genes on the array, and then calculate enrichment or depletion of categories with genes that have changed expression ${ }^{40}$. Other related tools like, FatiGO, Onto-Express, GoSurfer etc. are also implemented either in web or windows version. However, the real challenge of time is to develop a strategy in which the huge database generated from large number of experiments with same hypothesis but conducted in different biological samples can be pooled and mapped. The intra- and inter-species conservation of protein sequences, similar transcriptional nature of regulatory genes and emerging knowledge about the gene ontogeny should help the to develop a standard that can serve both research scientists and software developers.

\section{Matricellular vs. immunological mechanisms: marker, mediator or predictor?}

We have recently reported 48 genes overexpressed in failing hypertrophied hearts compared to compensated forms of cardiac hypertrophy. This study demonstarted an apparent split of the most of the overexpressed genes either as immune-related or extracellular matrix proteins. After further investigation, we noticed that thrombospondin-2, a matrix-related gene was critical for the myocardial matrix integrity, since most of the null-murant mice died of cardiac rupture after myocardial infarction or angiotensin infusion ${ }^{6}$. On the other hand, galectin-3 (a macrophage-derived cytokine), the gene most robustly and specifically overexpressed only in the failing hypertrophied hearts, led to cardiac fibrosis and induced HF after chronic infusion into the pericardial cavity of the healthy rats ${ }^{32}$. This suggests that there is a complex interplay of protective $v$ s. causative mechanisms in failing hearts. The gene array studies performed at a particular time-point snap a mixed picture of both of these mechanisms. Therefore, it is hard to conclude, based on the expression profile data that whether a particular differentially expressed gene in question is causative for HF or not. In order to avert these difficulties, we obtained myocardial biopsies from the rat model of hypertension and followed them up to discern whether these rats will rapidly develop HF or remain compensated. Both thrombospondin- 2 and galectin- 3 expression was 
increased at an early stage of cardiac hypertrophy specifically in the group of rats that later rapidly progressed to cardiac decompensation. In contrast, several other genes including brain natriuretic peptide were not overexpressed in early stage and thus just marked the actively failing hearts. The questions addressed by these studies are unique. The existing studies have largely focused to search for the transcriptomal imprint of HF in advanced stage. However, it is important to detect the critical mediators that are involved during the transition from compensated cardiac hypertrophy to HF. An early recognition of failure-prone hearts and intervention with newer therapeutic agents might gain additional benefit over the existing treatment strategies.

Until recently, the question on what constitute the cause and epiphenomenon of HF was not answered. Several studies have now investigated the role of various myocardial matrix proteins in various animal models using gene targeting strategy ${ }^{6,41}$. The evidence compiles on the fact that most of the matrix-related proteins are critical for the myocardial integrity and their increased expression in HF reflects an ongoing reparative response. These studies have an advantage of leading us towards the discovery of bio-markers or predictors of HF. Despite state of-the-art treatment, HF is still a progressive disorder characterized by high morbidity and mortality. Therefore, a new challenge of the time is to identify new causative mechanisms of HF. It is gradually becoming clear that the myocardial inflammation is a uniform accompaniment in the failing hearts. In our recent study, we found a role for early macrophage activation for the future transition to $\mathrm{HF}^{32}$. We have now learned more about the cytokine production, T-lymphocyte, natural killer cell and complement system activation in failing hearts. Whether monocytes are primed from the bone marrow or circulation to transmigrate to the heart and initiate HF or it is predominanily the effect of increased expression of local adhesion molecules, cytokines and leukocyte antigens thus leading to excess tissue damage and consequent scarring and loss of myocardial function, remains to be investigated. Hopes are ligh for the newly discovered molecules in HF (eg., galectin-3, gelsolin, osteopontin) that appear to activate the immune system and in the meantime, can contribute to the loss of cardiac function independent of immune activation ${ }^{7,32,42}$. 
Genes, gene array and genesis of heart fallure

Table 1. Characteristics, design and results of the selected high-density arrays performed within last 5-years to discern the heart failure-related genes

\begin{tabular}{|c|c|c|c|}
\hline Year & Author & Array Design & Gene Description \\
\hline 2000 & Yang at al & $\begin{array}{l}\text { Affymetrix He6800 GeneChip, } \\
7085 \text { genes, ICM and DCM Pts }\end{array}$ & Gelsolin, Elongation factor-2 \\
\hline 2001 & Bartans et al & $\begin{array}{l}\text { In-house CardioChip, } 10368 \text { genes, } \mathrm{HCM} \\
\text { Pts }\end{array}$ & Elongation fuctor-1, CTGF, Gelsolin \\
\hline 2001 & Jin et al & $\begin{array}{l}\text { Affynetrix Rat Genome Arrays, Ml in rat } \\
\text { models }\end{array}$ & $\begin{array}{l}\text { ANP, BNP, Collagen } 1 \text {, Fibronectin, Biglyean, } \\
\text { Thrombospondin-4, Lysyl oxidase, complement } \\
\text { B/C4 }\end{array}$ \\
\hline 2002 & Barrans et al & $\begin{array}{l}\text { In-house CardioChip, } 10848 \text { genes, DCM } \\
\text { pts }\end{array}$ & $\begin{array}{l}\text { ANP, EST (T60005), Elongation fretor } 1 \text {, Collagen } \\
\text { ol, Fibronectin, Natural killer cell enhancing factor }\end{array}$ \\
\hline 2002 & Hwang et al & In-house, 10272 genes, DCM and HCM pts & $\begin{array}{l}\text { DCM: ANP, Collagen } \alpha \text { l, Decorin, Lamican, TCR- } \\
\beta \text { chain, Elongation factor-2 } \\
\text { HCM: ANP, Decorin, Desmin, Elongation factor-2 }\end{array}$ \\
\hline 20002 & Tan et & $\begin{array}{l}\text { Affymetrix Hu6800fl GeveChip, } 6606 \\
\text { genes, DCM pts }\end{array}$ & $\begin{array}{l}\text { ANF, BNP, } \alpha \text {-collagen type } 1, \text { Lumican } \\
\text { Thrombospondin- } 4 \text {, CTOF }\end{array}$ \\
\hline 20003 & BHraxall et al & $\begin{array}{l}\text { Affymetrix HuGeneChip, } 6800 \text { genes, Pre- } \\
\text { and post LVAD pts }\end{array}$ & 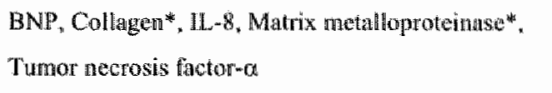 \\
\hline 2003 & Boheler et al & $\begin{array}{l}\text { Incyte (Human UniGem), } 10176 \text { genes, } \\
\text { DCM pts }\end{array}$ & $\begin{array}{l}\text { Absolute increase: } \\
\text { Lumican, MAP2K3 } \\
\text { Sex-dependent alteration: } \\
\text { Calponin, MAP4K5 }\end{array}$ \\
\hline 2003 & Chen et al & $\begin{array}{l}\text { Agilent Human } 1 \text { Catalogue Array, } 12814 \\
\text { genes, Pre- and post LVAD }\end{array}$ & $\begin{array}{l}\text { Natriuretic peptide precursor B, Cathepsin B, } \\
\text { MAPK4 }\end{array}$ \\
\hline 2003 & Grzeskowjak ef al & $\begin{array}{l}\text { Human UniGene database, } 30336 \text { genes, } \\
\text { DCM pes }\end{array}$ & MHC-LA, Complement-1 \\
\hline 2003 & Stemman et al & $\begin{array}{l}\text { Affymetrix HG-U95A array, } 12626 \text { genes, } \\
\text { DCM and ICM pos }\end{array}$ & 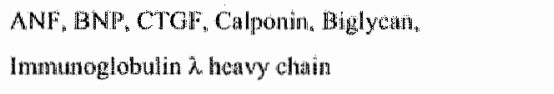 \\
\hline 2004 & Yung et al & $\begin{array}{l}\text { Affymetrix GeneChip } \mathrm{HG}-\mathrm{U} 133 \mathrm{~A}, 22283 \\
\text { genes. DCM pts }\end{array}$ & Collagen type XXI, Sarcoglycan, Cyelin $\mathrm{OL}$ \\
\hline 2004 & Schroen et & $\begin{array}{l}\text { Incyle Rat GEMD/3 cDNA library, } 12336 \\
\text { genes, Ren-2 rat model }\end{array}$ & $\begin{array}{l}\text { Thrombospondin*1, Thrombospondin-2, } \\
\text { Thrombospondin-3, Galectin-3, Collagen a 1, } \\
\text { Osteosetivin, Osteopontin, Fibronectin, Elongation } \\
\text { anctor-1, Lumican }\end{array}$ \\
\hline 2004 & Kittleson et al & Affymetrix U133A microarnays, ICM pts & $\begin{array}{l}\text { Immonoglobulin theavy chain, MAPK.7. Mannosa } \\
\text { receptor }\end{array}$ \\
\hline
\end{tabular}

ICM, ischemic cardiomyopathy; DCM, dilated cardiomyopathy; HCM, hypertrophic cardiomyopathy; ANP, atrial natriuretic peptide; ANF, atrial natriuretic factor; $B N P$, brain natriuretic peptide; CTGF, connective tissuc growth factor; TCR, T-cell receptor; IL, interleukin; MAP2K3, mitogen activated protein kinase kinase 3; MAP4K5, mitogen activated protein 4 kinase 5; MHC, major histocompatibility complex. 


\section{Bioinformatic analysis of expressed sequence tags}

With the aid of expressed sequence tag (EST) and microarray applications, both known and previously uncharacterized genes involved in the induction of HF can be analyzed simultaneously ${ }^{43}$. As an example, we chose 2 previously reported ESTs- ESTA, a 12.45 fold upregulated and ESTB, a 3.19 fold downregulated EST in $\mathrm{FF}^{8,44}$. These 2 ESTs were chosen as the index molecules for analysis based on therr robust change of expression in the presence of HF. ESTA sequence was identified in the national library dbEST database with Genbank sequence ID of T60005, which corresponds to Image Clone $79419\left(5^{\prime}\right)$ from human lung. This 329 nucleotide EST was found to be a part of Unigene cluster Hs 181418 (KIAA0152 gene product), located at chromosome 12q24.31. Similarly, ESTB was annotated with the sequence ID of AA306721. This 468 nucleotide EST was found to be a part of Unigene cluster O95905 (human SGT1, hSGT1 gene product). We also confirmed the correctmess of the identity of both the EST clones with their corresponding protein. sequences by a direct BLASTn of the clone sequence against EMBL.

We then used the CBS signal P Pinediction Server (V1.1) at the Centre for Biological Sequence (http://www.cbs.dtu.dk) to compare the presence of signal peptide, cleavage sites, glycosylation and phosphorylation sites of these 2 proteins ${ }^{45}$. NCBI search was applied to analyze and predict the function of conserved domains. The signal peptide prediction algorithm using neural network models showed KIAA0152 as a secretory protein. Human SGT1 (hSGT1) protein, a Gprotein coupled receptor-2 (GCR2) suppressor and transcriptional activator of glycolytic genes in. Saccharomyces cerevisiac, appeared to be non-secretory, as the sequence did not harbour a signal peptide. KIAA0152 had 6 serine, 3 threonine and 7 tyrosine phosphorylation sites whereas hSGT1 harboured 25 serine, 6 threonine and 4 tyrosine phosphorylation sites. KIAA0152 contained 1 glycosylation site at amino-acid position 261 and hSGTI had 2 sites at position 133 and 501 respectively. NCBI conserved domain search revealed that KIAA0152 shared a homology with KOG3593, a predicted receptor-like serine/threonine kinase domain. This indicated the probable involvement of this protein in signal transduction mechanisms. Protein hSGT, on the other hand, shared a homology with KOG2406, a MADS box transcription factor domain, showing that it can potentially be active in transcription process.

It is noteworthy that a gene-by-gene approach in elucidating the genes and mechanisms involved is time-consuming and cumbersome. Using expressed sequence tag technology, Chien and associates 
have recently generated a compendium of genes expressed in the human cardiovascular system, with the ultimate goal of assembling the intricacies of development and of disease, particularly the pathways leading to heart failure ${ }^{46}$. Therefore, the bioinformatic analysis of both KIAA0152 and Protein hSGT should be interpreted as an example but not as a mandate for how the ESTs should be translated to full-sequence proteins and how the functionality is predicted. The second important aspect of this analysis is, notwithstanding the exciting information obtained from advanced data analysis tools, the biological experiments constitute the final and definite steps before any meaningful conclusions about the new disease mechanisms can be drawn.

\section{Inter-array paradox in gene expression: biological effect or methodological heterogeneity?}

There is no consensus about the optimal statistical approach for finding differences in expression among thousands of genes. Because a number of sources of systematic variation can alter expression levels especially in across-array experiments (inter-array variability), evaluation of gene differential expression can be biased. For example, the study by Tan and asscociates compared expression profile between failing $v$. functionally compensated forms of ischemic and dilated cardiomyopathy patients and lound callponin as a 2.7-told downregulated gene in $\mathrm{HF}^{\mathrm{l}}{ }^{2}$. In contrast, the study performed by Steenman and associates in comparable patient cohorts showed the opposite results $^{16}$. A partial explanation for this descrepany became available when Boheler and associates, using general linear statistical model as a data analyis tool, attributed the altered expression of calponin to the gender-difference ${ }^{14}$. Although the near-complete ascertainment of genes in the human genome should make expression-profiling studies of human hearts more powerful, identification of the sources of experimental variability, and knowledge of the relative contribution of error from each source, is critical for appropriate interpretation of the array results.

\section{Chromosomal aggregation of heart failure susceptibility genes and scope for quantitative trait locus analysis}

The advent of sophisticated genomic techniques for gene mapping and microarray analysis has provided opportunities to map mRNA abundance to quantitative trait loci (QTL) throughout the genome ${ }^{47}$. Unfortunately, simple mapping of each individual mRNA trait on the scale of a typical microarray experiment is computationally intensive, subject to high sample variance, and therefore underpowered. However, indiwidual susceptibility to HF could still be guided by genetic component and chromosomal mapping of the genes offer promise for understanding the molecular mechanism of the etiology and provide new therapeutic targets. As an example, summarizing the chromosomal 
localization of the gene products that had an absolute change in expression of $\geq 1.8$-fold in multiple microarray analyses of human HF, revealed chromosome $1,2,11$ and 12 as the chromosomal hotspots of $\mathrm{HF}^{14}$. A closer look on the individual genes belonging to these chromosomal loci showed several genes ( $\mathrm{e}$, natriuretic peptide precursor $\mathrm{A}$ and $\mathrm{B}$, transforming growth factor- $\beta$, fibronectin, collagens, cathepsin $C$ and $F$, phospholipase $A$ etc.) consistently reported to be differentially expressed in falling hearts.

\section{Future directions}

In the next decade, it is anticipated that the Human Genome Project and related human and animal genome sequencing projects will exert a profound influence on our understanding and management of human disease. For HF, it still remains unclear which genes are most responsible for disease onset, even though patients often report a strong familial predisposition. Expectations are high for the potential of cardiovascular genomics to lead to major advances in our understanding of normal cardiovascular functioning and pathogenesis of HF, of interactions of genes with environment, of strategies for disease prediction, and in drug development. Using sophisticated cluster analyses, novel patterns in functional responses are seen to various stimuli, and clustered responses may be useful for identifying novel pathways for design and application of therapeutics.

At first glance, the task of deciphering the results from diverse database may seem confusing. First, casting the net for genome-wide changes in gene expression will inevitably identify variations. Establishing which of this is functionally important will require better informatics and more efficient means of confirming gene function experimentally than conventional methods of genetic engineering in mice. Second, changes in mRNA need not accompany changes in the corresponding protein's abundance or its state of activation. Clearly, progress in this field will require a new level of interdependence between specialists broadly in the biological sciences and those in the population and clinical sciences. The prospect of embarking on this voyage is at the same time daunting and exhilarating: researchers must rapidly 'get up to speed' on so many evolving new disciplines, but there is the opportunity to travel into uncharted territories to make discoveries at a great pace and on a large scale. 


\section{References}

1. Yousef GM, Yacoub GM, Polymeris ME, Popalis $\mathrm{C}_{9}$ Soosaipillai $\mathrm{A}$, Dianandis EP. Kallikrein gene downregulation in breast cancer. Br J Cancer. 2004;90:167-72.

2. Carella M, Volinia S, Gasparini P. Nanotechnologies and microchips in genetic diseases. J Nephrol. 2003; 16:597-602.

3. Cook SA, Rosenzweig A. DNA microarrays: implications for cardiovascular medicine. Cine Res. 2002;91:55964 .

4. Napoli C, Lerman LO, Sica V, Lerman A, Tajana G, de Nigris F. Microarray anallysis: a novel research tool for cardiovascular scientists and physicians. Heart. 2003;89:597-604.

5. Kittleson MM, Ye SQ, Irizarry RA, Minhas KM, Edness G, Conte JV, Parmigiani, G ML, Chen Y, Hall JL, Garcia JG, Hare JM. Identification of a gene expression profile that differentiates between ischemic and nonischemic cardiomyopathy. Circulation. 2004;110:3444-51.

6. Schroen B, Heymans S, Sharma U, Blankesteijn WM, Pokharel S, Cleutjens JP, Porter JG, Evelo CT, Duisters $\mathbb{R}$, van Leeuwen RE, Janssen BJ, Debets JJ, Smits JF, Daemen MJl, Crijns HJ, Bornstein P., Pinto YM. Thrombospondin-2 is essential for myocardial matrix integrity: increased expression identifies failure-prone cardiac hypertrophy. Circ Res. 2004;95:515-22.

7. Yang J, Moravec CS, Sussman MA, DiPaola NR, Fu D, Hawthorn L, Michell CA, Young JB, Francis GS, McCarthy PM, Bond M. Decreased SLMM1 expression and increased gelsolin expression in failing humain hearts measured by high-density oligonucleotide arrays. Circulation. 2000;102:3046-52.

8. Barrans JD, Allen PD, Stamatiou D, Dzau VJ, Liew CC. Global gene expression profiling of endi-stage dilated cardiomyopathy using a human cardiovascular-based cDNA microarray. Am J Pathol. 2002;160:2035-43.

9. Jin H, Yang R, Awad TA, Wang F, Li W, Williams SP, Ogasawara A, Shimada B, Williams PM, de Feo G, Paoni NF. Effects of early angiotensin-converting enzyme inhibition on cardiac gene expression after acute myocardiall infarction. Circulation. 2001;103:736-42.

10. Barrans JD, Stamatiou D, Liew C. Construction of a human cardiovascular cDNA microarray: portrait of the failing heart. Biochem Biophys Res Conmun, 2001:280:964-9.

11. Hwang JJ, Allen PD, Tseng GC, Lam CW, Frananapazir L, Dzau VJ, Liew CC. Microarray gene expression profilles in dilated and hypertrophic cardiomyopathic end-stage heart failure. Physiol Genomics. 2002;10:3144.

12. Tan FL, Moravec CS, Li J, Apperson-Hansen C, MoCarthy PM, Young JB, Bond M. The gene expression fingerprint of human heart failure. Proc Nall Acad Sci U S A. 2002;99:1 1387-92.

13. Blaxall BC, Tschannen-Moran BM, Milano CA, Koch WJ. Differential gene expression and genomic paticnt stratification following left ventricular assist device support. $J \mathrm{Am}$ Coll Cardiol. 2003;41:1096-106.

14. Boheler KR, Volkova M, Morrell C, Garg R, Zhu Y, Margulies K, Seymour AM, Lakatta EG. Sex- and agedependent human transcriptome variability: implications for chronic heart failure. Proc Natl Acad Sci US.A. $2003 ; 100: 2754-9$.

15. Chen MM, Ashley EA, Deng DX, Tsalenko A, Deng A, Tabibiazar R, Ben-Dor A, Fenster B, Yang E, King JY, Fowler M, Robbins R, Johnson FL, Bruhn L, McDonagh T, Dargie H, Yakhini Z, Tsao PS, Quertermous 
T. Novel role for the potert endogenows inotrope apelin in human cardiac dygfunction. Circulation. $2003 ; 108: 1432-9$.

16. Stearman $M$, Chen $Y W$, Le Cunff $M$, Lamirault $G$, Varo A, Hoffman $E$, Leger Ju, Transcriptomal analysis of falling and nonfaling human hearts. Phystol Genomics, 2003,12:97-112.

17. Graskowiak $\mathrm{R}$, Witt $\mathrm{H}$, Drungowski M. Themann R, Mening $\mathrm{S}$, Perrot A, Osterziel KJ, Klingbiel D, Scheid $S$, Spang R, Letrach H, Rut P. Expression profling of human idiopathic dilated cardiomyopathy. Cardiovasc Res. $2003,59: 400111$.

18. Yung CK, Halperin VL, Tomaselli GF, Winslow RL. Gene expression profiles in end-stage human idiopathic dilated cardiomyopathy: altered expression of apoptotic and cytoskeletal genes. Genomics. 2004;83:281-97.

19. Hwang DM, Dempsey AA, Wang RX, Rezwan M, Barrans JD, Dai KS, Wang HY, Ma I, Cukeman E, Liu YQ. Gu JR, Zhang $1 \mathrm{H}$, Tsui SK, Waye MM, Fung KP, Lee CY, Liew CC. A genome-based resource for molecular cardiovascular medicine: toward a compendium of cardiovascular genes. Circulation. $1997,96: 4146-203$.

20. Tadesse MG, Ibrahim JG. A bayesian hierarchical model for the analysis of Affymetrix arrays. Ann $N Y$ Acad Se. 2004; $1020 ; 41-8$

21. Gottardo R, Pannucci JA, Kuske CR, Brettim T. Statistical analysis of microartay data: a Bayesian approach. Biostatistics. $2003 ; 4,597-620$.

22. Savoie Cu, Aburatani S, Watanabe S, Eguchi $\mathrm{Y}$, Muta S, Imoto S, Miyano S, Kuhara S, Tashiro K. Use of gene networks from full genome microartay libraries to identify functionally relevant drug-affected genes and gene regulation cascades DNA Res. 2003;10:19-25.

23. Yang $C$, Bakshi BR, Rathman JF, Blower PE, Ir. Multiscale and Bayesian approaches to data analysis in genomics highth-throughput screening. Curr. Opin Drug Discov Devel. 2002;5;428-38.

24. Brazma A, Sarkans UJ, Robinson $A$, Vilo J, Vingron $M$, Hoheisel $J$, Fellenberg $K$. Microaray data representation, annotation and storage. Adw Biochem Eng Biotechnol, 2002;77:113-39.

25. Brazma A, Hingamp P, Quackenbush J, Sherlock G, Spellman P, Stoeckert C, Aach J, Ansorge W, Ball CA, Causton HC, Gansterland $T_{1}$ Glenisson $P$, Holstege FC, Kim IF, Markowitz V, Matese JC, Parkinson $H_{\text {, }}$

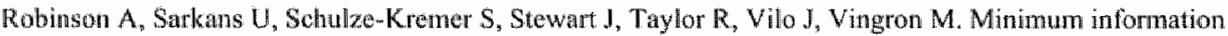
about a microartay expetment (MLME)-toward standards for microatray data. Nat Genet. 2001;29:365-71.

26. Bendall JK, Heymes C, Ratajcak P, Samuel JL. Extracellular matrix and cardiac remodelling Arch $M a l$ Cour Vaiss. 2002;95:1226-9

27. Boluyt MO, O"Neill L, Meredith AL, Bing OH, Brooks WW, Connd CH, Crow MT, Lakatta EG. Alterations in cardiac gene expression during the transition from stable hypertophy to heart failure. Marked upregulation of getnes encoding extracellutar matrix components, Circ Res. 1994;75:23-32.

28. Scot JE. Protoodermatan and proteokeratan sulfate (decorin, lumicantrobonodulin) proteins are horseshoe shaped. Implications for their interactions with collagen. Biachemistry. 1996,35:8795-9.

29. Jepsen K., Wu F, Peragallo JH, Paul J, Roberts L, Ezura X, Oldberg A, Birk DE, Chakrawarti S, A syndrome of joint laxity and impaned tendon integrity in lumican-and fibromodulin-delicient mice. B Biol Chem.

$2002: 277 ; 35532-40$ 
30. Palazzo AF, Eng CH, Schlaepfer DD, Marcantonio EE, Gundersen GG, Localized stabilization of microtubules by integrin- and FAK-facilitated Rho signaling. Science. 2004;303:836-9.

31. Eblen ST, Slack-Davis JK, Tarcsafalvi A, Parsons JT, Weber MJ, Catling AD. Mitogen-activated protein. kinase feedback phosphorylation regulates MEKI complex formation and activation during cellular adhesion. Mol Cell Biol. 2004;24:2308-17.

32. Sharma UC, Pokharel $S$, van Brakel TJ, van Berlo JH, Cleutjens JP, Schroen B, Andre S, Crijns HJ, Gabius $\mathrm{HJ}_{8}$ Maessen $\mathrm{J}_{8}$ Pinto YM. Galectin-3 marks activated macrophages in failure-prone hypertrophied harts and contributes to cardiac dysfunction. Circulation. 2004;110:3121-8.

33. Barrans JD, Ip J, Lam CW, Hwang IL, Dzau VJ, Liew CC. Chromosomal distribution of the human cardiovascular transcriptome. Genomics. 2003;81:519-24.

34. Hwang $\mathbf{J}$, Dzau VJ, Liew CC. Genomics and the pathophysiology of heart failure. Curr Cardiol Rep. 2001:3:198-207.

35. Ryazanov AG. Ca2+/calmodulin-dependent phosphorylation of elongation factor 2. FEBS Lett. 1987;2 14:3314.

36. Ryazanov AG, Shestakova EA, Natapov PG. Phosphorylation of elongation factor 2 by EF-2 kinase affects rate of translation. Nature. 1988;334:170-3.

37. Shultz LD, Sweet HO, Davisson MT, Coman DR. "Wasted", a new mutant of the mouse with abnormalities characteristic to ataxia telangiectasia. Nanure. 1982;297:402-4.

38. Dahlquist KD, Salomonis N, Vranizan K, Lawlor SC, Conklin BR. GenMAPP, a new lool for viewing and analyzing microarray data on biological pathways. Nar Genet. 2002;31:19-20.

39. Doniger SW, Salomonis $\mathrm{N}$, Dahlquist KD, Vranizan K, Lawlor SC, Conklin BR. MAPPFinder: using Gene Ontology and GenMAPP to create a global gene-expression profile from microarray data. Genone Biol. $2003 ; 4: R 7$.

40. Zeeberg BR, Feng W, Wang G, Wang MD, Fojo AT, Sunshine M, Narasimhan S, Kane DW, Reinhold WC, Lababidi S, Bussey KJ, Riss J, Barrett JC, Weinstein JN. GoMiner: a resource for biological interpretation of: genomic and proteomic data. Genome Biol. 2003:4:R28.

41. Trueblood NA, Xie Z, Communal C, Sam F, Ngoy S, Liaw L, Jenkins AW, Wang I, Sawyer DB, Bing OH, Apstein CS, Coluce WS, Singh K. Exaggerated left ventricular dilation and reduced collagen deposition after myocardial infarction in mice lacking osteopontin. Circ Res, 2001;88:1080-7.

42. Singh $\mathrm{K}$, Sirokman $\mathrm{G}_{2}$ Communal $\mathrm{C}$, Robinson $\mathrm{KG}$, Conrad $\mathrm{CH}$, Brooks WW, Bing OH, Colucci WS. Myocardial osteopontin expression coincides with the development of heart failure. Hypertension. 1999;33:663-70.

43. Adams MD, Kelley IM, Gocayne JD, Dubnick M, Polymeropoulos MH, Xiao H, Merril CR, Wu A, Olde B, Moreno RF, et al. Complementary DNA sequencing: expressed sequence tags and human genome project. Science. 1991;252:1651-6.

44. Boguski MS, Lowe TM, Tolstoshev CM. dbEST'-database for "expressed sequence tags". Nat Genet. 1993;4:332-3.

45. Nielsen H, Engelbrecht $J$, Brunak $S$, von Heine G. Identification of prokaryotic and eukaryotic signal peptides and prediction of their cleavage siles. Protein Eng. 1997:10:1-6. 
Chapter 2

46. Chien KIR. Stress pathways and heart falure Cell. 1999;98:555-8.

47. Steinmetz LM, Sinha H, Richards DR, Spiegelman J1, Defner PJ, McCusker JH, Davis R.W. Dissecting the architecture of a quantitative trait locus in yeast. Nature. $2002 ; 416: 326-30$. 


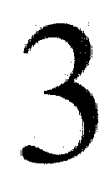

\title{
Identification of Novel Immunological and Matrix-related Genes in Heart Failure and Effect of Early Angiotensin-II Receptor Blockade
}

\author{
Umesh C. Sharma', Saraswati Pokharel ${ }^{1}$, Rudolf A. de Boer ${ }^{2}$, Rudy Duisters ${ }^{1}$, \\ J. Gordon Porter ${ }^{3}$, Chris Evelo", Jos F. M. Smits', Yigal M. Pinto'
}

\footnotetext{
${ }^{1}$ Department of Cardiology/CARIM, University of Maastricht, Maastricht, The Netherlands ${ }^{2}$ Department of Cardiology, University Hospital Groningen, Groningen, The Netherlands. ${ }^{3}$ Incyte Inc, California, USA
}

Part of these data are published in Circulation Research 2004;95:515-22 


\begin{abstract}
This study was designed to elaborate the genes differentially expressed during the transition from compensated liypertrophy to failure. Following the insertion of reningene, the homozygous hypertensive Ren-2 rats diwerge to yield two entirely different pathological states: heart failure (HF) or compensated hypertrophy. We used microarray strategies to discern the mechanism involved in HF development in this model. The transition to failure in Ren-2 rats was found to be accompanied by marked changes in the expression of arrays of genes predominantly associated with immune function and extracellulax matrix (ECM). In addition to previously identified genes in HF e.g., collagens, fibronectin and asteopontin, we report some novel genes like galectin-3, osteoactivin and several other ECM related genes. Most of the upregulated genes normalized following a 4 week course of angiotensin II receptor blockade. However, a proportion of ECM-related genes failed to normalize, and these areas can be the targets of new therapeutic approaches.
\end{abstract}




\section{Introduction}

Cardiac functional decompensation is characterized by myocardial hypertrophy, influx of immune mediators and excessive accumulation of extracellular matrix (ECM) leading to impaired ventricular performance ${ }^{1,2}$. A rat model of hypertension has been extensively used to better understand structural, functional and genetic changes associated with cardiac hypertrophy and failure ${ }^{3}$. Male homozygous transgenic rats carrying 2 copies of mouse renin- 2 genes (Ren- 2 rats) exhibit moderate hypertension, myocardial hypertrophy and excessive fibrosis associated with overproduction of angiotensin-II (Ang-II). These pathological changes can begin as early as 6 weeks of age and $50 \%$ of these rats progress to HF (HF-S) by 13 weeks while the other half remain compensated at least till 17 weeks. This discrepancy may stem from differential expression of key genes orchestrating the transition from mere hypertrophy to failure. Therefore, this model provides an opportunity to compare the gene expression profile in HF susceptible group to that of the resilient group in the same genetic background. Microarrays can provide an effective platform to examine this mechanism in terms of mRNA expression.

We present here application of cDNA microarray technology to identify gene expression profile that distinguishes the 2 groups of Ren-2 rats from age matched wild type control, Sprague Dowley (SD) rats. A total of 12,336 unique cDNA clones collected from rat cDNA library were printed onto microarray and profiled for expression. In order to confirm the data obtained from microarrays we spotted all the up-regulated genes found elevated at least 1.7 fold more in HF-S rats than in HF-R on macroarray after sequence verification of the clones and comparison was made between HF-S and HF-R rats. To explore the possible role of Ang-II involvement, a group of rats were treated with sub-pressure dose of ATI blocker (ARB) from 7 to 11 weeks and subjected to same expression studies. 


\section{Materials and Methods}

Drug and minipump: Candesartan, an ARB was a kind gift from Astrazeneca. It was dissolved in $0.1 \mathrm{M} \mathrm{NaHCO} 3$ in $0.9 \% \mathrm{NaCl}$ according to the manufacturer's instruction. Final dose of $0.05 \mathrm{mg} / \mathrm{kg} / \mathrm{day}$ was administered by an osmotic minipump (Alzet osmotic minipumps, Palo Alto, CA, USA) inserted subcutaneously. Rats were treated for 4 weeks starting from 7 weeks of age.

\section{Homoxygous Ren-2 rats}

The procedures for the care and treatment of animals were approved by the institutional animal care use committee. Homozygous Ren-2 rats were obtained from the Max Delbrück Zentrum für Molekulare Medizin, Berlin, Germany. Sprague Dawley (SD) served as controls. Thirty male Ren2 rats were closely monitored and selected for study upon signs of congestive HF (HF-S). HF-R was studied when clinical signs of congestion had not appeared by $\Perp 7$ weeks of age. A group of rats were treated with $0.05 \mathrm{mg} / \mathrm{kg} / \mathrm{day}$ of candesartan from 7-11 weeks of age and sacrificed at that age. From each group two hearts were used to obtain total RNA for duplicate microarray analysis comparing HF-S to HF-R and each of those with control (SD) using the Incyte ratGEM2 CDNA microarray.

\section{cDNA microarrays}

cDNA clones isolated from a nomalized rat cDNA library were chosen for analysis on microarrays using an Incyte GEM-2/GEM-3 rat cDNA library (total 12,336 genes). PCR-amplified inserts of each cDNA were printed as high-density arrays on treated glass surfaces. Duplicate hybridizations were performed on these array elements with two SD and six Ren-2 rat myocardial mRNAs at 3 different time points. Log transformation of the values was done in order to homogenize the data and only differences in expression of $>1.7$ fold were considered differentially expressed. The protocol for data mining and validation was adopted, as detailed previously ${ }^{4.5}$.

\section{Sequencing, membrane spotting, and cDNA hybridization for macroarray}

Clones of the differentially expressed genes identified by microarray were obtained from Incyte genomics and sequenced with a s'-GGTGACACTATAGAAGAGC-3'primer Eurogentec, Seraing, Belgium). After confurming the identity by sequencing, the plasmid inserts were amplified by a PCR reaction with 5'-ACCATGATTACGCCAAGCTC-3' and 3'-

ACGACGGCCAGTGAATTGAA-5' primers. Each clone was then spotted in duplicate on nylon membranes (macroarray). The dot blots were scanned with a personal fx-phospho imager (Cyclone 
System Packard, Meriden, CO, USA). Individual hybridisation signals were identified and quantified densitometrically using Quantity One, Version 4.2.3 software (BioRad, Munich, Germany). Glyceraldehyde-3-phosphate dehydrogenase (GAPDH) was selected as a housekeeping gene for internal normalization of the blots.

\section{Statistical analyses}

Data are presented as mean \pm SEM. The data for each study group were compared using one-way analysis of variances (ANOVA) in combination with a Dunnett post-hoc analysis to correct for multiple comparisons. SD rats were used as an internal control cohort. Analyses were performed using the statistical package SPSS 10.0 (Chicago, IL, USA). $P$-values $<0.05$ were considered to be statistically significant. 


\section{Results}

\section{Rapid transition to overt HF and death in a subset of Ren-2 rats}

Hypertrophied left and right wentricles were noticed in the 8 rats that were sacrificed at 10 weeks and also in other untreated rats that were sacrificed at later dates. No left ventricular hypertrophy was noticed in SD controls. Six. out of 14 Rem-2 rats on placebo rapidly transited towards overt clinical HF between 12 to 14 weeks of age and had depressed cardiac functional indices compared to the 8 rats that remained compensated throughout the observation period of 17 weeks. Pleural effusion and sharp fall in $\mathrm{dP} / \mathrm{dt}_{\max }$ were noted in HF-S rats; these changes were not apparent in $\mathrm{HF}$ $\mathrm{R}$ rats (Table 1). Angiotensin II blockade completely prevented the development of cardiac hypertrophy and failure (LV weight/body weight \%, 2.52 $10.36, \mathrm{dP} / \mathrm{dt} \mathrm{t}_{\max }, 8400 \pm 202$ ) when evaluated in sacrificed animals at 13 weeks.

Table 1. Hemodynamic parameters and reciprocated tissue and body weights at 12 to 14 -week (HF in susceptible group) and 17-week (compensated hypertiophy) rats

Parameters $12-14$ weeks $(\mathrm{N}=6)$

\begin{tabular}{lllll} 
& SD & Ren-2 (HF group) & SD & Ren-2 (Comp) \\
LVW/BW & $2.21 \pm 0.5$ & $3.91 \pm 0.9^{*}$ & $2.57 \pm 0.1$ & $3.60 \pm 0.5^{*}$ \\
$\mathrm{dP} / \mathrm{dt}_{\max }$ & $9297 \pm 221$ & $3764 \pm 198^{*}, \mathrm{t}^{\dagger}$ & $7612 \pm 124$ & $7814 \pm 658$ \\
$-\mathrm{dP} / \mathrm{dt}_{\text {raax }}$ & $9648 \pm 514$ & $3251 \pm 312^{*}, t$ & $6937 \pm 845$ & $6967 \pm 654$ \\
\hline
\end{tabular}

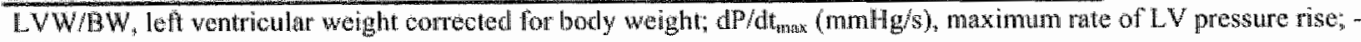

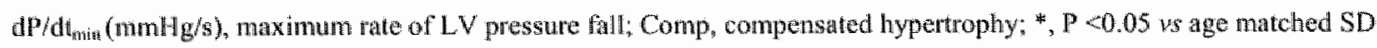
rats: ${ }^{*}, \mathrm{P}<0.01$ ws 17 -woek Ren-2 rats.

\section{Microarray revealed 48 over-expressed genes in HF-susceptible rats}

For microarray analysis, we first examined biological variability in gene expression between $H F-S$ and HF-R groups. The expression levels of most genes in the two HF-S and HF-R groups were very similar. Out of a total of 12,336 genes profiled for expression, only 48 genes survived the multi-step data mining strategy and were oven-expressed in HF-S rats (Tablle 2). Similarly, 14 genes were identified as down-regulated genes in HF. Notably, expression of galectin-3, osteoactivin, TSP-2, several pro-collagens, MHC-II and thrombospondins were increased. Many of the identified genes 
encode proteins with known functions whereas others correspond to genes of unkanown function; including novel genes and genes not previously detected in the heart.

Table 2. Genes significantly differentially regulated in HF rats compared to compensated rats

\begin{tabular}{|c|c|c|c|}
\hline No & Gene Wame & Accession & $\begin{array}{l}\text { Fold Change in } \\
\text { expression }\end{array}$ \\
\hline \multicolumn{4}{|c|}{ Up-regulated genes } \\
\hline $\mathbb{1}$ & Galectin-3 & 502962 & 5.25 \\
\hline 2 & Collagen alphal type 1. & 278279 & 4.6 \\
\hline 3 & Osteoactivin & $Y 13714$ & 4.6 \\
\hline 4 & Promalpha-2 collagen & AF 121217 & 4.55 \\
\hline 5 & Collagen type II & L.48440 & 3.7 \\
\hline 6 & Osteopontin & $\mathrm{ABO01382}$ & 3.7 \\
\hline 7 & Pro alpha 1 collagen & $\times 70369$ & 3.7 \\
\hline 8 & MHC class Il-associated invariant chain & $\times 14254$ & 3.5 \\
\hline 9 & Cryptidlin-4 & $\mathrm{AF} 178040$ & 3.2 \\
\hline 10 & Fibronectin & $X 15906$ & 3.2 \\
\hline$\| 1$ & Tenasicin & D 90343 & 3.0 \\
\hline 12 & Matrix metalloprotease inhibitor (TIMP.1) & L3 1.883 & 3.0 \\
\hline 13 & fribrillin-1 & A.F 135059 & 2.9 \\
\hline 114 & Osteoblast specific factor 2 & $\mathrm{XM} 342245$ & 2.8 \\
\hline 15 & S-100 related protein mRNA & 503627 & 2.7 \\
\hline 16 & Apolipoprotein E gene & $J 02582$ & 2.7 \\
\hline 17 & Lumican & $\times 84039$ & 2.4 \\
\hline 18 & High affinity IgG Fo receptor & M61 171 & 2.3 \\
\hline 19 & Diabetic BB MHC class II alpha chain & $\mathrm{Y} 00480$ & $2 \times 3$ \\
\hline 20 & RTL.B- Ichain of integral membrane protein & $X ! 4879$ & 2.3 \\
\hline 21 & Steroid sensilive gene-1 & $\mathrm{A}: 223677$ & 2,3 \\
\hline 22 & Vimentin & Y07738 & 2.3 \\
\hline 23 & Follistatin-related protein precursor & U06864 & 2.3 \\
\hline 24 & Ferritim light chain & $K 01930$ & 2.3 \\
\hline 25 & Thymosin beta-10 & $M 34043$ & 23 \\
\hline 26 & Cathepsin B & $\times 82396$ & 2.2 \\
\hline 27 & Microfibril-associated glycoprotein-2 & AF180805 & 2.2 \\
\hline 28 & Thrombospondin-1 & $M 62470$ & 21 \\
\hline 29 & Thrombospondin 3 & $\llcorner 24434$ & $2 \times 1$ \\
\hline 30 & Schwannoma-associated protein & $\mathrm{AF} 026124$ & 2.1 \\
\hline 31 & Collagen XII alpha I & U57362 & 2.1 \\
\hline 32 & GPI anchored ceruloplasmin mRNA & AF202115 & 2.1 \\
\hline 33 & Heme-oxygenase gene & $5: 02722$ & 2.1 \\
\hline 34 & Purine-nuclcoside phosphorylase & AA858647 & $2: 1$ \\
\hline 35 & Microfibril-associated glyooprotein & AF 180805 & 21 \\
\hline
\end{tabular}




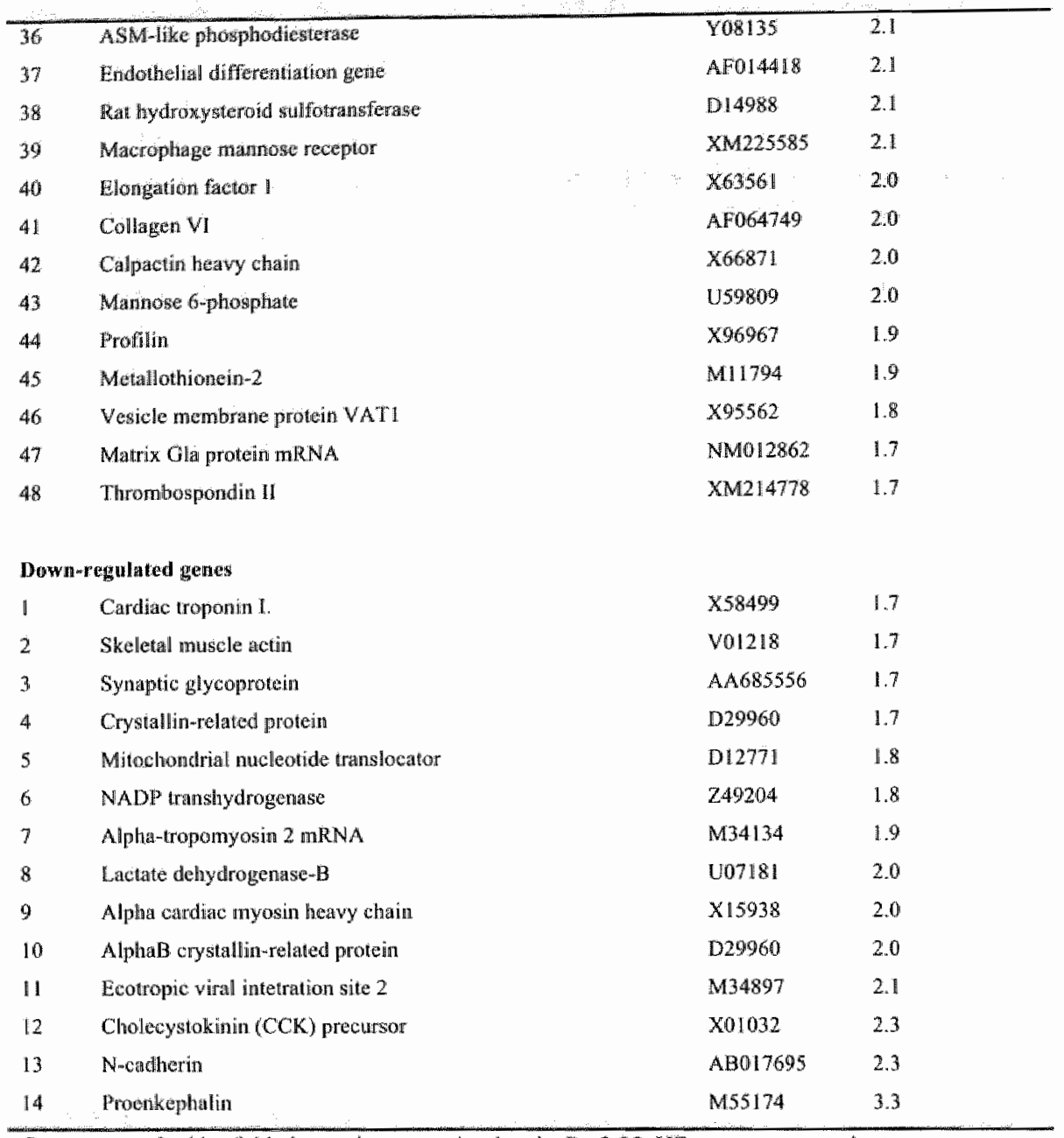

Genes are ranked by hold shange in expression levels. $P<0.05$, HF vs. compensated nats.

\section{Macroarray showed normalization of HF susceptibility genes by angiotensin II blockade}

To confirm the role of the renin-angiotensin system (RAS) activation in this angiotensin-driven model of HF, we re-assessed the expression of the target genes identified by microarray after treating a subgroup of Ren-2 rats with a sub-pressor dose of candesartan from 7 to 13 weeks of age. In addition to improving the hemodynamics, ARB treatment prevented the over-expression of all HF-related candidate genes (data not shown). 


\section{Discussion}

We have used cDNA microarrays to identify the differentially expressed genes during the transition from compensated hypertrophy to failure in homozygous Ren-2 rats. Cowordinated changes in the expression of genes related to immunological and extracellular architecture are consistent with the remodelling process of the failing heart. Many of the identified genes encode proteins with known functions whereas others correspond to genes of unknown function, including novel and genes prewiously not implicated in HF.

Gallectin-3 emerged as the most prominently over-expressed gene with more than 5-fold rise in HF rat myocardium (Table 2). In addition, major histocompatibility complex antigen II (MHC-II), $\mathrm{MHC}$-associated invariant chain peptide, macrophage mannose receptor and immunoglobulin receptors genes were among the over-expressed genes. Up-regulation of immune-related genes, mainly related to the mechanisms of antigen presentation, autoimmune tissue destruction and immunoglobulin receptors indicates that both innate as well as adaptive arms of immune system can influence adversely on cardiac myocyte function and survival. An altered pattern of protein expression can be interpreted as foreign by the immune system leading to an unusual sequence of antigen presentation and clonal expansion of self-reactive cells. This can consequently lead to the production of autoantibodies and pro-inflammatory cytokines. A reduction in immune gene expression following ARB treatment also emphasises the probable anti-inflammatory role of this drug.

Confirming the ability of the current study to identify differentially expressed genes, a number of genes that showed ellevated expression were previously reported as such in HF utilising traditional

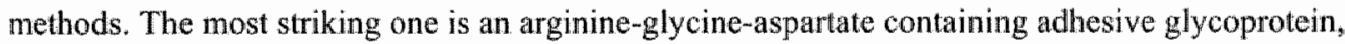
osteopontin ${ }^{6}$. Osteopontin is expressed in several tissues in response to injury suggesting a role in reparative process, and appears capable of mediating diverse biological functions including cell adhesion, chemotaxis and signalling ${ }^{7.9}$. Given the importance of inflammation and ECM reaction. in the pathophysiology of $\mathrm{HF}^{10,11}$ and the known biological activity of osteopontin, it is possible that this interstitial matrix protein plays an important role in the pathogenesis of HF. In our series, a 23-fold increase in osteopontin mRNA expression was noted in HF-S compared to HF-R rats. This was not totally surprising as Ang-II stimulates osteopontin expression by cardiac fibroblasts ${ }^{12}$. In line with this, a 4-week treatment with ARB sharply attenuated the overexpression of osteopontin in Ren-2 rats (HF-S/ATI blockade, 30 fold). 
An interesting novel finding was marked over-expression of osteoactivin (OA), a protein considered to be expressed uniquely in osteoblasts actively engaged in matrix production and maturation ${ }^{13}$. Little is known about the function of this protein in relation to cardiac pathophysiology. Knowledge of the expression behaviour under different conditions, combined with structural and functional analyses of the gene and its regulation should be used to elucidate the function. However, combining clustered expression data structural information for a gene will possibly help in predicting the function. Angiotensin II could still be a crucial factor inducing the expression of OA gene in HF-S rats as we could see 23 fold up-regulation of this gene compared to that in HF-R rat myocardium. Equally interesting was the dramatic fall in OA gene expression following a 4 week ARB treatment (HF-S/ATl blockade, 50-fold).

We observed an increase in several other genes implicated in HF. In keeping with the results of previous investigators, we noted at least 2-fold up-regulation of collagen type I, II, III, XII and XIV in HF-S rats; the over-expression was attenuated by early ARB therapy. We have previously shown that induction of fibronectin expression is an intrinsic feature of development of HF in Ren-2 rats and increased production of fibronectin is linked to excessive fibrosis. We found here a similar pattern i.e., up-regulation of fibronectin in HF-S rats. Interestingly, this gene also revealed a very high sensitivity to ARB. However, some components of ECM gene like vimentin and collagen type IX $\alpha-3$ were apparently unaltered with the treatment with sub-pressure dose of ARB therapy indicating that the expression of these genes could be predominantly blood pressure dependent.

Further, up-regulation of immune genes, mainly related to the mechanisms of antigen presentation, autoimmune tissue destruction and immunoglobulin receptors indicates that both innate as well as adaptive arms of immune system can influence adversely on cardiac myocyte function and survival. An altered pattern of protein expression can be interpreted as foreign by the immune system leading to an unusual sequence of antigen presentation and clonal expansion of self-reactive cells. This can consequently lead to the production of autoantibodies and pro-inflammatory cytokines. A reduction in immune gene expression following ARB treatment also emphasises the probable antiinflammatory role of this drug.

The data presented in this study refer to a large number of genes putatively involved in HF. These could still be associated with limited number of shared regulatory motifs and transcriptional factors 
that are yet to be defined. Similarly, further research needs to be done in order to distinguish the HF causative genes from the merely over-expressed genes as an epiphenomenon of HF.

Finally, we conclude that gene expression profile identified in this study represents a genetic fingerprint for human HF. A large number of genes that encode immunological and ECM-related proteins displayed an enhanced expression and early ARB treatment effectively counteracted the up-regulation of most of HF-related genes. 


\section{References}

1. Zihe MR, Brutsaert DL. New concepts in diastolic dysfunction and diastolic heart failure: Part I: diagnosis, prognosis, and measurements of diastolic function. Circulation. 2002:105:1387-93.

2. Wilson EM, Spinale FG. Myocardial remodelling and matrix metalloproteinases in heart failure: turmoil within the interstitium. Ann Med. $2001 ; 33: 623-34$.

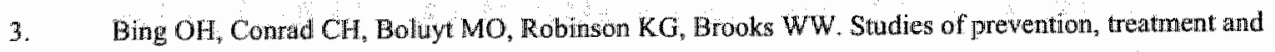
mecheinisms of heart failure in the aging spontaneously hypertensive rat. Heart Fail Rev. 2002;7:71-88.

4. Tan FL, Moravec CS, Li I, Apperson-Hansen C, MoCarthy PM, Young JB, Bond M. The gene expression fingerprint of human heart failure. Proc Natl Awod Sci U S A. 2002;99:11387-92.

5. Bandman O, Coleman RT, Loring $\mathrm{JF}$, Seilhamer JJ, Cocks BG. Complexity of inflammatory responses in endothelial cells and vascular smooth muscle cells determined by microarray analysis. Am NY Acad Sci. 2002:975:77-90.

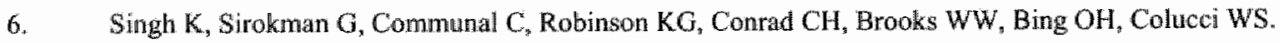
Myocardial osteopontin expression coincides with the development of heart failure. Hypertension. $1999 ; 33: 669-70$.

7. Murry $\mathrm{CE}_{\mathrm{n}}$ Giachelli $\mathrm{CM}$, Schwartz SM, Vracko R. Macrophages express osteopontin during repair of myocardial necrosis. Am J Parhol. 1994; 145:1450-62.

8. Williams EB, Halpert I, Wickline S, Davison G, Parks WC, Rottman JN. Osteopontin expression is increased in the heritable cardiomyopathy of Syrian hamsters. Circulation. 1995;92:705-9.

9. Panda D, Kundu GC, Lee BI, Peri A, Fohl D, Chackalaparampil I, Mukherjee BB, Li XD, Mukherjee DC, Seides $S$, Rosenberg $J_{3}$ Stark $K$, Mukherjee $A B$. Potential roles of osteopontin and alpha Vbeta 3 integrin in the development of coronary artery restenosis after angioplasty. Proc Nar Acad Sci U S A. 1997;94:9308-13.

10. Weber KT. Extracellular matrix remodeling in heart failure: a role for de novo angiotensin Il generation. Circulation. 1997;96:4065-82.

11. Carver W, Molano I, Reaves TA, Barg TK, Terracio L. Rolle of the alpha I beta 1 integrin complex in collagen gel contraction in witro by fibroblasts. d Cell Physiol. 1995;165:425-37.

12. Ashizawa N, Graf K, Do YS, Nunohiro T, Gachelli CM, Meehan WP, Tuan TL, Hsueh WA. Osteopontin is produced by rat cardiac fibroblasts and mediates A(II)-induced DNA synthesis and collagen gel contraction. $J$ Clis Inwest. 1996;98:2218-27.

13. Satadi FF, Xu J, Smock SL, Rico MC, Owen TA, Popoff SN. Cloning and characterization of osteoactivin, a novel cDNA expressed in osteoblasts. $/ \mathrm{Cel}$ Biochem. 2001;84:12-26. 


\section{4}

\section{Galectin-3 Marks Activated Macrophages in Failure Prone Hypertrophied Hearts and Contributes to Cardiac Dysfunction}

Umesh C. Sharma, MB BS, MSc ${ }^{1,2}$, Saraswati Pokharel, MB BS', Thomas J. van Brakel, MD², Jop H. van Berlo, MD' Jack P.M. Cleutjens, $\mathrm{PhD}^{3}$, Blanche Schroen, $\mathrm{MSc}^{1}$, Sabine André, PhD ${ }^{4}$, Harry J.G.M. Crijns, $\mathrm{MD}, \mathrm{PhD}^{1}$, Hans-J. Gabius, $\mathrm{PhD}^{4}$, Jos Maessen, $\mathrm{MD}, \mathrm{PhD}^{2}$ and Yigal M. Pinto, MD, $\mathrm{PhD}^{1}$

'Experimental and Molecular Cardiology Laboratory, Department of Cardiology, Cardiovascular Research Institute Maastricht (CARIM), University Hospital Maastricht, Maastricht, The Netherlands ${ }^{2}$ Department of Cardiothoracic Surgery, University Hospital Maastricht, Maastricht, The Netherlands ${ }^{3}$ Department of Pathology, CARIM, University of Maastricht, Maastricht, The Netherlands ${ }^{4}$ Institute of Physiological Chemistry, Faculty of Veterinary Medicine, Ludwig-Maximilians University, Munich, Germany

Circulation 2004;110:3121-8

Abstract presented in the Scientific Sessions of American Heart Association Meeting, 2004 


\begin{abstract}
Background: Inflammatory mechanisms have been proposed to be important in heart failure (HF), and cy tokines have been implicated to add to the progression of $\mathrm{HF}$. However, it is unclear whether such thechanisms are already activated when hypertrophied hearts still appear well-compensated and whether such early mechanisms contribute to the development of HF.

Methods and Reswils: In a comprehensive micro-array study, galectin-3 emerged as the most robustly overexpressed gene in failing ws. functionally compensated hearts from homozygows transgenic TGRmRen2-27 (Ren-2) rats. Myocardial biopsies obtained at an early stage of hypertrophy before apparent HF showed that expression of galectin-3 was increased specifically in the rats that later rapidly developed HF. Galectin-3 co-localized with activated myocardial macrophages. We found galectin-3 binding sites in rat cardiac fibroblasts and the extracellular matrix. Recombinant galectin-3 induced cardiac fibroblast proliferation, collagen production and cyclin D1 expression. A 4-week continuous infusion of low-dose galectin-3 into the pericardial sac of healthy Sprague Dawley rats led to left ventricular dysfunction with a 3-fold differential increase of collagen I over collagen III. Myocardial gallectin-3 expression was increased in aortic stenosis patients with depressed ejection fraction.
\end{abstract}

Conclusions: This study shows that an early increase in galectin-3 expression identifies failureprone hypertrophied hearts. Galectin-3, a macrophage-derived mediator, induces cardiac fibroblast proliferation, collagen deposition and ventricular dysfunction. This implies that HF-therapy aimed at inflammatory responses may need to be targeted at the early stages of HF and probably needs to antagonize multiple inflammatory mediators, including galectin-3. 


\section{Introduction}

Despite state-of-the art treatment, heart failure (HF) is still a progressive disorder characterized by high morbidity and mortality, suggesting that important pathogenic mechanisms remain active and unmodified by current treatment'. A growing body of evidence links macrophage activation and fibrosis to the pathogenesis of $\mathrm{HF}^{2,3}$. Accordingly, there has been increasing interest in developing therapeutic agents with anti-cytokine properties that might be used as adjunctive therapy in patients with HF. In particular, the growing appreciation of elevated levels of the pleiotropic cyiokine TNF$\alpha$ in patients with HF culminated in clinical studies on TNF-a inhibition. However, these trials did not support the utility of TNF- $\alpha$ antagonism as a treatment modality of HF ${ }^{4.5}$. Therefore, the question arises whether inflammatory mechanisms merely reflect a general stress-response of an organism in severe HF or whether such inflammatory response already starts early in the pathogenesis of HF, and comprises a broader range of cardio-toxic mediators.

Our recent micro-array study performed in a rat model of hypertensive $\mathrm{HF}$ allowed us to evaluate immunological mediators specific to hypertrophied hearts that have transited to failure ${ }^{6}$. Among a number of candidate genes, we have focused on galectin-3 as the most robustly over-expressed mediator in failing hearts. Galectin-3 is a member of a large family of $\beta$-galactoside-binding animal lectins. Macrophages show increased galectin-3 expression at phagocytic cups and phagosomes during the process of phagocytosis ${ }^{7}$. Gallectin-3 interacts with various ligands located at the extracellular matrix including laminin, collagen, synexin and integrins ${ }^{8,9}$. The route of import for galectin-3 from extracellular milieu to cytoplasm is shown to be mediated by $\beta 1$-integrin". Extracellular galectir-3 mediates cell migration and cell-cell interactions, while intracellular galectin-3 regulates cell cycle and apoptosis ${ }^{10}$. Galectin-3 overexpression causes changes in the expression levels of cell cycle regulators, including cyclin DI and the growth promoting activity of galectin-3 is predominantly dependent on cyclin D 1 promotor activity ${ }^{\prime \prime}$.

Here we report that myocardial galectin-3 expression is already increased at an early time-point in rats that later rapidly progressed to HF. Furthermore, recombinant galectin-3 infused into the pericardial sac of healthy Sprague Dawley rats induced HF and excess collagen deposition. At the molecular level, galectin-3 increased the expression of cyclin DI in dividing fibroblasts and failing myocardium. This study demonstrates a novel pathogenic role of macrophage activation and galectin-3 production in the deterioration of cardiac architecture and function. 


\section{Materials and methods}

\section{Characteristics of the $\operatorname{Ren}-2$ rats}

We studied 14 male homozygous Ren-2 rats and 9 age-matched Sprague-Dawley (SD) rats (MaxDelbruck-Zentrum, Berlin, Germany). Of the 14 Ren-2 rats, 6 were sacrificed at $12-14$ weeks upon clinical signs of HF, and remaining \& Ren-2 rats were monitored and sacrificed at 17 weeks when clinical signs of falure had not appeared. At 10 weeks, none of the Ren-2 rats developed HF, and at this stage all the Ren-2 rats had comparable LV hypertrophy, irrespective of the future consequence of either failure or prolonged compensation. We have separately reported the cDNA microarray experiment (total 12,336 genes; Incyte Genomics, CA, USA, rat GEM2/3) that showed an increased expression of 48 genes and decreased expression of 14 genes in failing hypertrophied as opposed to compensated hypertrophied hearts ${ }^{6}$. The current study is based on the further validation and mechanistic elucidation of the inflammatory and fibrotic response seen specifically in failing hearts.

\section{Myocardial biopsies from 10-week $\operatorname{Ren}-2$ rats}

A total of 12 Ren- 2 and 4 SD rats were anesthetized with $2 \%$ isoflurane and a blunt 20 -gauge needle was placed in the trachea for intubation, which was connected to a volume-cycled rodent respirator (model 683, Harvard Apparatus, South Natick, MA) on room air with a tidal volume of 2.5 to $3 \mathrm{ml}$ and respiratory rate of 80 breaths/min. With the visual help of a micro-dissecting microscope, a $5 \mathrm{~mm}$ incision at the left $4^{\text {th }}$ intercostal space was made to access the thorax. Three biopsy specimens were taken from the lateral LV myocardium of each rat using a custom-made $0.35 \mathrm{~mm}$ needle. Nine out of 12 Ren- 2 rats survived the procedure and were followed up. Five rats developed HF by 12-14 weeks, whereas remaining 4 rats stayed compensated until the end of the observation period of 18 weeks. The institutional animal care committee approved the procedure for care and treatment of animals.

\section{Recombinant gallectin-3 production and infusion into the pericardial space}

Murine recombinant galectin-3 expressed from plasmid prCBP35s was purified by aflinity chromatography on lactosylated Sepharose $4 \mathrm{~B}$, produced by divinyl sulfone activation. The purity of the obtained protein was studied by gel filtration and one- and two-dimensional gel electrophoresis to exclude any contamination or protein modification ${ }^{12}$.

We infused recombinant galectin-3 into the pericardial cavity of 6 SD rats. Similarly, 6 additional SD rats underwent an identical surgical procedure but received normal saline infusion. Three separate SD rats received biotinylated galectin-3 intrapericardially, to locate galectin-3 binding sites 
in the myocardium. To install the pericardial catheter, rats were anesthetized with subetuneous pentobarbital sodium $(50 \mathrm{mg} / \mathrm{kg}$ ) and a high midine thoracotomy was performed. A small incision in the pericardial sac was made, and a silicone catheter (diameter: $0.51 \mathrm{~mm}$; Degania Bet, Israe) was inserted. The catheter was subcutaneously fixed and connected to an osmotic minipump that was set to pump $0.5 \mu \mathrm{g}$ galectin-3 per hour for a total duration of 4 weeks. The dose of galectin-3 was calculated based on reported bio-activity, adjusting for the local advantage of pericardial delivery ${ }^{13}$.

\section{Measurement of cardiac geometry and function}

Echocardiography was done at 0,14 and 28 days of galectin- 3 infusion in rats sedated with $2 \%$ isoflurane. Standard views were obtained in 2-D as well as M-Mode with a 12-MHz transducer (Hewlett Packard, Amsterdam, The Netherlands) with approximately 220 frames per recording and the data analysis was made by a blinded observer.

Before sacrifice, hemodynamic parameters were measured. Following anaesthesia by intraperitoneal injection of urethane $(1 \mathrm{~g} / \mathrm{kg})$, the right carotid artery was cannulated with a 2 French high-fidelity micromanometer (Millar Instruments, Houston, TX), and the catheter was advanced into the left ventricle. The output signal from the micromanometer was digitized at $4000 \mathrm{~Hz}$ with a MacLab system (ADI Instruments, Castle Hill, Australia).

\section{RNA isolation and real time PCR}

A complete list for the primers and probes of the galectin-3 gene transcripts is presented as the supplementary material (data addendum 1). RNA was isolated from rat left ventricle with the RNeasy ${ }^{6}$ Mini Kit following the RNeasy Mini Protocol (QIAGEN, Hilden, Germany) and stored at $-80^{\circ} \mathrm{C}$. RNA was isolated from rat and human heart biopsies with the Picopure ${ }^{2}$ RNA Isolation Kit (Arcturus, CA, USA) according to manufacturer's instructions. Optimal PCR conditions were found to be $12.5 \mu \mathrm{l} 2 \times$ PCR Master Mix for Tagrnan ${ }^{\mathrm{M}}$ assays with final concentration of $5 \mathrm{mM} \mathrm{MgCl} \mathrm{I}_{2}$, $300 \mathrm{nM}$ of each primer, $200 \mathrm{nM}$ probe and $10 \mathrm{ng}$ cDNA-lemplate in a total volume of $25 \mu 1$.

\section{Protein isolation and Western blotting}

Protein isolation and Western blotting were performed as described previously ${ }^{14}$. Primary antibodies (Galectin-3, Bioreagents, Breda, The Netherlands; Collagen-I and Collagen-III, Abcam, Cambridge, UK; ED-1 and OX-6, a kind gift from Dr. M. de Winther, Department of Molecular 
Genetics, University of Mastricht, The Netherlands; Cyclin D1, Cell Signaling Technologies, Leusden, The Netherlands) were diluted 1/1000 in tris-buffer saline with tween-20 (TBS-T). Secondary antibody (horseradish-peroxidase conjugated $\operatorname{lgO}_{*}$ Cell Signaling Technology, Leusden, The Netherlands) was diluted $1 / 2000$ in TBS-T. Protein bands were visualized by enhanced chemiluminescence technique.

\section{In-situ hybridization, immunohistochemistry, galectin-3 cytochemistry and confocal microscopy}

To localize galectin-3 mRN.A, we used a non-radioactive in-situ hybridization assay. A. DIG-labeled oligonucleuotide probe was used for the hybridization according to the manufacturer's instructions (GeneDetect, Auckland, New Zealand). The extent of specific binding was visualized by application of avidin-biotin-peroxidase complex (ABC) kit reagents (Vector Labs, Burlingame, CA, USA). The expression of galectin-3 protein and accessible binding sites were visualized by a specific anti-galectin-3 monoclonal antibody and biotinylated galectin-3, as described. previously ${ }^{12}$. For confocal laser scanning microscopy experiments, galectin-3 binding sites were detected by FITC-labelled avidin. A Texas-red labelled secondary antibody was used to visualize immunocytochemically the proliferating nuclear antigen (PCNA). Further details on the procedure are available elsewhere ${ }^{15}$.

\section{Cardiac fibroblast proliferation and proline incorporation assays}

Rat cardiac fibroblasts were isolated from 2-day-old neonatal Sprague-Dawley rats, as described previously ".t. Cells were cultured in Dulbeco's modification of Eagle's medium (DMEM) supplemented with $10 \%$ foetal bovine serum (FBS), along with $1 \% \mathrm{~L}$-glutamate, $50 \mathrm{U} / \mathrm{mL}$ penicillin, and $0.1 \mathrm{~g} / \mathrm{L}$ streptomycin, and were incubated at $37^{\circ} \mathrm{C}$ in a humidified $5 \% \mathrm{CO}_{2}$ atmosphere. Synchronized cells were treated with murine recombinant galectin-3 (control, $10 \mu g / \mathrm{ml}$ and $30 \mu \mathrm{g} / \mathrm{ml}$ ) for 24 hours. The number of dividing cells was determined by radio-labelled methyl$\left[{ }^{3} \mathrm{H}\right]$ thymidine incorporation $(0.5 \mu \mathrm{Ci}$ per well) assay. Collagen production by these cells was measured by $\left[{ }^{3} \mathrm{H}\right]$ proline uptake, following a $72-$ hour treatment of galectin-3 (control, $10 \mu \mathrm{g} / \mathrm{ml}$ and $30 \mathrm{\mu g} / \mathrm{ml}$ ). The assays were done in triplicate for fibroblast preparations.

\section{Human studies}

We obtained cardiac biopsies from patients undergoing aortic valve replacement for aortic stenosis. For the study of gene expression in these human biopsies, we selected 5 aortic stenosis patients with 
cardiac hypertrophy and relatively depressed ejection fraction $(<55 \%)$, and 17 aortic stenosis subjects with LV hypertrophy and normal or elevated ejection fraction. Patients underwent a detailed cardiovascular assessment by echocardiography (ECHO) before operation (Table 1). The myocardial biopsies were collected and snap-frozen in liquid nitrogen. Informed consent was obtained from the patients and the institutional medical ethical committee approved the study.

\section{Statistical analyses}

Data are presented as mean \pm SEM. The paired comparisons were made by unpaired $t$-test. For multiple comparisons, one-way analysis of variances (ANOVA) in combination with a Dunnett post-hoc analysis was made. Analyses were performed using the statistical package SPSS 10:0 (Chicago, IL, USA). P-values $<0.05$ were considered to be statistically significant.

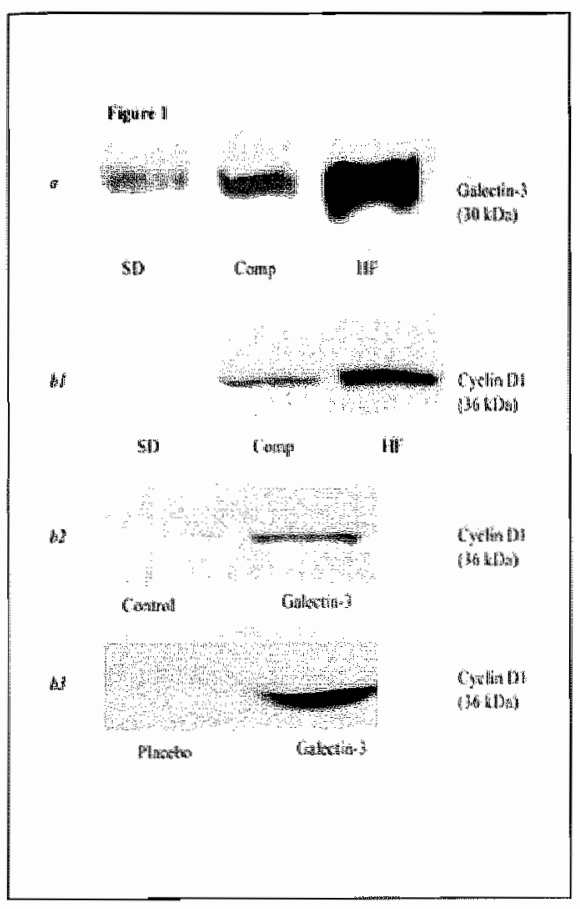

Figare 1. Immunoblot for the detection of galectin-3 and cyclin D1. $a$, Representative blot for galectin-3 in failing and compensated rat myocardial homogenates and SD controls; $b_{1}$, comparison for cyclin D1 expression in failing and compensated Ren-2 rat hearts and SD controls; $b_{2}$, induction of cyclin D1 in cardiac fibroblasts treated with gallectio- 3 compared to controls; $b_{3}$ induction of cyclin DI after intrapericardial infusion of galectin -3 compared to placebo infused tat hearts. HF, hearl failure; Comp, compensated; SD, Sprague Dawley; $\mathrm{N}=4-6$ for each experimental group. 


\section{Results}

\section{Increased myocardial colligen content in failing Ren-2 rats}

A computer-assisted densitometric analysis of the picrosirius red stained sections for the quaritification of myocardial collagen revealed higher degree of interstitial collagen content in the failing Ren-2 rats, compared to compensated and wild-type rats (interstitial collagen volume fraction \%: HF, $7.8 \pm 0.38 ;$ compersated, $3.8 \pm 0.54$; wild type, $2.5 \pm 0.3, \mathrm{P}<0.05$ vs. compensated and wild type).

\section{Microarray data revealed an inflammatory gene profile in failling hearts}

The micro-array analysis has been described separately, and the differentially expressed genes are available as supplementary material for that paper". In this study, we focused on galectin-3, which emerged as the most prominently overexpressed gene with a more than 5 -fold rise in HF rat myocardium compared to compensated hypertrophied myocardium. In addition, major histocompatibility complex antigen II (MHC-II), MHC-associated invariant chain peptide, macrophage mannose receptor and immunoglobulin receptors genes were among the overexpressed genes.

\section{Western blotting showed high galectin-3 expression in failing myocardium}

Given the robust transcriptional increase in galectin-3, we measured its protein levels in the myocardium. Comparable to the results obtained in the microarray, the highest expression level of galectin-3 protein was observed in the same group of animals that had the highest degree of cardiac fibrosis and had developed heart faihure by 12-14 weeks (densitometric units, HF, 94.66 19.5 ; compensated, $35 \pm 5.6 ;$ controls, 27.216.2; $\mathrm{P}<0.05$ vs. compensated and controls) (Figure 1 a).

\section{Localization of galectin-3 to activated macrophages}

We evaluated the source and distribution of galectin-3 in the rat myocardium by in situ hybridization and immunohistochemistry. Importantly, galectin-3 positivity was seen in the areas of fibrosis (Figure 2 all). Galectin-3 positive areas co-localized with macrophage specific staining (Figure 2 bl). These macrophages strongly expressed MHC-II antigen too, indicating an active role of these cells in antigen presentation (Figure $2 \mathrm{cl}$ ). These characteristics were present only in HF rats and not in compensated rats (Figure $2 a 2, b 2$ and $c 2$ ) and wild-type SD rats (Figure 2 a3, b3 and $c 3$ ). The galectin-3 mRNA expression, as shown by in situ hybridization, localized to the cells. 
infiltrated to the areas of myocardial tissue damage (Figure $2 d I$ ). The nomal SD rat myocardum, in contrast, lacked the galectin-3 producing cellular infiltrates (Figure $2 \mathrm{~d} 2$ ).

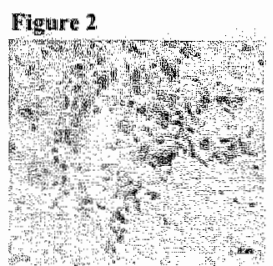

47

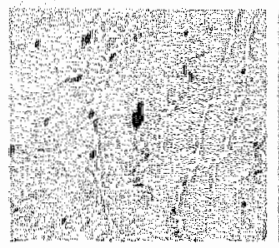

42

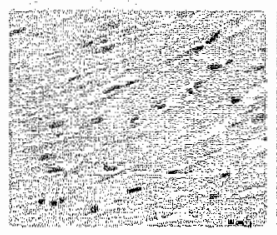

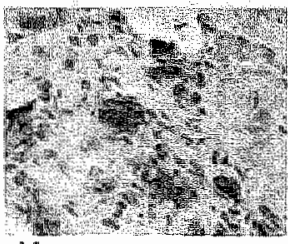

br

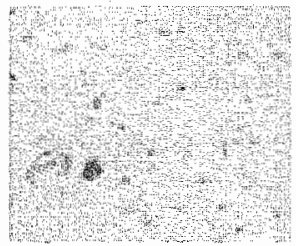

b2

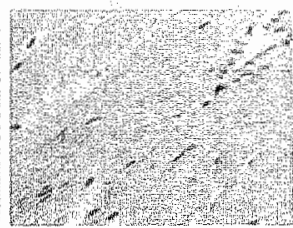

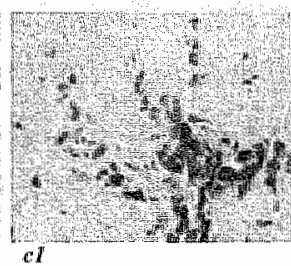
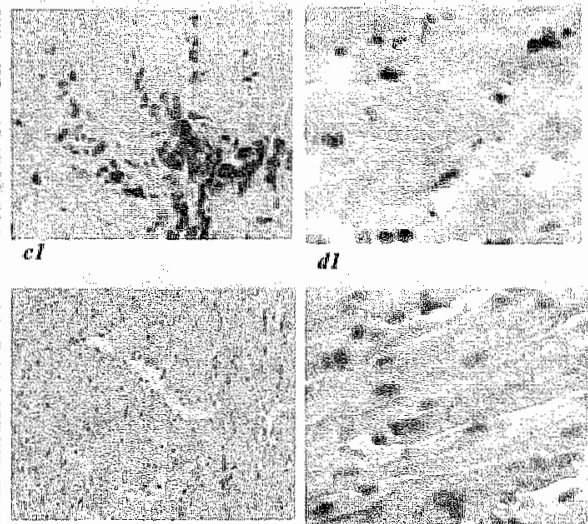

(2)
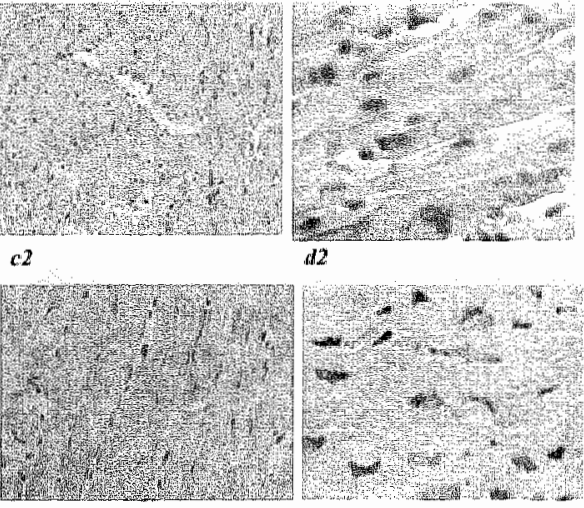

Figure 2. Immunoluistochemistry, in situ hybridizations and ligand histochemistry to localize galectin-3 and its binding sites in rat myocardium. $a l, b l$ and $c l_{\text {. }}$ Myocardial sections obtained from failing Ren-2 rat hearts stained for anti-galectin-3, macrophage specific anti-CD68 and major histocompatibility complex II (MHC-11) specific OX-6 antibody respectively. $a 2, b 2$ and $c 2$, galectin -3 , macrophages and MHC-II probed in the sections obtained from compensated Ren-2 rat hearts; $a 3, b 3$ and $c 3$, the same nolecules tested in the sections obtained from nomal wild-typo rats. $d I$ and $d 2$, in situ hybridization of galectin-3 mRNA in failing Ren-2 (panel d1) and nomal wild-type rat nyyocardium (panell d2) where intense brown staining indicates galectin-3 mRNA localized to the cell infiltrates between the larger non-stained myocytes in the damaged myocardium of failing hearts; $e$, ligand histochemistry after I-week of intrapericardial infusion of biotinylated galectin-3 to localize the cell types inwolwed in the active binding of galectin-3; magnification $(a-e, \times 200)$. 


\section{Galectin-3 binding sites in extracellular matrix and cardiac fibroblasts}

We infused biotinylated galectin-3 into the pericardial sac to visualize galectin-3 binding sites in wivo in the myocardium. Galectin 3 binding sites predominantly localized to the myocardial matrix and fibroblasts (Figure $2 e$ ). In vitro, gallectin-3 binding sites were seen as diffuse cytoplasmic staining in resting cells (Fugure 3 a). However, proliferating fibroblasts showed enhanced staining around the nucleus, revealing a mitosis-related alteration in staining profile (Figure 3 b). We performed similar experiments in isolated cardiomyocytes to localize accessible galectin-3 binding sites. In contrast to cardiac fibroblasts, galectin-3 binding sites were absent from cardiomyocytes (Figure 3 c). Confocal microscopy confirmed compact presence of accessible galectin-3 ligands around the nucleus in proliferating (i.e., PCNA positive) cardiac fibroblasts (Figure $3 d$, $e$ and $f$ ) reflecting that in mitotic cells, galectin-3 binding sites migrate to peri-nuclear areas ${ }^{16}$.

\section{Aigure 3}

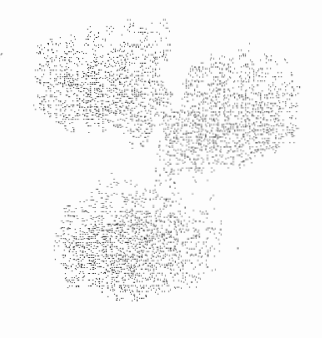

a

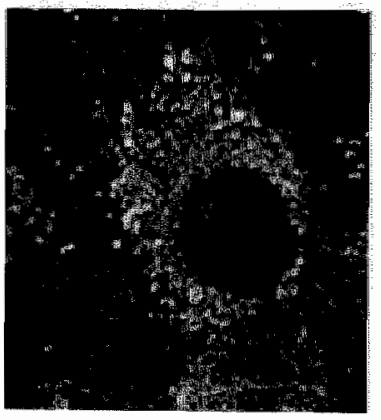

$d$

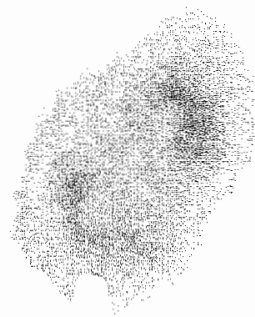

b

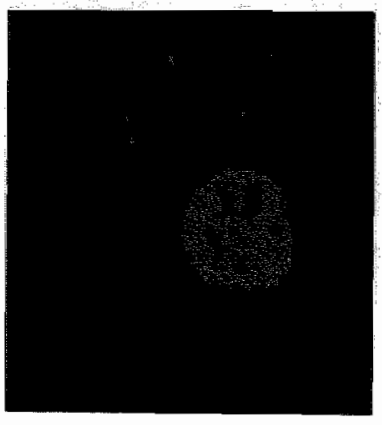

$e$

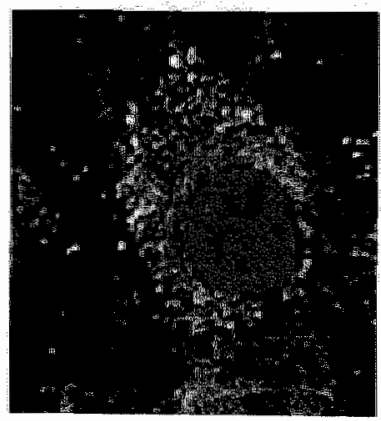

f

Figure 3. Galectin-3 ligand cytochemistry and confocal mictoscopy. a, Serum-depleted cells showed diffuse cytoplasmic as well as perinuclear presence of galectin-3 binding sites; $b$, serum-enriched cells showed mitosis with predominantly perinuclear galectin-3 binding sites; $c$, cardiomyocytes stamed negative for galectin-3 binding sites; $d$, immunofluoresent microscopy for galectin-3 binding sites (shown in green); $e$, nuclei stained for PCNA in red; $f$, con-focal mode from the same plane of focus. 


\section{Galectin-3 induced fibroblast proliferation and collagen production in vitro}

Exogenous recombinant galectin-3 (10 and $30 \mu \mathrm{g} / \mathrm{ml})$ significantly increased cardiac fibroblast proliferation as determined by ${ }^{3} \mathrm{H}$-Thymidine incorporation (galectin-3 at $30 \mu \mathrm{g} / \mathrm{ml}, 347 \pm 17.5$ counts per minute (cpm); galectin-3 at $10 \mu \mathrm{g} / \mathrm{ml} 309 \pm 4.8 \mathrm{cpm}$; control, $145 \pm 4.8 ; \mathrm{P}<0.05$ w. 10 $\mu \mathrm{g} / \mathrm{ml}$ and control) (Figure $4 \mathrm{a}$ ). We then monitored the collagen production by cardisac fibroblasts with the addition of exogenous galectin-3 using radioactive proline-incorporation assays. With 30 $\mu \mathrm{g} / \mathrm{ml}$ of galectin-3 in the medium, proline incorporation increased by approximately $66 \%$ (galectin-3 at $30 \mu \mathrm{g} / \mathrm{ml}, 1066 \pm 56 \mathrm{cpm}$; control, $707 \pm 52.8 \mathrm{cpm} ; \mathrm{P}<0.05$ ). A lower concentration of galectin-3 failed to produce significant effects (galectin-3 at $10 \mu \mathrm{g} / \mathrm{ml} 992 \pm 72 \mathrm{cpm} ; \mathrm{P}=0.13$ ) (Figure $4 b$ ).

\section{Real time PCR showed high galectin-3 expression in failure-prone Ren-2 rat and dysfunctional human hearts}

To evaluate the expression of galectin-3 in the myocardium at the stage before Ren-2 rats progressed to HF (i.e., 10 weeks of age), we obtained cardiac biopsies in vivo in the spontaneously beating rat heart. Measured by real-time PCR, myocardial expression of gallectin-3 gene was increased only in the rats that later progressed to $\mathrm{HF}$ (relative expression, 5.8 \pm 0.11 ), while it was expressed at relatively lower levels in the rats that subsequently remained compensated (3.4t0.21), and in non-transgenic control rat hearts (2.5 10.047) (Figure 5 a). In human myocardial biopsies, there was significantly higher myocardiall galectin-3 mRNA expression in hypertroplied hearts with relatively impaired ejection fraction as compared to the compensated forms of cardiac hypertrophy (relative expression- failure, $7.08 \pm 1.17 \mathrm{vs}$, hypertrophy, $4.60 \pm 0.51 ; \mathrm{P}<0.05$ ) (Figure 5 b). To measure galectin-3 mRNA expression in non-hypertrophied hearts, we obtained myocardial biopsies from the patients without aortic stenosis, undergoing cardiac surgery for coronary artery bypass grafting (CABG). Compared to the expression levels observed in aortic stenosis, real-time PCR analysis showed that galectin-3 mRNA expression was lowest in non-hypertrophied hearts from patients undergoing $\mathrm{CABG}$ (relative expression, normalized to cyclophilin $\mathrm{A}, 3.4 \pm 0.21, \mathrm{~N}=5$ ).

\section{Intrapericardial infusion of gallectin-3 induced LV dysfunction and increased collagen I/II} ratio

To address whether chronically elevated levels of galectin-3, specifically in the heart, can induce HF and to avoid potential systemic effect of galectin-3, we designed a novel approach of intrapericardial infusion of galectin-3 in healthy rats. At baseline, there was no significant 
difference in cardiac function between the galectin-3 and placebo infused rats. Rats infused with galectin-3 for 4 weeks into the pericardial space showed depressed LV ejection fraction, fractional shortening and the amplitude of the megative slope of DP/ $\mathrm{dt}_{\text {max }}$ and increased lung weight to body weight ratio, compared to rats receiving placebo infusion $=($ Table 2$)$. Quantification of collagen content from the LV myocardium showed increased collagen volume fraction in galectin-3 infused rats (figure 6 a). Western blotting revealed a marked increase in collagen I in galectin-3 infused myocardium (densitometric units, galectin-3 infused, $149 \pm 13$; placebo, 44 $\pm 6, \mathrm{P}<0.01$ ). However, no difference was observed in the level of collagen III (galectin-3 infused, $84 \pm 14$; placebo, $70 \pm 2$, $\mathrm{P}=\mathrm{NS}$ ) (Fugure 6 b). The relative abundance of collagen type I was discernible as there was 3-fold increase in collagen type I/III ratio (Figure $6 c$ ).

\section{Figure 4}

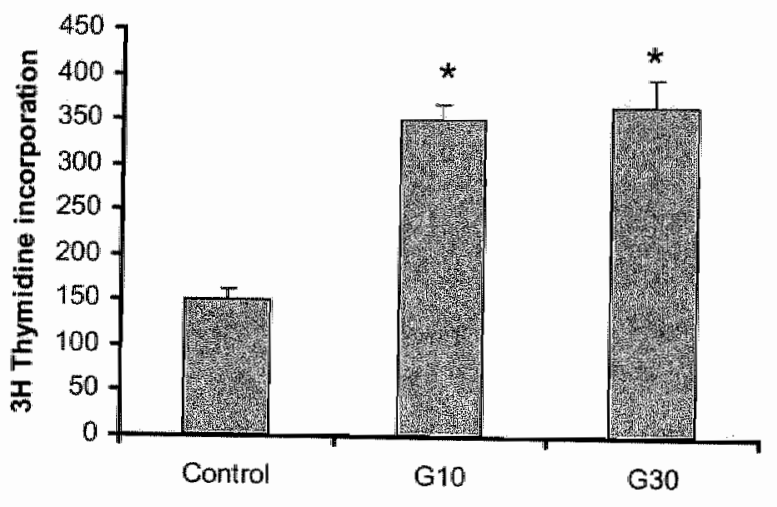

Figure 4. Effects of gallectin-3 on cell proliferation and collagen praduction. $a$, Effect of galectin-3 on tritiated-thymidine incomporation by dividing fibroblasts, $b$, effect of galectin-3 on tritiated-proline incorporation as a measurement of collagen production in vitro $*, P<0.05$ us control. G10 and G30 refer to presence of 10 and $30 \mathrm{\mu g} / \mathrm{ml}$ of galectin- 3 in the medium, respectively.

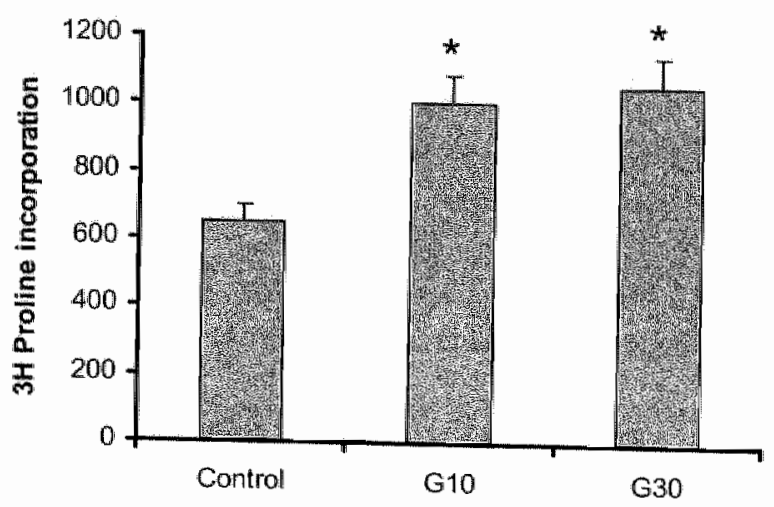




\section{Galectin-3 induced cyclin D1 expression in vivo and in vitro}

We analyzed a potential mediator of the proliferative effects of galectin-3 by measuring the inducible expression of cyclin D1, an important early cell cycle regulator. Failing Ren 2 rats had a higher level of myocardial cyclin D1 expression compared to compensated Ren-2 and wild-type SD rats (densitometric units, $\mathrm{HF}_{3}, 38.7 \pm 5.5$; compensated, $3.7 \pm 1.7 ; \mathrm{SD}, 2.3 \pm 0.6 ; \mathrm{P}<0.05$ HF ws. compensated) (Figure $1 b_{1}$ ). In proliferating cardiac fibroblasts, galectin-3 increased cyclin D1 expression (galectin-3 treated, $4.2 \pm 0.57$; controls; $1.4 \pm 0.41 ; \mathrm{P}<0.05$ ) (Figure $1 b_{2}$ ). In vivo, intrapericardial galectin-3 infusion also led to increased myocardial expression of oyclin D1 (gallectin-3 infused, $18.6 \pm 1.33$; placebo, $0.9 \pm 0.05 ; \mathrm{P}<0.05$ ) (Figure 1 b3).

\section{Figure 5}

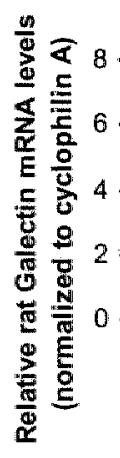

a

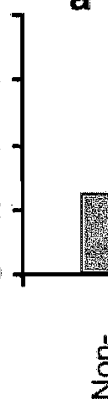

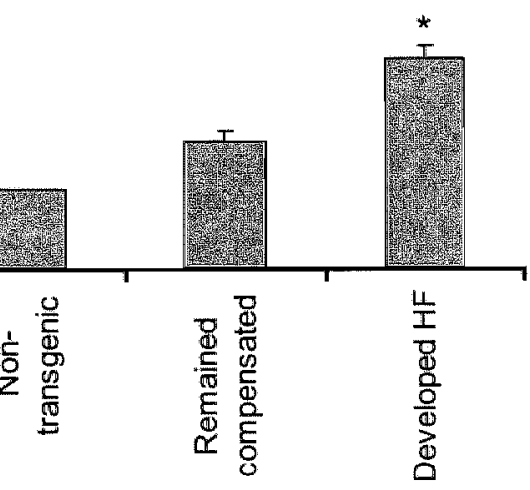

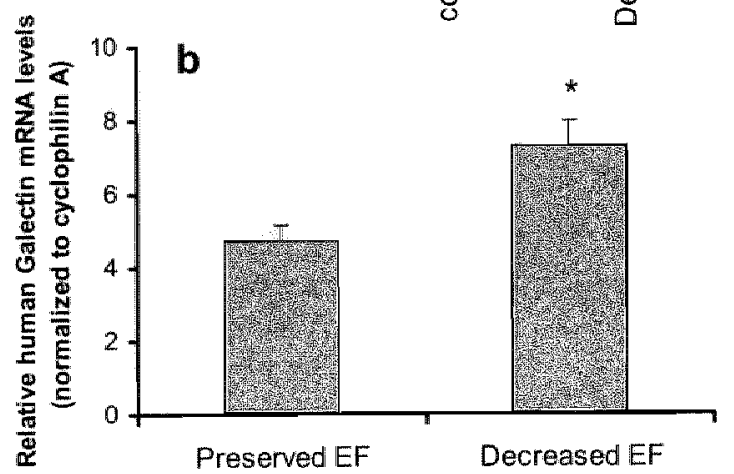

Figure 5. Real-time PCR to determine galectin-3 gene expression in rat and human myocardial biopsies. The relative expression. of galeetin-3 (normalized to cyclophilin A. gene) was significantly higher in the myocardial biopsies obtained at 10-weeks from the $a$, Ren- 2 rats that later progressed to rapid cardiac decompensation compared to those that remained compensated and non-transgenic controls; * $\mathrm{P}<0.01 \mathrm{HF}$ versus compensated groups and controls and from $b$, aortic stenosis patients with relatively lower ejection fraction; *. $\mathrm{P}<0.01$. 


\section{Discussilon}

A role for inflammatory mediators in HF has often been shown and is thought to be a rather universal response to the complex local and systemic changes in HF. In contrast to that notion, we now document that increased expression of the macrophage-derived mediator galectin-3 is already apparent in the stage of compensated hypertrophy of fallure-prone hearts, before they progress to overt failuire. We further demonstrate that galectin-3 induces HF in normal rats. These findings suggest that inflammatory and pro-fibrotic mediators could still be viable therapeutic targets in HF. This supports the idea that an early recognition of failure-prone hearts and intervention with broader spectrum anti-inflammatory agents could have an additional benefit over existing treatment strategies.

Figur

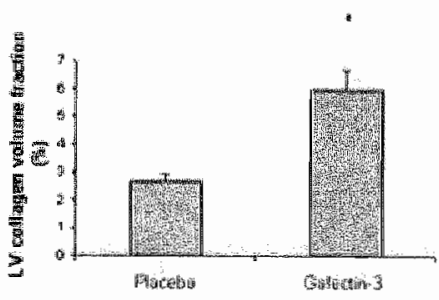

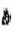
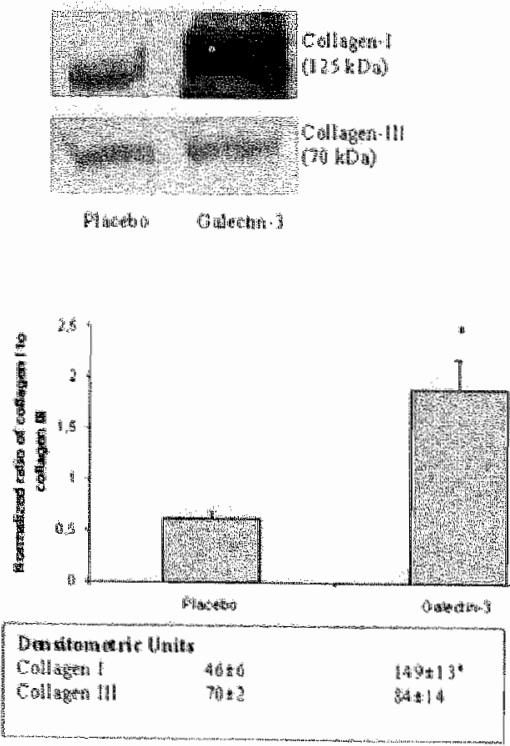

Figure 6. Quantification of LV collagen volume fraction and comparison of collagen type 1 and III ratio. $a$, Bar diagram showing $L \mathrm{~V}$ collagen volume fraction quantified from picrosirius red stained rat myocardial sections after 4-week intrapericardial infusion of galectirn-3 or placebo; $b$, Immunoblot detection of collagen type I and type III in galectin-3 or placebo infused rat thearts; $c$, a comparison of collagen type L/III ratio; *, $\mathrm{P}<0.05$. 


\section{Galectin-3 structure, functions and relevance for cardiac remodeling}

Identified first as an antigen on the surface of peritoneal macrophages, galectin-3 is the only chimera-type member of the galectin family ${ }^{17}$. It belongs to a lectin family sharing the jelly-roll-like folding pattern and calcium-independent specificity to $\beta$-galactosides as well as proteins ${ }^{1819}$. Besides its anti-apoptotic and growth promoting actions, galectin-3 plays a critical role in phagocytosis by macrophages when cross-linked by the Foy receptor (Fo $\mathrm{R}$ ) ${ }^{7}$. In agreement with the abundant fibrosis observed in failing ren-2 and galectin- 3 infused rats, increased galectin-3 expression has also been shown in a rat model of post-radiation pulnonary fibrosis ${ }^{20}$. Other studies have shown that galectin-3 expressed by liver-analogues of macrophages (i.e., Kupffer cells) induce the synthesis of excess fibril-forming collagens in liver" ${ }^{2}$. Earlier studies have demonstrated the relation between galectin-3 expression and the cell cycle. Nuclear galectin-3 expression is associated with cell proliferation, and this effect is mediated through enhanced cyclin DI promoter activity ${ }^{\prime}$. Cyclin D1 forms a complex with cyclin-dependent kinases and regulates progression of the early to mid G1 phase of the cell cycle ${ }^{22}$. This suggests that galectin-3 can induce cardiac fibroblast proliferation via the activation of cyclin DI-dependent cell cycle, thus allowing a macrophage derived mediator to affect cardiac fibroblasts.

\section{Kinetics of galectin-3 binding sites in cardiac fibroblasts}

In line with the pro-fibrotic effects of galectin-3 in vivo, we show that galectin-3 binds to intracellular receptors and induces cardiac fibroblast proliferation and increases collagen production in vitro. Though originally discovered as a carbohydrate binding protein, galectin-3 is known to specifically interact with intracellular targets besides glycoconjugates ${ }^{23}$. However, it is still not known what induces the rapid perinuclear migration of galectin-3 binding elements in proliferating cells. Whether it is an export of galectin-3 binding sites from the dividing nucleus (cenrifugal migration $)^{24}$ or it is a directed cytosolic to nuclear transition (centripetal migration) of these receptors, needs further exploration.

\section{Significance of interstitial fibrosis and collagen I production by galectin-3}

Collagens are essential components of the myocardium, maintaining its structural and functional integrity. In the heart, fibrillar types of collagen form a delicate sheath that interconnects bundles of contractite units. Increased collagen deposition may therefore have a major impact on the diastolic and systolic function of the heart. Whereas collagen III forms an elastic network storing kinetic energy as elastic recoil, collagen I represents a stiff fibrillar protein providing tensile strength ${ }^{25,26}$. 
Only the collagen 1 , and not collagen III promoter is studded with SP-1 binding sites. Therefore, the differential increase of collagen 1 over collagen $I I$ in galectin-3 infused animals could be explained by the possible differences in the molecular makeup of their promoter sites $^{27}$.

\section{Conclusions and implications}

The current study, by demonstrating macrophage activation and increased galectin-3 production preceding overt HF, expands on previous publications that have described the possible involvement of inflammatory mechanisms in the advanced stages of HF. Our finding that galectin-3 is overexpressed well before the transition to overt HF suggests the novel concept that already in the compensated phase, some hypertrophied hearts recruit macrophages and pro-inflammatory mechanisms. We show that exogenous galectin-3, chronically given intrapericardially to healthy hearts, can induce cardiac dysfunction, which makes it likely that this early recruitment and activation of galectin-3 producing macrophages can drive the progression from compensated hypertrophy towards overt HF. Galectin-3 is the only member of the galectin family with an unusually broad activity including protein-carbohydrate and protein-protein interactions in nuclei, cytoplasm, plasma membrane and extracellular matrix ${ }^{8,23}$. Our in witro data underscore that this macrophage-derived effector molecule specifically binds to cardiac fibroblasts and induces fibroblast proliferation, also reflected by its ability to upregulate cyclin D1. Relevant for fibrosis, it also induces collagen I production. Failure-prone and dysfunctional rat and buman heart specimen, all share an increased lectin presence. Therefore, an early recognition of failure-prone hearts and intervention with new anti-inflammatory and anti-fibrotic agents might provide additional benefit over existing treatment strategies. These results shape the concept to consider galectin-3 as a new target for therapeutic intervention at an early stage of compensated hypertroplyy in failure-prone hearts. 
Table 1. Characterization of cardiac function in aortic stenosis patients

\begin{tabular}{llllll}
\hline & N & $\begin{array}{l}\text { Age } \\
(\text { Yrs })\end{array}$ & $\begin{array}{l}\text { Gender } \\
(\% \text { Male })\end{array}$ & $\begin{array}{l}\text { EF } \\
(\%)\end{array}$ & $\begin{array}{l}\text { LV mass index } \\
\left(\mathrm{g} / \mathrm{m}^{2}\right)\end{array}$ \\
\hline Preserved EF & 17 & $66.1 \pm 7$ & 47.5 & $64 \pm 4.7$ & $121 \pm 25$ \\
\hline Decreased EF & 5 & $67.2 \pm 4.5$ & 60 & $51 \pm 5.4^{*}$ & $136 \pm 23$
\end{tabular}

$\overline{\mathrm{EF}}$, ejection fraction; $\mathrm{N}$, group size; LV mass index, left ventricular mass corrected for body weight; *, $\mathrm{P}<0.05$

Table 2. Comparison of Echocardiographic and Hemodynamic parameters and reciprocated tissue and body weights in rats after 4-week intrapericardial infusion of galectin-3 or placebo

\begin{tabular}{|c|c|c|c|}
\hline & & Placebo & Galectin-3 \\
\hline \multicolumn{4}{|c|}{ Echocardiogaraphic measurements } \\
\hline \multirow[t]{2}{*}{ LV ejection fraction $(\%)$} & Baseline & $67.3 \pm 2.5$ & $66.1 \pm 1.6$ \\
\hline & 4-weeks & $66.0 \pm 0.4$ & $51.8 \pm 3.1^{*}$ \\
\hline \multirow[t]{2}{*}{ Fractional Shortening $(\%)$} & Baseline & $38.8 \pm 2$ & $37.8 \pm 1.1$ \\
\hline & 4-weeks & $38.3 \pm 0.8$ & $25.2 \pm 1.0^{*}$ \\
\hline \multirow[t]{2}{*}{ LV end-diastolic volume ( $\mathrm{ml}$ ) } & Baseline & $0.31 \Perp 0.02$ & $0.29 \pm 0.03$ \\
\hline & 4-weeks & $0.27 \pm 0.01$ & $0.33 \pm 0.05$ \\
\hline \multicolumn{4}{|l|}{ Hemodynamic measurements } \\
\hline Heart rate (bpm) & & $337 \pm 45$ & $350 \pm 65$ \\
\hline Systolic blood pressure (mmHg) & & $133 \pm 21$ & $132+21$ \\
\hline $\mathrm{DP} / \mathrm{dt}_{\text {masar-bustiseline }}(\mathrm{mmHg} / \mathrm{sec})$ & & $3622 \pm 843$ & $3605 \pm 1880$ \\
\hline $\mathrm{DP} / \mathrm{dt}_{\max \text {-dobtuamine }}(\mathrm{mmHg} / \mathrm{sec})$ & & $7449 \pm 742$ & $6172 \pm 2126$ \\
\hline$-\mathrm{DP} / \mathrm{dt}_{\text {max }}$-baseline $(\mathrm{mmHg} / \mathrm{sec})$ & & $3262 \pm 262$ & $2680 \pm 855$ \\
\hline$-\mathrm{DP} / \mathrm{dt}_{\mathrm{max} \text {-dobutanine }}(\mathrm{mmHg} / \mathrm{sec})$ & & $5256 \pm 389$ & $3076 \pm 584^{*}$ \\
\hline \multicolumn{4}{|l|}{ Tissue and body weights } \\
\hline Heart weight/Body weight $(\%)$ & & $0.30 \pm 0.01$ & $0.33 \mathbb{\Perp} 0.01$ \\
\hline Lung wellghtBody weight $(\%)$ & & $0.33 \pm 0.02$ & $0.47 \pm 0.07$ * \\
\hline
\end{tabular}


Chapter 4

\section{Acknowledgements}

This study was supported by a VIDI grant $(016.036 .346)$ from the Netherlands Organization for Scientific Research (NWO) to Dr. Y. M. Pinto, Profileringsfonds from Academic Hospital Maastricht to Dr. Jos Maessen and the Mizutani Foundation for Glycoscience to Dr. H.-J. Gabius. We acknowledge the technical assistance of Rudy Duisters and Rick wan Leewwen and thank Dr. Bianca Schrans for hellping us with in situ hybridization experiments. 


\section{References}

1. Yndestad A, Ueland T, Oie E, Florholmen $\mathrm{G}_{n}$ Halvorsen B, Attramadal H, Simonsen S, Froland SS, Gullestad L, Christensen G, Damas JK, Aukrust P. Elevated levels of activin A in heart faillure: potential role in myocardial remodeling. Circulation. 2004;109:1379-85.

2. Weber KT, Gerling IC, Kiani MF, Guntaka RV, Sun Y, Ahokas RA, Postlethwaite AE, Warrington KJ. Aldosteronism in heart failure: a proinflammatory/fibrogenic cardiac phenotype. Search for biomarkers and potential drug targets. Curr Drug Targets. 2003;4:505-16.

3. Cingolani $\mathrm{OH}$, Yang XP, Cavasin MA, Carretero OA. Increased systolic performance with diastolic dysfunction in adult spontaneously hypertensive rats. Hypertensiont. 2003:41:249-54.

4. Mann DL, McMurray JJ, Packer M, Swedberg K, Borer JS, Colucei WS, Djian J, Drexler H, Feldman A, Kober L, Krum H, Liu P, Nieminen M, Tavazzi L, Van Veldhuisen DJ, Waldenstron A, Warren M, Westheim A, Zannad F, Fleming T. Targeted Anticytokine Therapy in Patients With Chronic Heart Failure: Results of the Randomized Etanercept Worldwide Evaluation (RENEWAL). Circulation. 2004.

5. Chung ES, Packer M, Lo KH, Fasanmade AA, Willerson JT. Randomized, double-blind, placeba-controlled, pilot trial of infliximab, a chimeric monoclonal antibody to tumor necrosis factor-alpha, in patients with moderate-to-severe heart failure: results of the anti-TNF Therapy Against Congestive Heart Failure (ATTACH) trial. Circulation. 2003;107:3133-40.

6. Schroen B, Heymans S, Sharma U, Blankestejin M, Pokharel S, Cleutjens J, Gordon Porter J, Evelo CTA, Duisters R, Leeuwen REW, Janssen BJA, Debets JJM, Smits JFM, Daenen MJAP, Crijns H, Bornstein P' and Pinto YM. Thrombospondin-2 is essential for myocardial matrix integrity: increased expression identifies failure-prone forms of cardiac hypertrophy. Circ Res (on press). 2004.

7. Sano H, Hsu DK, Apgar JR, Yu L, Sharma BB, Kuwabara I, Izui S, Liu FT. Critical role of galectin-3 in phagocytosis by macrophages. $J$ Clin Imest. 2003;1 12:389-97.

8. Ochieng J, Furtak $\mathrm{V}$, Lukyanov P. Extracellular functions of galectin-3. Glycoconj $J$. 2004;19:527-35.

9. Furtak V. Hatcher F, Ochieng I. Galectin-3 mediates the endocytosis of beta-1 integrins by breast carcinoma cells. Biochem Biophys Res Commun. 2001;289:845-50.

10. Kim HR, Lin HM, Biliran H, Raz A. Cell cycle arrest and inhibition of anoikis by galectin-3 in human breast epithelial cells. Cancer Res. 1999;59:4148-54.

11. Lin HM, Pestell RG, Raz A, Kim HR. Galectin-3 enhances cyclin D(1) promoter activity through SPI and a cAMP-responsive element in thuman breast epithelial cells. Oncogene. 2002;21:8001-10.

12. Gabius $1-[J$. Influence of type of linkage and spacer on the interaction of beta-galactoside-binding proteins with immobilized affinity ligands. Antal Biochem. 1990;189:91-4.

13. Hemans J, van Essen H, Struijker-Boudier HA, Johnson RM, Theeuwes F, Smits JF. Pharmacokinetic advantage of intrapericardially applied substances in the rat. I Pharmacol Exp Ther. 2002;301:672-8.

14. Pokharel S, Rasoul S, Roks AJ, van Leeuwen RE, van Luyn MJ, Deelman LE, Smits JF, Carretero O, van Gilsi WH, Pinto YM. N-acetyl-Ser-Asp-Lys-Pro inhibits phosphorylation of Smad2 in cardiac fibroblasts. Hypertension. 2002;40:155-61.

15. Broers JL, Machiels BM, van Eys GJ, Kuipers HJ, Manders EM, van Driel R, Ramaekers FC. Dynamics of the nuclear lamina as monitored by GFP-tagged A-type lamins. I Cell Sci. 1999;112 ( Pt 20):3463-75.

16. Bravo R, Macdonald-Bravo H. Existence of two populations of cyclin/proliferating cell nuclear antigen during the cell cycle: association with DNA replication sites. J Cell Biol. 1987;105:1549-54.

17. Cherayil BJ, Chaitovitz $\mathrm{S}$, Wong $\mathrm{C}$, Pillai $\mathrm{S}$. Molecular cloning of a human macrophage lectin specific for galactose. Proc Narl Acad Sci US A. 1990;87:7324-8.

18. Hughes RC. Mac-2: a versatille galactose-bunding protein of mammalian tissues. Glycobiology 1994:450 12.

19. Gabius HJ. Glycohistochemistry: the why and how of detection and localization of endogenous lecins. Anat Histol Embryol. 2001:30:3-31.

20. Kasper M, Hughes RC. Immursocytochemical evidence for a modulation of galectin 3 (Mac-2), a carbollydrate binding protein, in pulmonary fibrosis. $J$ Pathol. 1996;179:309-16.

21. Maeda N, Kawada N, Seki S, Arakawa T, Ikeda KK, Iwao H, Okuyama H, Hirabayashi J, Kasai K, Yoshizzato K. Stimulation of proliferation of rat hepatic stellate cells by galectin-1 and galectin-3 through different intracellular signaling pathways. $J$ Biol Chem, 2003:278:18938:44. Pines I. Cyclins and cyclin-dependent kinases: theme and variations. Adv Cancer Res. 1995;66:181-212.

23. Liu FT, Patterson RJ, Wang JL. Intracellular functions of galectins. Biochim Biophys Acra 2002;1572:263-73.

24. Tsay YG, Lin NY, Voss PG, Patterson RJ, Wang JL. Export of galectin-3 from ntuclei of digitoninpermeabilized mouse 3T3 fibroblasts. Exp Cell Res. 1999;252:250-61.

25. Lapiere CM, Nusgens. B, Pierard GE. Interaction between collagen type I and type III in conditioning bundles organization. Connect Tisswe Ress. 1977;5:21-9. 


\section{Chapter 4}

26. Pauschinger M, Knop D, Petschauer S, Doenter A, Poller W, Schwimmbeck PL, Kuhl U, Schultheiss HP. Dilated cardionyopathy is associated with significant changes in collagen type 1/II ratio. Circulation. $1999,992750-6$

27. Briggs MR, Kadonaga JT, Bell SP, Tjian $\mathbb{R}$. Purification and biochemical characterization of the promoterspecific transeription factor, Sp1. Science. 1986;234:47-52. 


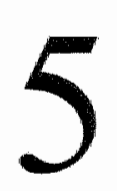

Real-time in vivo Imaging of Apoptotic Cell Membrane Changes in Monocytes and Macrophages

Umesh C Sharma, MB BS, MSc ${ }^{1,2}$, Leo Hofstra, MD, $\mathrm{PhD}^{2}$, Yigal M Pinto, MD, $\mathrm{PhD}^{2}$, Jos $\mathrm{G}$ Maessen, $\mathrm{MD}, \mathrm{PhD}^{2}$

${ }^{1} H y p e r t e n s i o n$ and Vascular Research Division, Henry Ford Health System, Detroit, Michigan, USA

${ }^{2}$ Academic Hospital Maastricht, Maastricht, The Netherlands

Apoptosis 2005; 10: 1187-1189 


\section{Introduction}

Most of the existing studies use DNA fragmentation, such as terminal deoxynucleotidyl transferase (TdT)-mediated dUTP nicks end-labeling (TUNEL) and DNA laddering assays to detect apoptosis. Such experiments are performed in fxed samples, yielding static information on processes captured only at the time window when fixation of cells or tissues had occurred. Techniques that would allow a real-time approach to monitor apoptotic changes at the cellular level of living organisms would obviously be preferable. Previous studies have demonstrated the non-invasive detection of tumor implantation and angiogenesis in the living animal, using fluorescence detection probes ${ }^{1}$. Recently, Dumont et al. showed the enhanced binding of annexin-V labeled with the strong fluorescence probe Oregon Green (Anx-V-OG) to apoptotic myocardial tissue specimens, ex wivo ${ }^{2}$. Using modifications of a previously reported technique that studied apoptotic cell membrane changes in beating murine hearts ${ }^{3}$, we investigated the clodronate-induced membrane apoptotic changes in monocytes and macrophages in vivo. We used Anx-V-OG as the detection probe for apoptosis-specific membrane changes. Annexin $\mathrm{V}$ has strong affinity for phosphatidylserine (PS), a membrane phospholipid that is rapidly translocated from the inner to the outer leaflet of the cell membrane following activation of programmed cell death.

\section{Methods}

Clodronate is a known pro-apoptotic agent which is specific to monocytes and macrophages ${ }^{4}$. We injected clodronate (gift from Roche Diagnostics GmbH, Mannheim, Germany) and Anx-V.OG into the tail-vein of experimental rats. During surgery and the imaging procedure, body temperature was maintained at $36.5^{\circ} \mathrm{C}$. In the anaesthetized rats with laparotomy, we monitored the green fluorescence in liver, spleen and kidneys at 30-minute intervals. In a dark room setting, we used ultraviolet light as an excitation source for the green fluorescence. Selective excitation of Anx-VOG was produced through a 470/50-nm band-pass filter and emitted green fluorescence was collected through a band-pass filter of $525 / 50 \mathrm{~nm}$ on a Hamamatsu C4742-95 cooled chargecoupled-device (CCD) camera (Hamamatsu Photonics Systems, Hamamatsu City, Japan). Of technical note, CCD cameras are solid-state image sensors that provide low light level detection, with high signal-to-noise ratio and a wide dynamic range. The Peltier cooling system attached to the camera reduces dark noise and minimizes thermal drift during the procedure. Photobleaching and tissue burn was minimized by reducing the exposure time to $330 \mu \mathrm{s}$. Images were processed and analyzed with the use of Hipic and AquaCosmos software (Hamamatsu). 


\section{Results}

At maximal magnification ( 160$)$, green fluorescence was observed in the lwer (Figure $A$ ) and spleen (Figure B) after 2 hours of clodronate and Anx-V-OG injection, The liven and the spleen are the secondary lymphoid organs that house large numbers of nonocytes and nacrophages. After 4 hours of clodronate and Anx-V-OG infusion, kidneys showed a gradual morease in green fluorescence which reached maximum at 6 hours. We confirmed these observations by staining for specific macrophage markers as well as visualizing the green fluorescence in mucroscopic sections from liver, spleen and kidneys. The peri-follicular aggregation of $\mathrm{CD}-68$ positwe mactophages in a histological section of spleen matched to the pattern of green fuorescence enithed m real-tinje imaging of clodronate-induced macrophage depletion in spleen (Figure C). The sections obtained from kidneys from the clodronate and Anx-V-OG-infused rats showed discrete fworescence in the proximal tubules. The accumulation of dye inside the tubular epithelial cells snggested that the fluorescent dye is primarily secreted from the proximal tubules. The glomerul staned negative. Therefore, the observed fluorescence in the knidneys was due to the excretion of amexin V from the proximal tubular cells (Figure D). Together, these observations indicate that this model maging system allows for the study of cellular apoptosis in the living animal. 

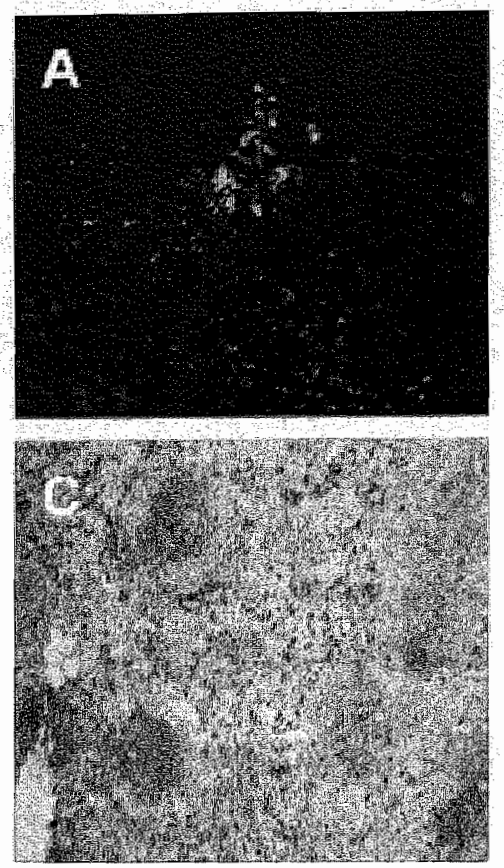
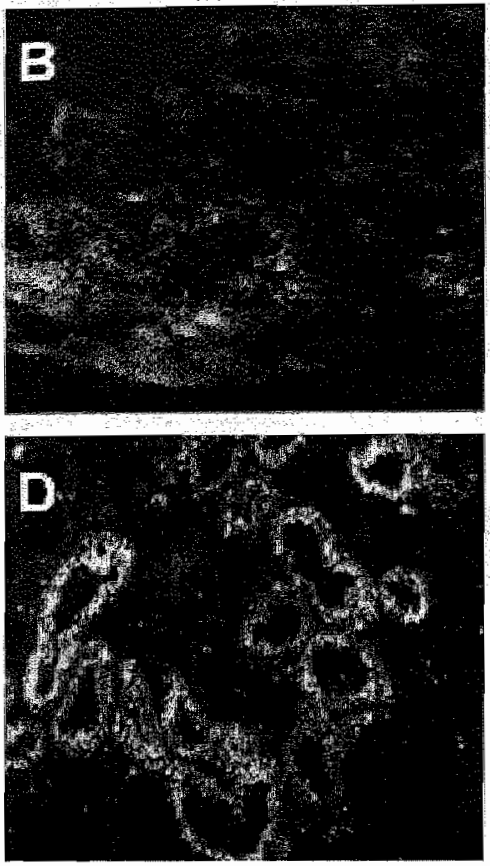

In viwo imaging of apoptosis-specific membrane changes in monocytes and macrophages. $\mathbf{A}$.

Green fluorescence observed in liver 2 hours after the injection of clodronate and Anx-V-OG showing apoptosis-related membrane changes. B. At the same time point, the fluorescence in spleen shows marginal follicular pattern, consistent with normal histological distribution of macrophages. $C$. Corresponding to the pattern of macroplage distribution in figure $B$, anti-

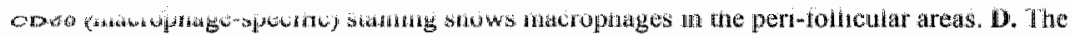
fluorescence showing the secretion of Anx-V-OG into the proximal renal tubular epithelium, six hours after the intravenous injection. 


\section{Discussilion}

The possibility of investigating membrane alterations of cytotoxic agent-induced apoptosis at the single-cell level provides the opportunity to study cell biology in a natural environment. The development of such unique imaging techniques will help us to investigate the pathogenesis of different diseases such as myeloid leukemia and osteoclastic bone tumors, in wo Mutational loss of apoptosis constitutes the most recently proposed mechanism for tumor resistance to chemotherapy ${ }^{5}$. Therefore, serial monitoring of the response to chemotherapy and observation of the emergence of new malignant cells refractory to chemotherapy in patients with hematopoietic and skin tumors would constitute a most exciting discovery th the field of cancer treatment. Undoubtedly, this and other new imaging techniques will enhance our ability to understand the molecular mechanisms of diseases and their respective responses to therapy. By using this method, real-time functional data indicating the apoptotic regression of tumor cells could be acquired at multiple times during the course of a disease. Single animals could be followed over time, removing inter-sample variability, with the net result of improved statistical analyses. Additionally, an interesting option may be the use of technetium-labeled annexin- $V$ and detection of monocyte and macrophage apoptotic changes with muclear imaging in humans. Finally, this technique may potentially be broadened by applying multi-probe technology or using infrared and spin-label electron spin resonance methodology to investigate the molecular interactions within and between the cells. 


\section{References}

1. Sweeney T, Mallander Y Tudker A A, Olomu AB, Zhang W, Can Y, Negrin RS, Contag CH. Visualizing the

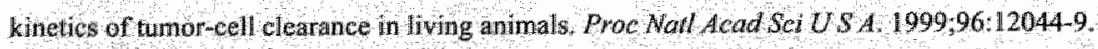

2. Dumont E, Hofstra L, van Heerde WL, van den Ejnde S, Doevendans PA, DeMuinck E, Daemen MA, Smits

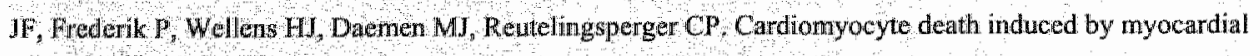
iscluema and reperfosiont measurement with tecomb hant human anmexin $V$ in a mouse model. Cincalation. $2000,102,1564-8$

3. Dumont EA, Retitelingsperger CP,Smits JF, Daemen MJ, Doevendans PA., Wellens HJ, Hofstra L. Real-time imaging of apoptotic cell-membrame changes at the single-cell level in the beating murine heart. Nat Med. $2001,7+152-5$

4. Van Rooljen N, Sanders A. Liposome mediated depletion of macrophages: mechanism of action, preparation of liposomes and applications. I Jnmunol Methods. 1994;174;83-93.

5. DerlanoL, Guipaud 0 , Merle-Beral $H$, Binet JL, Ricoul M, Potocki-Veronese G, Favaudon $V$, Maciorowski $Z$, Muller C, Salles B, Sabatier L, Delic J. Human chronic lymphocytic leukemia B cells can escape DNA damage-induced apoptosis through the non-homologous end-joining DNA repair pathway. Blo0d. 2005. 


\section{6}

Presence of Cardiomyopathy and Anti-Heat Shock Protein-47 Autoantibodies after Macrophage Depletion in Hypertensive Rats

Umesh C Sharma ${ }^{1,2}$, Saraswati Pokharel ${ }^{1}$, Thomas van Brakel ${ }^{2}$, Leo Hofstra ${ }^{3}$, Adrian Duijvestein ${ }^{4}$, Nico van Rooijen ${ }^{5}$, Jos G Maessen ${ }^{2}$ and Yigal M Pinto ${ }^{3}$

${ }^{1}$ Hypertension and Vascular Research Division, Henry Ford Health System, Detroit, Michigan, USA

${ }^{2}$ Department of Cardiothoracic Surgery, University Hospital Maastricht, Maastricht, The Netherlands

${ }^{3}$ Experimental and Molecular Cardiology Laboratory, Cardiovascular Research Institute Maastricht, Maastricht, The Netherlands

${ }^{4}$ Department of Immunology, Cardiovascular Research Institute Maastricht, Maastricht, The Netherlands

${ }^{5}$ Department of Cell Biology and Immunology, Faculty of Medicine, Vrije Universiteit, Amsterdam, The Netherlands

\section{Manuscript submitted}

Abstract accepted for poster presentation in Scientific Sessions, American Heart Association, 2005 Selected for podium presentation and wimner of the Best Abstract Award in the Second Annual Symposium of Henry Ford Hospital, 2005 


\begin{abstract}
Macrophage infiltration and cytokine production into the failing hearts of hypertensive animals is a subject of intense investigation. To investigate the role of macrophage depletion in candiac function, we injected either liposonal clodronate (LC) or liposomes containing PBS (PL) in hypertensive Ren-2 rats from the age of 7 unti1 13 weeks. LC treatment reduced the number of blood monocytes and decreased the number of macrophages in the myocardium. Compared to PL treatment, LCtreatment rapidly worsened cardiac function in hypertensive rats. LC-treated Ren-2 rat hearts showed areas of myocyte loss with abundant inflammatory cell infiltration. Characterizations of the inflammatory infiltrates showed that majority of the cells were CD4 positive T-lymphocytes. The sera from LC treated Ren-2 rats showed reactivity against a $47-\mathrm{kDa}$ protein expressed in rat cardiomyocytes and fibroblasts. This antigenic protein was identified as heat shock protein-47 (HSP47) by computer-assisted antigenicity prediction and enzyme-linked immunoassays. The current study shows that lack of macrophages is associated with myocardial T-lymphocyte infilltration and autoantibody production in hypertensive rats. Such auto-reactive antibodies directed against HSP47 expressed by cardiac fibroblasts and myocytes can contribute to myocardial tissue damage and deterioration of cardiac function.
\end{abstract}




\section{Introduction}

Although heart failure (HF) is considered to be caused by a variety of mechanical and neurohumoral stress, the role of macrophages and inflammatory mechanisms in this process is currently a subject of intense investigation ${ }^{1,2}$. After the identification of increased activity of inflammatory cells and cytokines in patients with HF, it has been postulated that inflammatory mechanisms can contribute to HF by progressive tissue damage and alteration of myocardiall architecture ${ }^{3,4}$. We have recently shown that activated macrophages produce galectin-3, which contributes to the progression towards. HF in a model of hypertensive cardiac hypertrophy and failure 5 . This recent study underlined that macrophages are activated early in the pathogenesis of HF. These activated macrophages can impair cardiac fumction by producing inflammatory and profibrotic mediators in the heart. Accumulating evidence on the pathophysiological consequences of sustained expression of pro-inflammatory mediators in preclinical and clinical HF models resulted. in a series of multi-center clinical trials that used "targeted" approaches to neutralize tumor mecrosis factor (TNF) in patients with moderate to advanced $\mathrm{HF}^{6,7}$. However, these targeted approaches have not yielded the desired effects. In combination with our earlier findings, one may surmise that activated macrophages produce many more adverse mediators, so that activated macrophages need to be antagonized in a much broader way in order to prevent their detrimental influence.

In our recently published study ${ }^{5}$, we characterized hypertensive homozygous Ren-2 rats as a representative animal model to study the rapid progression of hypertension through the stage of compensated left ventricular hypertrophy to HF. Importantly, in failing Ren-2 rat hearts, we noted abundant macrophage infiltration that expressed major histocompatibility complex-II (MHC-II). We chose this model to study the effects of macrophage depletion on cardiac function. Previously, we also reported a new technique for monitoring clodronate-induced membrane apoptotic changes in monocytes and macrophages in vivo. In current study, we injected liposomal clodronate (LC) intravenously, which is an established method to deplete macrophages ${ }^{9,10}$. Free clodronate will not pass cell membranes, and has an extremely short half-life in the circulation.. It is removed from the circulation by the renal system and therefore has no other adverse effects on cell types that do not phagocytose the liposomes ${ }^{10-12}$.

Six weeks of LC treatment induced cardiac dysfunction in the hypertensive Ren-2 rats. The LCtreated Ren-2 rat hearts showed areas of cardiomyocyte loss and excess infiltration of CD4 ${ }^{+v e} \mathrm{~T}$ lymphocytes. Searching for the contributory mechanism of myocardial $\mathrm{T}$-cell infiltration and 
Chapter 6

cardiac functional deterioration after macrophage depletion in Ren-2 rats, we performed immunoblotting, in silico antigenicity prediction analysis and enzyme-linked immunoassays. This revealed a presence of circulating autoantibodies directed against HSP47 in clodronate-treated Ren2 rats. 


\section{Methods}

\section{Rat characteristics and measurement of cardiac function}

Malle homozygous Ren-2 and Sprague Dawley (SD) rats were purchased from M\&B (Bonholtvej: Denmark) at the age of 6 weeks. Clodronate was a gift from Roche Diagnostics GmbH, Mannhein, Germany. $L C$ and PL were prepared as described previously. Under a light isoflurane-anesthesia; 10 male homozygous Ren-2 rats received weekly injection of LC ( $4 \mu \mathrm{l} / \mathrm{gram}$ body weight) via the tail vein. As a control for the liposomally encapsulated clodronate, liposomes filled with PBS were injected in 7 Ren-2 rats. In addition, 4 healthy SD rats received LC and 4 age-matched SD rats received PL. Rats were euthanized at 13 weeks. In all 4 experimental groups, blood pressure was measured by tail-cuff method. Echocardiography was pertormed at $0,14,28$ and 42 days of $L C$ or PL treatment in rats sedated with $2 \%$ isoflurane. Standard views were obtained in $2-\mathrm{D}$ as well as MMode with a 12-MHz transducer (Sonos 5500, Hewlett Packard) with approximately 220 frames per recording and the data analysis was made by a blinded observer. The institutional animal care committee approved the procedure for care and treatment of animals.

\section{Flow cytometry}

Using anti-CD68 antibody, we counted the monocyte population 48 hours and 7 days after the intravenous infusion of LC or PL in Ren-2 rats. In addition, we counted T-helper and cytotoxic Tlymphocytes using anti-CD4 and anti-CD8 antibodies, respectively. Anticoagulated blood $(200 \mu \mathrm{L})$ was incubated for 30 minutes $\left(4^{\circ} \mathrm{C}\right)$ with mouse anti-rat RPE-conjugated anti-CD4, CD 8 and CD 68 antibodies (Serotec). FACS lysing solution (1:20 dilution) was added for 15 minutes. The residual cells were washed (x1500 RPM, 5 minutes, $4^{\circ} \mathrm{C}$ ) in FACS medium (PBS, 1\% BSA, 0.02\% sodium azide) and suspended for flow cytometry. Monocytes and lymphocytes were identified according to their relative size, side-scattering, and fluorescence.

\section{Cardiomyocyte and fibroblast isolation and Western blotting}

Cardiomyocytes and fibroblasts were isolated from 2-day-old neonatal Sprague-Dawley rats according to a previously described study protocol ${ }^{13,14}$. Initial screening of sera for the presence of autoantibodies was performed on cardiomyocyte and cardiac fibroblast proteins. These proteins were separated by SDS-gel electrophoresis on a 4-20\% gel and transferred to a PVDF membrane. For Western blotting, rat sera were diluted 50-fold in PBS and used as the primary antibodies. Antirat IgG-specific mouse antibody (horseradish-peroxidase conjugated IgG, Cell Signaling 
Technology) was diluted $1 / 2000$ in TBS- $I$ and used as the secondary antibody. Protein bands were visualized by the enhanced chemiluminescence technique.

\section{Immunohistochemical localization of infiltrated and apoptotic macrophages, and $T$ -}

\section{Iymphocytes}

Irmmunohistochemistry was performed on cryo-fixed myocardial sections. After drying the sections for 15 minutes, ice-cold methanol ( $100 \%$ ) was added for 10 minutes; the sections were washed 3 times with PBS and blocked with $5 \%$ horse serum for 60 minutes. Anti-CD3, CD4, CD8 and CD68 (Serotec) and anti-annexin V (BioVision) antibody (1:250 in 0.1\% BSA in PBS) were applied and incubated overnight at $4^{\circ} \mathrm{C}$. Horseradish peroxidase-conjugated secondary antibodies were applied for 4 hours at room temperature followed by horseradish peroxidase-labeled streptavidin for 60 minutes. After washing 3 times for 5 minutes in PBS, 3,3'-diaminobenzidine tetrahydrochloride reagent was applied to visualize the reaction.

\section{ELISA for determining anti-HSP47 autoantibody titers}

After identifying an autoantigen of approximately $47 \mathrm{kD}$, we performed an ELISA to test for autoantibodies against HSP47 by a method described previously ${ }^{15}$. Briefly, recombinant rat $\mathrm{HSP}_{4} 7$ protein (Sigma) diluted at $1 \mu \mathrm{g} / \mathrm{ml}$ in $50 \mathrm{mM}$ sodium carbonate buffer ( $\mathrm{pH}$. .6 ) was immobilized on a 96-well microplate. The wells were blocked with 2\% BSA in PBS and then incubated with 100fold diluted rat sera. Specific binding of rat serum IgG to HSP47 was detected by subsequent incubation of horseradish peroxidase-conjugated goat antibodies specific to the $\gamma$-chain of rat IgG (Dako) and 3,3,5,5-tetramethylbenzidine (TMB) substrate. After terminating the reaction with equal volume of $1 \mathrm{M}$ phosphoric acid, absorbance at $450 \mathrm{~nm}$ was measured to calculate the antibody titer.

\section{Stutistical analyses}

Data are presented as mean $\pm \mathrm{SD}$. The comparisons were made by unpaired $t$ test. For multiple comparisons, 1-way ANOVA in combination with a Dunnett's post hoc analysis was made. Analyses were performed by use of the statistical package SPSS 10.0. Probability values of $P<0.05$ were considered to be statistically significant. 


\section{Results}

\section{Reduction of blood monocytes and tissue macrophages by LC infusion}

Baseline monocyte level in PL-treated Ren-2 rats was $2.28 \pm 0.15 \%$ of total white blood cells (WBC)

(Figure $1 \mathrm{~A}$ and B). Two days after $\mathrm{LC}$ injection in Ren-2 rats, number of monocytes was sharply reduced to $0.81 \pm 0.21 \%$ of WBC (Figure $1 \mathrm{C}$ and D), whereas CD4 and CD8 count remained

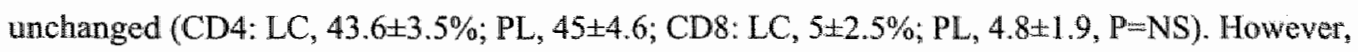
the monocyte count returned almost to baseline levels $(1.8 \pm 0.38)$ by 7 days. Presence of macrophages in the hearts was shown by CD68-specific monoclonal antibody. In the Ren-2 rats that received PL, macrophages were abundantly present in the myocardium (Table 1). However, LCtreated Ren-2 rats showed identically scattered cells of macrophage morphology with annexin $\mathrm{V}$ positivity, suggesting LC-induced apoptotic membrane changes in the macrophages (Figure $2 \mathrm{~A}$ ). However, annexin V positivity was not remarkable in LC-treated Ren-2 rats (Figure 2 B) and SD controls with LC (Figure 2 C) and PL (Figure 2 D) treatment.

Table 1. Morphometric data to compare the cellular infiltration and apoptotic changes in the myocardium of LC or PL-treated rats

\begin{tabular}{lcccc}
\hline & \multicolumn{5}{c}{ Cell counts/HPF } \\
& Ren2-LC & Ren2-PL & SD-LC & SD-PL \\
& $(\mathbf{N}=7)$ & $(\mathbf{N}=7)$ & $(\mathbf{N}=4)$ & $(\mathbf{N}=4)$ \\
Mononuclear cells (HE-staining) & $89.3 \pm 26^{*}$ & $7 \pm 2.4$ & $13.8 \pm 2.1$ & $8.5 \pm 1$ \\
Macrophages (CD68) & $1.8 \pm 0.31$ & $13.8 \pm 3.3 \dagger$ & $0.66 \pm 0.4$ & $2.5 \pm 0.7$ \\
T-lymphocytes (CD3) & $49 \pm 13.3^{*}$ & $3.3 \pm 0.68$ & $4.8 \pm 1.1$ & $4.3 \pm 0.8$ \\
T-helper cells (CD4) & $33.8 \pm 13.7^{*}$ & $1.8 \pm 0.31$ & $3.5 \pm 0.7$ & $3.1 \pm 0.8$ \\
Cytotoxic T-cells (CD8) & $2.8 \pm 0.4$ & $2.3 \pm 0.50$ & $2.1 \pm 0.4$ & $2.3 \pm 0.51$ \\
Apoptotic cells (Annexin-V) & $10.5 \pm 4.2^{*}$ & $2.1 \pm 0.66$ & $3.1 \pm 0.7$ & $1.1 \pm 0.4$ \\
\hline
\end{tabular}

HPF, high power field; LC, liposomal clodronate; PL, PBS liposomes; SD, Sprague Dawley; " $\mathrm{P}<0.05$ v. Ren2-PL, SD-LC and SD-PL; $†, P<0.05$ vs. Ren2-LC, SD-LC and SD-PL. 
Table 2. Baseline, 2-week, 4-week and 6-week Echocardiographic parameters in LC or PL-treated Ren-2 rats and SD controls

\begin{tabular}{lllccc}
\hline $\begin{array}{l}\text { LV Functional } \\
\text { Parameters }\end{array}$ & Time-point & $\begin{array}{c}\text { Ren2-LC } \\
(\mathrm{N}=10)\end{array}$ & \multicolumn{1}{c}{$\begin{array}{c}\text { Ren2-PL } \\
(\mathbf{N}=7)\end{array}$} & $\begin{array}{c}\text { SD-LC } \\
(\mathrm{N}=4)\end{array}$ & $\begin{array}{c}\text { SD-PL } \\
(\mathrm{N}=4)\end{array}$ \\
\hline LVEF (\%) & Baseline & $65.2 \pm 4.1$ & $67 \pm 3.1$ & $64 \pm 4$ & $65.5 \pm 1.9$ \\
& 2-weeks & $64.6 \pm 4.9$ & $66.9 \pm 3.04$ & $63.3 \pm 3.4$ & $63.7 \pm 2.7$ \\
& 4-weeks & $57 \pm 6.6$ & $64.3 \pm 6.4$ & $62.6 \pm 2.3$ & $64.5 \pm 3.9$ \\
& 6-weeks & $49 \pm 5.4 *$ & $62 \pm 5.3$ & $63 \pm 3.8$ & $66.4 \pm 1.0$ \\
LVFS (\%) & Baseline & $32.7 \pm 4.2$ & $34.8 \pm 4.2$ & $31.2 \pm 3.8$ & $36.7 \pm 0.5$ \\
& 2-weeks & $30 \pm 4$ & $30.2 \pm 4$ & $30.2 \pm 1.5$ & $35.2 \pm 1.2$ \\
& 4-weeks & $26 \pm 3.2$ & $26.5 \pm 3.2$ & $28.5 \pm 3.7$ & $34.2 \pm 2.2$ \\
& 6-weeks & $22.8 \pm 4.8^{*}$ & $30.2 \pm 4.2$ & $30.7 \pm 3.5$ & $34.4 \pm 3.2$ \\
& Baseline & $0.41 \pm 0.26$ & $0.40 \pm 0.17$ & $0.44 \pm 0.15$ & $0.40 \pm 0.07$ \\
& 2-weeks & $0.55 \pm 0.21$ & $0.41 \pm 0.16$ & $0.41 \pm 0.1$ & $0.4 \pm 0.05$ \\
& 4-weeks & $0.81 \pm 0.35$ & $0.43 \pm 0.09$ & $0.41 \pm 0.07$ & $0.4 \pm 0.06$ \\
& 6-weeks & $1.1 \pm 0.68^{*}$ & $0.43 \pm 0.16$ & $0.42 \pm 0.03$ & $0.42 \pm 0.07$ \\
\hline
\end{tabular}

$\mathrm{EF}$, ejection fraction; FS, fractional shortening; $\mathrm{EDV}$, end diastolic volume; $\mathrm{LC}$, liposomal clodronate; PL, PBS liposome; SD, Sprague Dawley; *, P<0.05 ws. Ren-2 placebo and SD rats.

\section{Deterioration of cardiac function in Ren-2 rats after 6-week LC infusion}

The Ren-2 rats that received LC from 7-13 weeks of age developed significant deterioration of

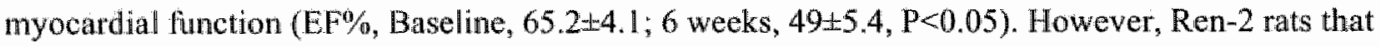
received PL had only a mild and non-significant decrease in cardiac performance (EF\%, Baseline, $67 \pm 3.1 ; 6$ weeks, 62 \pm 5.3 ). The Sprague Dawley controls did not show a significant alteration in

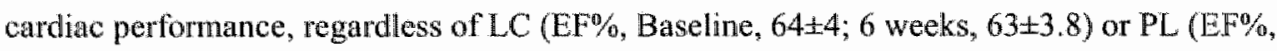
Baseline, $65.5 \pm 1.9 ; 6$ weeks, 66.4 1.0 ) administration (Table 2). This suggests that persistent macrophage depletion in hypertensive hearts with abundant macrophage infiltration accelerates functional deterioration. There was no significant difference in body weight between the 4 experimental groups. Ren-2 rats were hypertensive and had significantly increased heart weight to body weight ratio compared to controls. However, these parameters were not significantly different between LC and PL-treated rats (Table 3 ). 
Table 3. Blood pressure, heart weight and body weight of LC and PL treated rats

\begin{tabular}{ccccc}
\hline & $\begin{array}{c}\text { Ren2-LC } \\
(\mathbf{N}=7)\end{array}$ & $\begin{array}{c}\text { Ren2-PL } \\
(\mathbf{N}=7)\end{array}$ & $\begin{array}{c}\text { SD-LC } \\
(\mathbf{N}=4)\end{array}$ & $\begin{array}{c}\text { SD-PL } \\
(\mathbf{N}=4)\end{array}$ \\
\hline BP (mmHg) & $253 \pm 15^{*}$ & $259 \pm 10^{*}$ & $131 \pm 4.7$ & $128 \pm 10$ \\
BW (gr) & $314 \pm 18$ & $310 \pm 23$ & $314 \pm 13.5$ & $308 \pm 8.9$ \\
HW/BW $(\%)$ & $0.47 \pm 0.04^{*}$ & $0.50 \pm 0.05^{*}$ & $0.36 \pm 0.03$ & $0.35 \pm 0.03$
\end{tabular}

LC, liposomal clodronate; PL, PBS liposomes; SD, Sprague Dawley; BP, blood pressure; BW, body weight; HW/BW, heart weight to body weight ratio; *, P<0.05 ks. SD-LC and SD-PL.

\section{Cardiomyocyte loss and $\mathrm{CD}^{+v e} \mathrm{~T}$-lymphocyte infiltration in LC-treated Ren-2 rat hearts}

The Ren-2 rats that received LC-treatment for 6 weeks showed areas of cardionyocyte damage (Figure 3 A), which was not discernible in control groups (Figure 3 B, C and D). Despite the remarkable decrease in macrophages, we noticed abundant focal infiltration of mononuclear cells in the myocardium in LC-treated Ren-2 rat hearts. Morphologically, the infiltrated cells showed round nucleus with myocardial interstitial pattern of distribution (Figure $3 \mathrm{~A}$ ). Immunohistochemical analysis revealed that these round cells expressed CD3 antigen, which identifies them as $T$ lymphocytes (Figure 4). Further characterization confirmed that these cells also expressed CD4 antigen. Taken together, this shows that the macrophage depleted Ren-2 rat hearts harbor increased $\mathrm{CD} 4^{\text {twe }} \mathrm{T}$-helper cells in the myocardium. Only few $\mathrm{T}$-helper cells were observed in the myocardium of Ren-2 rats that received PL and Sprague Dawley controls that received either PL or LC. There was no significant difference in the number of CD8-positive T-cells in different experimental groups (Table 1 ). 


\section{Chapter 6}

Figure 1
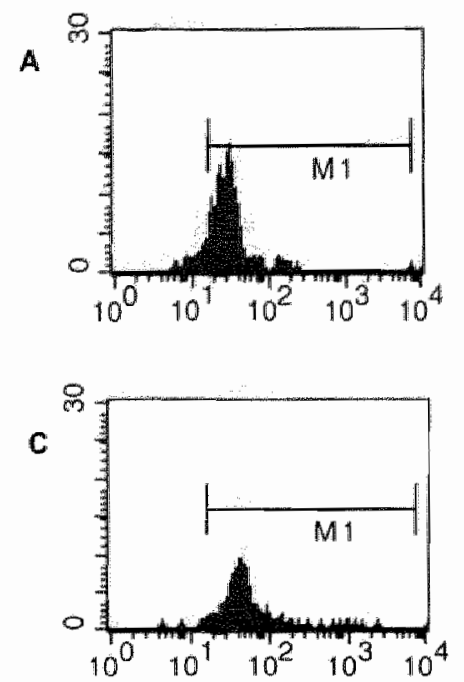
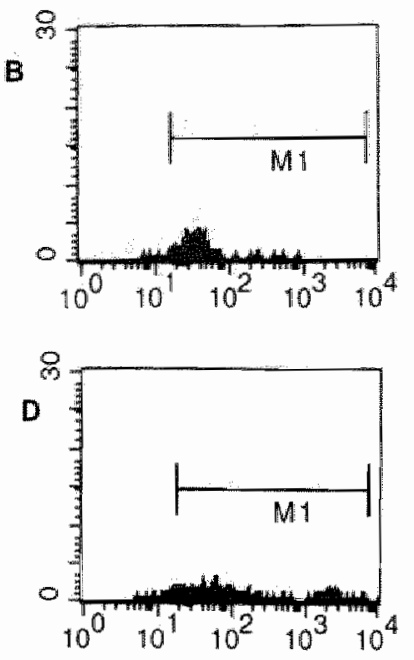

Figure 1. Flow cytometric analysis of blood monocyte population after the infusion of LC or PL in Ren- 2 rats. We injected PL or LC in Ren-2 rats and collected the blood samples after 48 hours. Height of the histogram represents monocyte population. A, FACS analysis of $\mathrm{CD} 68$ positive cells in the blood in PL-treated Ren-2 rats. $\mathbf{B}$, Isotype control for panel A. C, CD68 positive cells in LC-treated Ren-2 rats. D. Isotype control for panel C. 


\section{Recognition of a 47-kDa protein reactive against the autoantibodies present in LC-treated}

\section{Ren-2 rats}

Areas of cardiomyocyte damage and the presence of abundant $T$-helper cell infiltration surrounding the cardiomyocytes suggested a chronic inflammatory reaction in LC-depleted Ren-2 rat hearts. In order to test whether autoimmunity could explain increased lymphocytic infiltration and accelerated cardiac dysfunction in LC-treated Ren-2 rats, we screened the autoantibodies by immunoblotting of the cell lysate obtained from rat cardio-myocytes and fibroblasts. Serum samples collected from the PL or LC-treated rats served as the primary antibodies. The sera from LC-treated Ren-2 rats showed reactivity directed against a $47-\mathrm{kD}$ a protein, both in cardiac fibroblasts and cardiomyocytes. Skra from PL-treated Ren-2 rats and PL or LC-treated Sprague Dawley controls did not recognize this 47 $\mathrm{kDa}$ protein (Figure $5 \mathrm{~A}$ ).
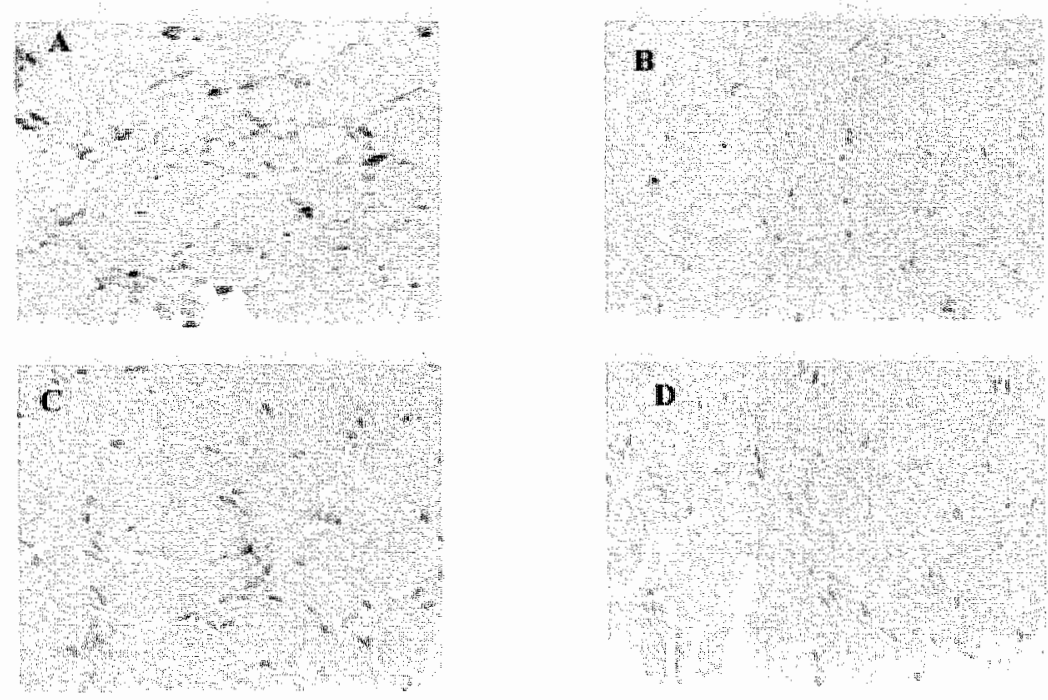

Figure 2. Demonstration of apoptosis-specific changes by annexin $V$ positivity $A$, Anti-annexin $W$ staining showing apoptosis of macrophages in 1 C-treated Ren-2 rat heants. B, C and D, Anti-annexin $V$ staining in PL-treated Ren-2 rats, LC-treated SD rats and PL-treated SD rats, respectively. 


\section{Identification of HSP47 as the potential autoantibody target}

To identify the potential autoantibody target with a molecular weight of $47 \mathrm{kDa}$, we searched the awailable protein database from $\mathrm{NCBI}$ and Expert protein anallysis system (ExPasy) public repository (htp:/wwwncbi,nlminihgov, http:/www expasy.org). We then calculated the antigenicity indices of these $47 \mathrm{kDa}$ proteins (e.g., GTPase family proteins [LGTP, TGTP, LRG-47, IRG-47, GTPI and IIGP], vascular endothelial cell surface protein, fibronectin-binding protein, heat shock protein 47 , phagocyte oxidase component, human nuclear protein, platelet substrate of protein kinase $\mathrm{C}$, protein $\mathrm{F}$ l etc:) using the algorithm proposed by Hopp and Woods ${ }^{16}$. This revealed that heat shock protein 47 harbored an area of high antigenicity, with an antigenicity index of more than 3 (background $<1$ ).

A

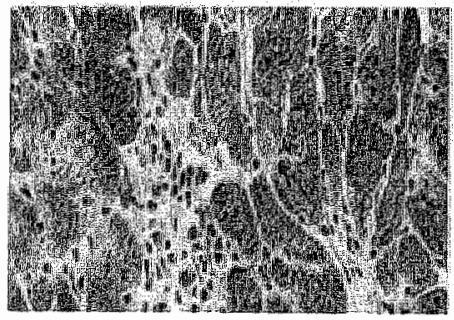

$\mathrm{C}$

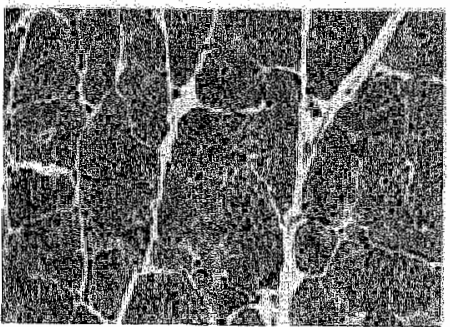

B

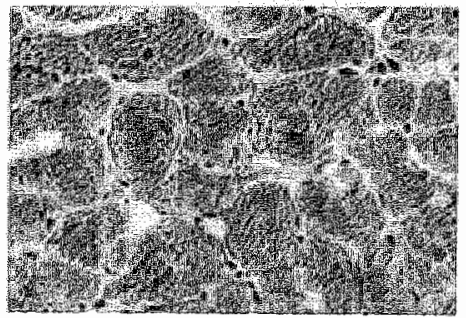

D

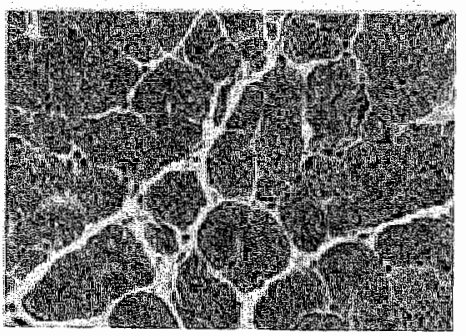

ligure 3. Histological analysis of the morphological changes in the myocardium in LC-treated Ren2 rats and controls. A, Hematoxytine-eosin stained myacardial sections showed areas of cardiomyocyte darnage and mononuclear cellular infiltration in LC-treated Ren-2 rats. These changes were not remarkable in PL-treated Ren-2 (panel B), LC-treated SD (panel C) and PL-treated SD (panel D) rat hearts. 


\section{Presence of anti-HSP47 autoantibodies in LC-treated Ren-2 rat serum}

Based on the above computational analysis, we determined the titers of autoantibodies against HSP47 in the rat sera by ELISA. We immobilized recombinant rat HSP47 protein by coating onto microtiter plates and used diluted sera from Ren-2 rats and Sprague Dawley controls as the primary antibody. Consistent with the prominent 47-kDa band observed in Western blotting of rat cardiomyocyte or fibroblast homogenates, LC-treated Ren-2 rats had the highest titer of anti-HSP 47 autoantibody. In contrast, the autoantibody titers against HSP47 from the sera of other experimental group (Ren-2 with PL, Sprague Dawley with LC and Sprague Dawley with PL) were significantly lower (Figure 5 B). These results indicate that the sera from the hypertensive Ren-2 rats with systemic depletion of monocytes/macrophages develop a brisk autoimmune reaction that specifically targets a self-protein, HSP47 expressed in heart.

A.

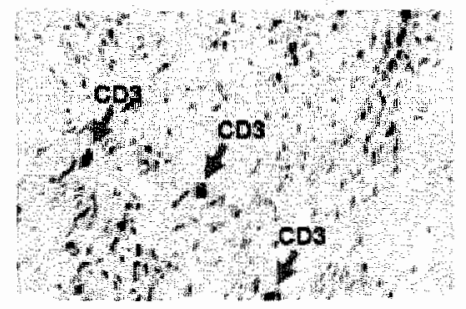

C

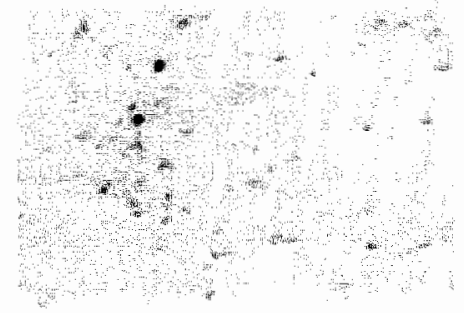

B

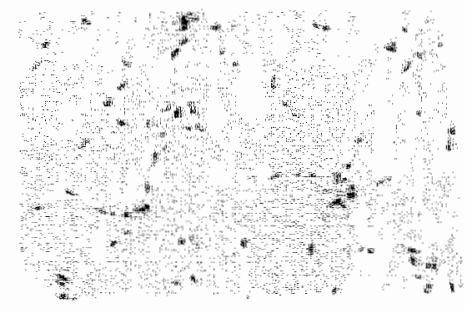

D

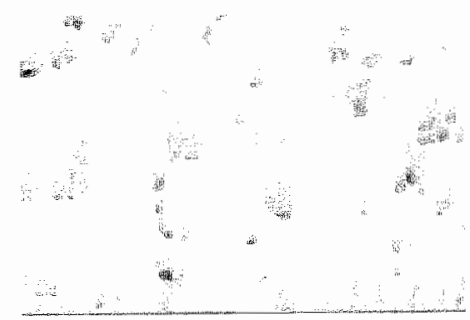

Figure 4. Demonstration of T-lymphocyte infiltration in LC-treated Ren-2 rat hearts. A, AntiCD3 staining showing abundance of T-lymphocytes in the hearts of Ren-2-rats treated with LC, B, C and D, Anti-CD3 staining in PL-treated Ren-2, LC-treated SD and PL-treated SD rat hearts, respectively. 


\section{Ditscussion}

The results of the current study suggest a novel role for macrophages in hypertensive rat hearts. The first finding is that macrophage depletion worsens cardiac function in bypertension-induced cardiac hypertrophy. Secondly, macrophage-depleted hearts show excess helper T-lymphocyte infiltration and focal loss of cardiomyocytes. In addition, the sera from these animals harbor autoantibodies that are reactive against HSP47, a highly immunogenic protein expressed by cardiac fibroblasts and cardiomyocytes.

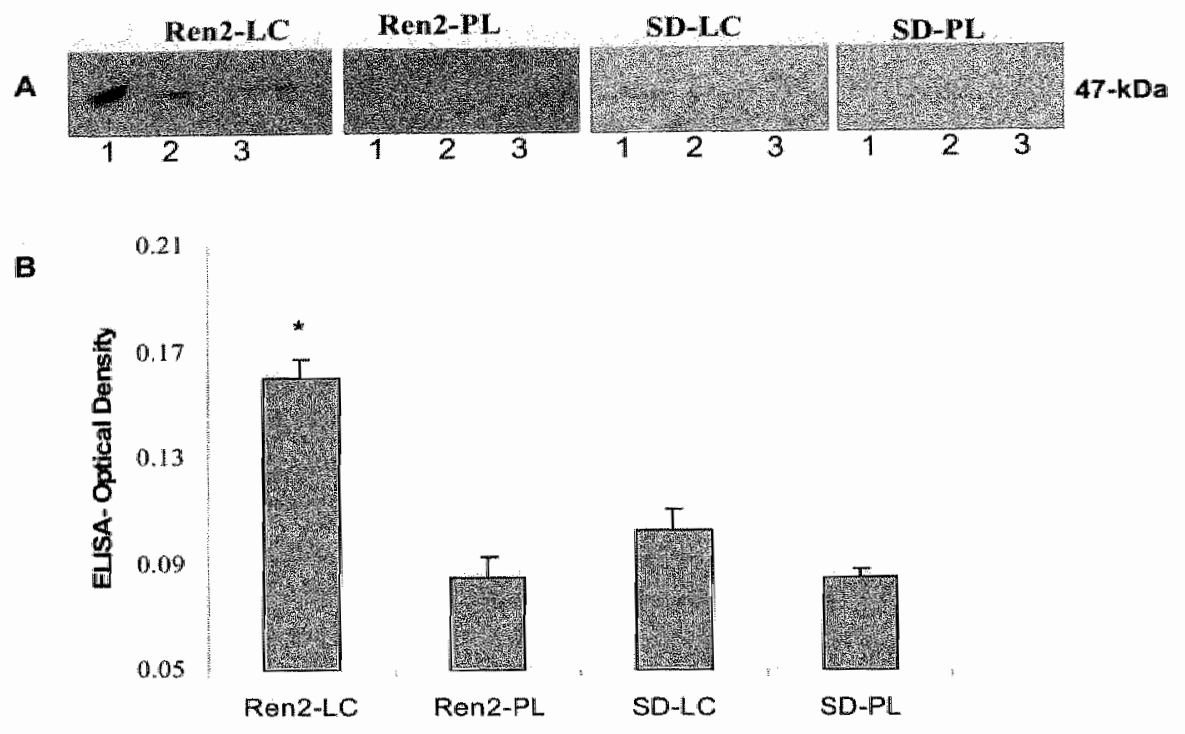

Figure 5. Immunoblotting of cardiomyocyte and cardiac fibroblast cell lysate and determination of autoantibody titer directed against HSP47 in the rat sera. A, Sera from a LC or PL-treated Ren-2 rats and SD controls were probed against rat recombinant MSP47 (lane 1) cardiac fibroblast proteins (lane 2) and cardiomyocyte proteins (ane 3). This showed a band $47 \mathrm{kD}$ suggesting the presence of autoantibodies against a $47 \mathrm{kD}$ antigen in cardiac filoroblasts and cardiomyocytes. B. An ELLSA that used rat recombinant HSP47 as an antigen. LC-treated Ren-2 rats had the highest titers of anti-HSP47 autoantibody in their serum while the autoantibody titers against HSP47 from the sera of other experimental groups (Ren-2 with PL, Sprague Dawley with LC and Sprague Dawley with $\mathrm{PL}$ ) were comparatively lower. * $P<0.05, N=5$ each group 
Several clinical as well as experimental studies measured the serum level of individual cytokines (e.g. IL-1, IL-6, TNF-a) to study the role of inflammation and cytokine production in $\mathrm{HF}^{1,1}$. Until recently, it was believed that the immune activation and macrophage infiltration in HF are part of the ongoing tissue damage process, and therefore macrophages were considered to be the bystander cells. However, we have shown that macrophages are activated at an early stage of cardiac hypertrophy, specifically in the hypertensiwe hearts that later progressed to rapid functional deterioration. These macrophages produced excess galectin-3, a pro-inflammatory and pro-fibrotio molecule both in human and rat $\mathrm{HF}^{5}$. This prompted us to investigate whether systemic depletion of macrophages can alter the cardiac architecture and function in angiotensin-II induced hypertension and cardiac hypertrophy.

The possible explanation for the deterioration of cardiac function in the absence of macrophages arises from the observation that macrophage depleted hearts showed abundant T-lymphocyte infiltration, probably because of the chemotactic property of un-phagocytosed cell debris and apoptotic bodies. These T-cells, in turn, can produce pro-inflammatory cytokines independent of the macrophages. Therefore, sustained depletion of macrophages might have contributed to the deterioration of cardiac function because of the loss of the beneficial aspects of macrophage function.

The appearance of autoimmune phenomenon in macrophage depleted state provides intriguing evidence about the role of monocyte-macrophage system for immune homeostasis in the hearts. Macrophages and monocytes are important for the clearance of self-reactive immunoglobulins and removal of cell debris that has potential to initiate autoimmune reaction ${ }^{18}$. Mammalian $T^{*}$. lymphocytes do not react against the self-proteins present in the cell surface in a healthy state. Therefore, a normal healthy heart is immune to autoimmune destruction". However, this immune privilege is lost when there is tissue damage and exposure of internal cellular constituents to the circulating lymphocytes. The second line of defense to avert the self-damage is a prompt removal of cell-debris and apoptotic bodies from the damaged myocardium. In the absence of macrophages, this process can slow-down substantially, thus rendering the hearts susceptible to be attacked from autoantibodies and T-lymphocytes. Recently Eriksson et al. have shown that antigens released from damaged myocardium could trigger an immune response. The response resulted in myocarditis and ultimately in dilated cardiomyopathy. In a series of in wivo and in witro studies, the authors showed 
that autoimmune mediated dilated cardiomyopathy results from an altered interaction between innate and adaptive immune response $\mathrm{e}^{20,21}$.

Although HSPs are well conserved through evolution, they are highly immunogenic and it has been postulated that they could activate antigen-stimulating cells, serving as a danger signal to the imnune system ${ }^{22}$. Among the HSP members; HSP47 (also designated as colligin) serves uniquely as a collagen-specific molecular chaperone ${ }^{23}$. The importance of HSP47 in vivo has been demonstrated by gene-disrupting of the molecule in the mouse, resulting in severe deficiency of the mature form of collagen and death in utero ${ }^{24}$. HSP47 locates in the endoplasmic reticulum of collagen-producing cells and plays a crucial role during the folding, maturation and secretion of pro-collagen. Therefore, the autoimmune targeting of this protein can lead to loss of collagen resillience, leading to the impairment of cardiac function. In addition, formation of antigen-antibody complexes can further damage the myocardium via further activation of complement system and production of pro-inflammatory cytokines.

\section{Perspectives}

In conclusion, the results of this study show a possible role of macrophages to regulate autoimmunity and self-damage to the myocardium. These observations suggest that complete depletion of macrophages can deprive the hearts from the beneficial effects of macrophages such as tissue scavenging and antigen processing. This can lead to the loss of immune tolerance against the proteins expressed in the heart, leading to autoantibody and lymphocyte-mediated myocardial damage and consequent loss of cardiac function.

\section{Acknowledgements}

This study was supported by a VIDI grant (016.036.346) from the Netherlands Organization for Scientific Research (NWO) to Dr. Y. M. Pinto and Profileringsfonds from Academic Hospital Maastricht to Dr. Jos Maessen. We acknowledge the technical assistance of Ms Maria Vroomen. 


\section{References}

1. Vasan RS, Sulliwan LM, Roubenoff R, Dinarello CA, Harris T, Benjamin EJ, Sawyer DHs, Levy D, Wilson PW, D:Agostino RB. Inflammatory markers and risk of heant fallure in elderly subjeets without prior myocandia infarction: the Framingham Heart Stady. Circulation 2003;107:1486-91.

2. Weber KT, Gerling IC, Kiani MF, Guntakn RV, Sun Y, Ahokas RA, Postlethwaite AE, Warrington KJ. Aldosteronism in heart fanlure: a promflammatory/fibrogenic eardiac phenotype. Search for bionarkers and potentisl drug targets. Cirnt Drug Targexs. 2003;4:505-16.

3. Shioi T, Matsumori A, Kihara $Y$, Inoko M, Ono K, Iwanaga $Y$, Yanada T, Jwasaki A, Matsushima K, Sasayama S. Increased expression of interleukin-1 beta and monocyte chemotactic and activating factor/monocyte chemoattractant protein-1 in the hypertrophied and failing heart with pressure overload. Circ Res. 1997;81:664-71.

4. Mamn DL. Inflammatory mediators and the failing heart: past, present, and the foreseeable future. Cinc Rex. $2002 ; 9: 988-98$.

5. Sharma UC, Pokharef S, van Brakel TJ, van Berlo IH, Cleutjens JP, Schroen B, Andre S, Crijns HJ, Gabius HJ, Maessen J, Pinto YM Galectin-3 marks activated macrophages in failure-prone hypertrophied hearts and contributes to cardiac dys function. Circulation. 2004:110:3121-8.

6. Mann DL, MeMurray JJ "Packer M, Swedberg K, Borer JS, Colucei WS, Djian J, Drexter H, Feldmatn A, Kober L, Krum H, Lilu P, Nieminen M, Tavazzi L, wan Veldhuisen DJ, Waldenstron A, Warren M, Westhein A, Zannad F. Fleming T. Targeted anticytokine therapy in patients with chronic heart failure: results of the Randomized Etanercept Worldwide Evaluation (RENEWAL). Circulation. 2004;109:1594-602.

7. Chung ES, Packer M, Lo KH, Fasammade AA, Willerson JT. Randomized, double-blind, placebo-controlled, pilot trial of infliximab, a chimeric monoclonal antibody to tumor necrosis factor-alpha, in patients with moderate-tosevere heart failure: results of the anti-TNE Therapy Against Congestive Heart Failure (ATli ACH) trial. Circulation. $2003 ; 107: 3133-40$.

8. Sharma UC. Hofstra L, Pinto YM, Maessen JG. Re eql-time in vivo imaging of apoptotic cell memorane changes in monocytes and macropliages. Apoprosis. 2005: in Press.

9. Van Rooijer N, Sanders A. Liposome mediated depletion of macrophages: mechanism of action, preparation of liposomes and applications. I Xmmol Wethods. 1994;174:83,93.

10. Danenberg HD, Frishbein: I, Gao J, Monkkonen J, Reich R., Gati I, Moernot E, Golomb G. Macrophage deplevion by ellodronate-containing liposomes reduces neointimal formation afler balloon injury in rats and rabbits. Cinculation. 2002:106:599-605.

11. Alwes-Rosa F, Stanganelli C. Cabrera J, wan Rooijen N. Palermo MS, Isturiz MA. Treatment wilh liposome. encapsulated clodronate as a new strategic approach in the managenent of mome thombocytopenic purpara in a mouse model. Blood. 2000;96:2834-40.

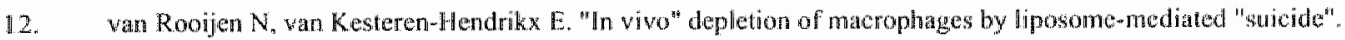
Methods Enzymor. 2003,373:3-16. 


\section{Chapter 6}

13. Gide $A J$, wan der LeE KA, Withemsen $P H, C$ hineti $G$, wan der Leij FR, wan der Vusge GJ, Staels $B$, van Bilsen $M$ Ferowisome prowferator-activated receptor (PPAR) alpha and PPARbetadelta, but not PPARgamma, modulaite the expression of genes involwed in cardiac lipid metabolisn. Cire Rem. 2003;92:518-24.

14. Pokharel S, Rasoul S, Roks AJ, van Leeuwen RE, van Luyn MJ, Deelman LE, \$mits JF, Carretero O, wan Gilst WH, Pinto YM. W-acety-Ser-Asp-Lys-Pro inhibits phosphoryllation of Smad2 in cardiac fibroblasts. Hypertension. 200,$2 ; 40: 155-61$.

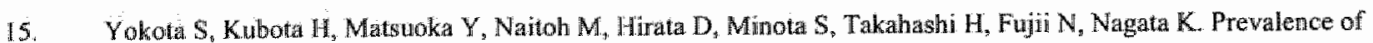
HSP47 antigen and autontibodies to HSP47 in the sera of patients with mixed connective tissue disease. Biochem Biophys Res Commun. 2003;303:413-8.

16. Hopp "WP, Woods KR. Prediction of protein antigenic determinants from amino acid sequences. Proc Nat Acad Sct U. $S^{\prime \prime} A .1981 ; 78: 3824-8$.

17. Nozaki $N_{,}$Yamaguchi $S_{n}$ Yamaoka $M_{*}$ Oknyama $M$, Nakamura H, Tomoike H. Enhanced expression and shedding of tumor mecrosis facior (TNF) receptors from mononuclear leukocytes in human heart failure. $/ \mathrm{Mol} \mathrm{Cell} \mathrm{Candiol}$. $1998 ; 30: 2003-12$

18. Striker GE, Mannik M. Tung MY. Role of marrow-derived monocytes and mesangial cells in removal of immune complexes from renal glomeruli. I Exp Med. 1979;149:127-36.

19. Latren S. How the Irmune Systern Works. In Ist ed: Blackwell Science; 1999:57-61.

20. MacLellan WR, Lusis AJ. Dilated cardiomyopathy: learning to live with yourself. Nat Med. 2003;9:1155-6.

21. Eriksson U, Ricei R, Ifunziker L, Kurrer MO, Ondit GY, Watts TH, Sonderegger I, Bachmaier K. Kopf M, Penninget JM. Dendritic cell-indnced autoimmune heart failure requires cooperation between adaptive and innate inmunity, Nat Med. 2003;9:1484-90.

22. Chen W, Syldath U, Bellman K, Burkart V, Kolb H. Human 60-kDa heat-shock protein: a danger signal to the inmate immune system. I Immunol. 1999;162:3212,9.

23. Samk J. Nikitakis N, Siavash H. Hsp47 a novel collagen binding serpin chapetone, autoantigen and therapeutic thrget. Font Bhoser. 2005: 10:107-18.

24. Nagai $N$, Hosokawa M, Iohara S, Adachi E, Matsushita T, Hosokawa N, Nagata K. Embryonic lethality of molecular chaperone hspa7 knockout mice is associated with defects in collagen biosynthesis. $J \mathrm{Cell}$ Biol. $2000 ; 150: 11499.500$. 


\section{7}

\section{Mice Lacking Galectin-3 Exhibit Preserved Cardiac Function and Decreased}

Fibrosis Following Angiotensin II Infusion

Umesh C Sharma ${ }^{1,2}$, Saraswati Pokharel ${ }^{1}$, Thomas van Brakel ${ }^{2}$, Fu-Tong Liu ${ }^{3}$, Hans-y Gabius ${ }^{4}$, Oscar A Carretero', Jos G Maessen ${ }^{2}$ and Yigal M Pinto

'Hypertension and Vascular Research Division, Henry Ford Health System, Detroit, Michigan, USA

${ }^{2}$ Department of Cardiothoracic Surgery, University Hospital Maastricht, Maastricht, The Netherlands

${ }^{3}$ Department of Dermatology, School of Medicine, University of California, Davis, Sacramento, California, USA

${ }^{4}$ Institute of Physiological Chemistry, Faculty of Veterinary Medicine, Ludwig-Maximilians University, Munich, Germany

${ }^{5}$ Experimental and Molecular Cardiology Laboratory, Cardiovascular Research Institute Maastricht, Maastricht, The Netherlands

\section{Manuscript under Preparation}

Abstract accepted for oral presentation in Scientific Sessions, American Heart Association, 2005 


\begin{abstract}
We previously found that in Ren-2 hypertensive rats with heart failure (HF), macrophage infituration and galectin-3 expression were increased. We also found that low-dose galectin-3 infusion into the pericardial sac of healthy Sprague-Dawley rats induced cardiac fibrosis and HF. Here we hypothesized that in angiotensin II-induced hypertension, galectin-3 mediates the development of cardiac fibrosis and dysfunction and that RNA interference (siRNA) of early growth regulator-1 (Egr 1 , a transcription factor that regulates the expression of collagen I) will prewent galectin-3-induced cardiac fibroblast proliferation and production of excess collagen 1 . To test this hypothesis, we infused Ang-II or placebo into galectin-3 knock-out (KO) mice and wildtype (WT) controls for 4 weeks. We examined cardiac function by 2-D echocardiography, assessed hemodynamic parameters and quantified myocardial collagen content. Using siRNA, we knocked down Egr-I from cardiac fibroblasts in witro and tested galectin-3-induced cardiac fibroblast proliferation and collagen production in Egr-l-positive and Egr $/$ - -deficient fibroblasts. Ang-II infusion led to cardiac dysfunction in WT mice. In contrast, galectin-3 $\mathrm{KO}$ mice and placebotreated controls showed normal cardiac function. Compared to wild-type mice, galectin-3 knock-out mice had lower level of myocardial collagen I content after Ang-II infusion. Egr-I knock-down from cultured cardiac fibroblasts prevented galectin-3-induced cardiac fibroblast proliferation and collagen production. Our data show that galectin-3 is a mediator of angiotensin II-induced collagen I production and cardiac dysfunction. Pharmacological antagonism of galectin-3 could lead to novel treatment strategies directed against cardiac fibrosis and dysfunction.
\end{abstract}




\section{Introduction}

Hypertension is a major contributing factor for cardiac hypertrophy and HF, Despite advances in the treatment of HF, it still remains a progressive disease with high morbidity and mortality, suggesting that important pathogenic mediators remain active and unmodified by the present treatment. Our recent studies have shown that in a model of high angiotensin II, macrophages are activated at an early stage of cardiac hypertrophy, especially in the bearts that later show rapid functional deterioration. We also found that macrophage-derived galectin-3 was 5 -fold overexpressed in failing hypertrophied hearts compared to compensated hypertroplaied hearts without dysfunction. Gallectin-3 induced cardiac fibroblast proliferation and collagen production. Characterization of collagen types showed that only the stiffer variant of collagen (collagen I) and not the elastic form (collagen III) was increased in galectin-3-infused hearts!

Galectin-3, originally described as Mac-2 antigen, is the only chimera-type member of the galectin family, a lectin group sharing calcium-independent specificity to $\beta$-galactosides and the jelly-roll. like folding pattern ${ }^{2,3}$. Galectin-3 is produced by macrophages ${ }^{1,4}$ and is predominantly located in the phagocytic cups. Galectin-3 functions as a growth factor in cardiac fibroblasts and mediates many intracellular signaling pathways similar to those induced by classical growth factors and cytokines $^{6,7}$.

The early growth response gene, $E g r-l$ is a nuclear transcription factor known to serve as an intermediary in a broad range of signal transduction processes ${ }^{6}$. A recent study showed that angiotensin II and other growth factors implicated in ventricular hypentrophy and cardiac fibrosis are associated with the induction of Egr-I gene ${ }^{8}$. Other studies have assigned Egr $/$ a new role as a master switch to amplify the gene expression ${ }^{9}$. Egr- $/$ mRNA is expressed in the myocardium and is rapidly induced in response to hypertrophic stimuli. Egr- $I$ gene expression is rapidly induced by mitogens or mechanical injury to fibroblasts via mitogen- and stress-activated protein kinases 10 . In a recent study, Alexander and associates transfected synovial fibroblasts with 2 different Egr-I expression vectors and showed that Egy- $/$ can contribute to fibrosis by activating the genes encoding the $\alpha \mathbb{l}$ and $\alpha 2$ chains of type I collagen ${ }^{11}$. Considering the ability of galectin- 3 to specifically increase expression of collagen 1, we opted to test the role of Egr-I as a specific transcriptional regullator of collagen I expression. 
Here, we report that galectin-3 mediates the cardiac dysfunction and collagen deposition induced by Ang II. Activation of Egr-1 is shown here to function as a switch activated by galectin-3 to trigger cardiac fibroblast proliferation and collagen I expression. Deletion of the gene encoding Egr-I strikingly diminished these effects in vitro. These studies define a central and unifying role for galectin-3 and Egr-I in the pathogenesis of Ang II -induced cardiac fibrosis and dysfunction. 


\section{Materials and methods}

\section{Galectin-3 KO mice and wild-type controls}

Galectin-3 knockout and age-matched wild-type control C57BL/6J mice were prowided by Professor Hans-J Gabius (Ludwig Maximilians University, Munich, Germany). We studied 16 gallectin-3 KO mice and 12 WT controls from the age of 12 to 16 weeks. Of the 16 male galectin-3 KO mice, 8 received a 4-week long angiotensin II (Ang-II) infusion ( $0.75 \mathrm{mg} / \mathrm{kg} /$ day) subcutaneouslly via an osmotic minipump. Remaining $8 \mathrm{KO}$ mice received placebo infusion for the same duration. Of the 12 age-matched WT controls, 6 received Ang-Il and remaining 6 received placebo infusion. The institutional animal care committee approved the procedure for care and treatment of animals.

\section{Recombinant galectin-3 production and infusion into the pericardial space}

Murine recombinant galectin-3 expressed from plasmid prCBP35s was purified by affinity chromatography on lactosylated Sepharose $4 \mathrm{~B}$, produced by divinyl sulfone activation. The purity of the obtained protein was studied by gel filtration and one- and two-dimensional gel electrophoresis to exclude any contamination or protein modification ${ }^{12}$. We infused recombinant galectin-3 into the pericardial cavity of 6 Sprague Dawley (SD) rats. Similarly, 6 additional SD rats underwent an identical surgical procedure but received normal saline infusion. Further details on the dose and duration of galectin-3 infusion and surgical methods for accessing the pericardial cavity were reported previously.

\section{Measurement of cardiac geometry and function}

Echocardiography was done at 0,14 and 28 days of Ang-II infusion in mice sedated with $2 \%$ isoflurane. Standard views were obtained in 2-D as well as M-Mode with a 12-MHz transducer (Hewlett Packard, Amsterdam, The Netherlands) with approximately 220 frames per recording and the data analysis was made by a blinded observer.

Before sacrifice, hemodynamic parameters were measured. Following andesthesia by intraperitoneal injection of urethane $(\mathrm{g} / \mathrm{kg})$, the right carotid artery was cannulated with a 2 French high-fidelity micromanometer (Millar Instruments, Houston, TX), and the catheter was advanced into the left ventricle. The output signal from the micromanometer was digitized at $4000 \mathrm{~Hz}$ with a MacLab system (ADI Instruments, Castle Hill, Australia).

\section{RNA interference}


Pre-designed siRNA specific to tat Egr-I gene (Accession, NM 012551) and siRNA transfection kit were purchased from Ambion. According to the manufacturer's instructions, rat cardiac fibroblasts were transfected with SIPORT lipid transfection agent along with the annealed doublestranded Egr-1 siRNA (Sense: GGACUUAAAGGCUCUUAAUt; Antisense:

AUUAAGAGCCUUUAAGUCCtg) at a fimal concentration of $20 \mathrm{~nm}$ for 72 hours. A scrambled sequence that bears no homology to the rat genome was used as a negative control. The extent of Egr- 1 knock down was measured by Western bloting.

\section{Protein isolation and Western blotting}

Protein isolation and Westem blotting were performed as described previously ${ }^{13}$. Primary antibodies (Collagen-I and III, Abcam; Egr-1, Cell Signaling) were diluted 1/1000 in tris-buffer saline with tween-20 (TBS-T). Secondary antibody (horseradish-peroxidase conjugated IgG, Cel]. Signaling) was diluted $1 / 2000$ in TBS-T. Protein bands were visualized by enhanced chemiluminescence technique.

\section{Candiac fibroblast proliferution assays}

Rat cardiac fibroblasts were isolated from adult Sprague-Dawley rats, as described previously ${ }^{13}$. Cells were cultured in Dulbecco's modification of Eagle's medium (DMEM) supplemented with $10 \%$ foetal bovine serum (FBS), along with $1 \% \mathrm{~L}$-glutamate, $50 \mathrm{U} / \mathrm{mL}$ penicillin, and $0.1 \mathrm{~g} / \mathrm{L}$ streptomycin, and were incubated at $37^{\circ} \mathrm{C}$ in a humidified $5 \% \quad \mathrm{CO}_{2}$ atmosphere. The number of dividing cells was determined by radio-labelled methyl $\left[{ }^{3} \mathrm{H}\right]$ thymidine incorporation $(0.5 \mu \mathrm{Ci}$ per well) assay. The assays were done in duplicate for fibroblast preparations.

\section{Statistical analyses}

Data are presented as mean \pm SEM. The pairec comparisons were made by unpaired $t$-test. For multiple comparisons, one-way analysis of variances (ANOVA) in combination with a Dunnett post-hoc analysis was made. Analyses were performed using the statistical package SPSS 10.0 (Chicago, $\mathbb{L}$, USA). P-values $<0.05$ were considered to be statistically significant. 


\section{Results}

\section{Preserved cardiac function after Ang II infusion in galectin-3 KO mice}

We documented baseline cardiac function by echocardiography in galectin-3 KO and WT mice. There was no significant change in LV ejection fraction (EF) and fractional shortening (FS) at the baseline. However, after 4-week infusion of Ang II, the WT mice showed deterionated cardiac function compared gallectin-3 $\mathrm{KO}$ mice (EF \%: galectin-3 KO, 64 \pm 2.3 ; WT, $49.3 \pm 6.1, \mathrm{P}<0.05$ ). Similarly, the WT mice that received Ang II showed decreased LVFS and increased LV enddiastolic volume. However, there was no significant difference in the LV mass between galectin-3 $\mathrm{KO}$ and WT mice (Table 1). In addition, the WT mice infused with Ang II for 4 weeks showed. decreased DP/dt $\max _{\max }, \mathrm{DP} / \mathrm{dt}_{\min }$ (Figure 1) and increased lung weight to body weight ratio, compared to KO mice and mice that received placebo infusion (Table 1).

Table 1. Echocardiographic measurements and tissue and body weight ratios in galectin-3 $\mathrm{KO}$ and WT mice with Ang-II or placebo infusion

\begin{tabular}{|c|c|c|c|c|c|}
\hline & & $\mathrm{AK}$ & $\mathrm{AW}$ & PK & PW \\
\hline \multicolumn{6}{|c|}{ Echocardiographic parameters } \\
\hline \multirow[t]{2}{*}{ LVEF $(\%)$} & Baseline & $67.3 \pm 2.3$ & $68.2 \pm 12.1$ & $64.3 \pm 2.2$ & $62.2 \pm 3.6$ \\
\hline & 4-weeks & $64 \pm 2.3$ & $49.3 \pm 6.1^{*}$ & $65.5 \pm 4$ & $66.4 \pm 1.68$ \\
\hline \multirow[t]{2}{*}{ LVFS $(\%)$} & Baseline & $32.2 \pm 1.8$ & $32.8 \pm 5.8$ & $29.8 \pm 1.5$ & $29.2 \pm 2.4$ \\
\hline & 4-weeks & $29.8 \pm 1.5$ & $21.5 \pm 4 *$ & $31.5 \pm 2.5$ & $31.4 \pm 1.9$ \\
\hline \multirow[t]{2}{*}{$\mathrm{LVEDV}(\mathrm{ml})$} & Baseline & $0.08 \pm 0.01$ & $0.08 \pm 0.03$ & $0.09 \pm 0.02$ & $0.06 \pm 0.01$ \\
\hline & 4-weeks & $0.07 \pm 0.01$ & $0.112 \pm 0.02$ & $0.08 \pm 0.01$ & $0.07 \pm 0.02$ \\
\hline
\end{tabular}

Tissue and body weight ratios

$\begin{array}{lllll}\text { HW/BW }(\%) & 0.46 \pm 0.01 & 0.52 \pm 0.01 & 0.44 \pm 0.01 & 0.44 \pm 0.1 \\ \text { LW/BW }(\%) & 0.48 \pm 0.01 & 0.65^{*} \pm 0.02 & 0.46 \pm 0.0 & 0.48 \pm 0.0\end{array}$

$\mathrm{AK}$, galectin-3 $\mathrm{KO}$ mice with 4 -week infusion of $\mathrm{Ang}$ I: $\mathrm{AW}$, WT mice with Ang II; PK, KO mice with placebo; $\mathrm{PW}$, WT mice with placebo; LV, left ventricle; EF, ejection fraction; FS, fractional shortening; EDV, end-diwstolic volume; HW/BW, heart weight body weight ratio; $L$ W/BW, lunig weight body weight ratio; *, $\mathrm{P}<0.05$ compared to rest of the groups, $N=6-8$ mice each group.

Attenuation of Ang II-induced collagen deposition in the myocardium of galectin-3 KO mice 
To investigate whether galectin-3 mediates the pro-fibrotic effects of Ang II in this mouse model, we measured LV collagen content in Ang II or placebo-treated galectin-3 KO mice and WT controls After a four-week infusion of Ang II, Western blotting showed a marked increase in myocardial collagen I content in WT compared to galectin-3 $\mathrm{KO}$ mice (densitometric units: WT, $1.1 \pm 0.14, \mathrm{KO}, 0.58 \pm 0,1, \mathrm{P}<0.05)$. However, no significant difference was observed at the level of myoeardial collagen 1 between galectin-3 KO and WT mice at baseline (densitometric units: KO, $0.43 \pm 0.1 ; W_{T}, 0.64 \pm 0.15, \mathrm{P}=\mathrm{NS}$ ) (Figure 2).

A

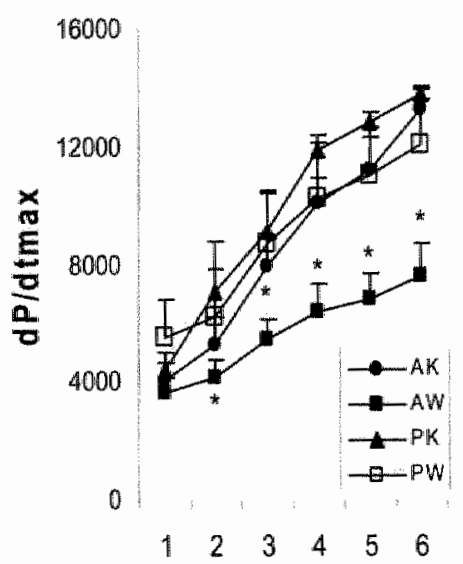

B

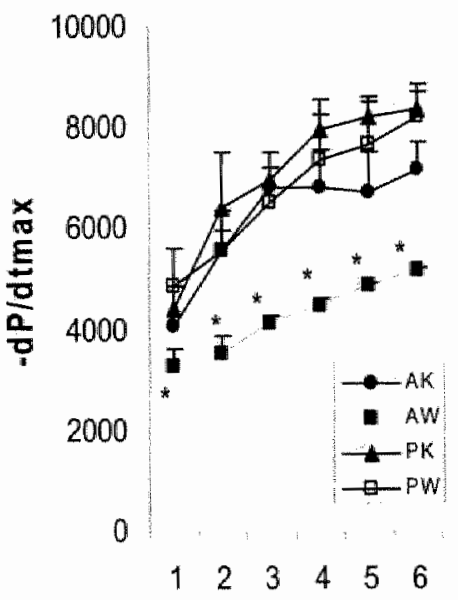

Figure 1. Serial measurement of $\mathrm{CV}$ pressure in the gallectin-3 KO and WT mice with esculating dose of dobutamine infusion. A, increase in peak positive $L V \mathrm{dP} / \mathrm{dt}$ in response to infusion of dobutamine. $B$, increase in peak negative $L V$ dP'dt in response to infusion of dobutamine. AK, galectin-3 KO mice with 4-week infusion of Ang III; AW, WT mice with Ang II; PK, KO mice with placebo; PW, WT mice with placebo, P<0.05 compared to the rest of the experimental groups. 


\section{Increased myocardial collagen content and $E g r-I$ expression in galectin-3 infused rats}

In our recently published study, we reported that galectin-3 increases cardiac fibroblast proliferation and collagen production in cultured rat cardiac fibroblasts. In addition, infusion of galectin 3 into the pericardial sac of healthy Sprague Dawley rats induced increased myocardial collagen deposition. Characterization of the collagen types showed that galectin-3 specifically increased the production of collagen I. In this study, we measured myocardial expression of Egp-1, a known transcription factor for collagen I, in galectin-3 and placebo-treated rats. Westem blotting of the myocardial homogenate showed a significantly increased $E g r-I$ expression in galectin-3-treated rats compared to the rats that received placebo (densitometric units: galectin-3,0.67 \pm 0.17 ; placebo, $0.39 \pm 0.18, \mathrm{P}<0.05)$.

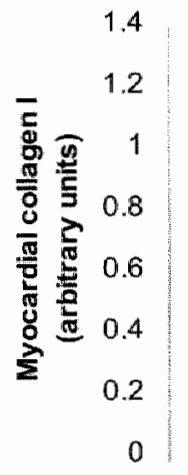

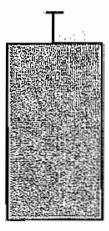

AK

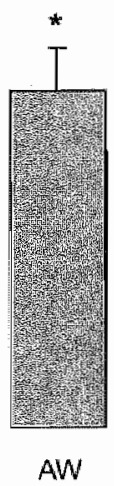

AW

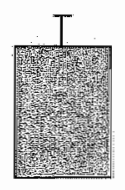

PK

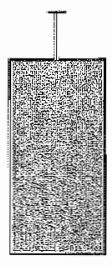

PW

Figure 2. Western blot for the detection of collagen I. Top panel, representative blot for myocardial collagen I expression in galectin-3 $\mathrm{KO}$ mice with 4 -week infusion of Ang II (AK), WT mice with Ang II (AW), KO mice with placebo (PK) and WT mice with placebo (PW). Bortom panel, quantification of collagen I in densitometric units in relation to a housekeeping protein GAPDH. $N=4-6$ for each experimental group, * $\mathrm{P}<0.05$ vs. rest of the comparison groups. 


\section{Prevention of galectin-3-induced cardiac fibroblast proliferation and collagen I production by}

\section{Egr-1 knockdown}

Given the evidence that Egr-I can regulate cell growth and collagen I transcription, we tested whether RNA interference of Egr-I could prevent galectin-3 induced cardiac fibroblast proliferation and collagen production. Galectin-3 increased the expression of $E g-I$ in cultured rat cardiac fibroblasts (densitometric units: control, $0.47 \pm 0.1$; galectin-3, $1.02 \pm 0.02$ ). The siPORT permeabilized fibroblasts treated with $E g r-1$ siRNA for 72 hours showed a significant decrease in Egr $-/$ protein expression (densitometric units: galectin-3+Egr-1 siRNA, $0.6 \pm 0.03$ ) (Figure 3). When treated with recombinant galectin-3, The Egr-l-knocked down cells showed decreased proliferation compared to WT cells (counts/minute: galectin-3, $1531 \pm 53$; galectin- $3+E g r-1$ siRNA, $1245 \pm 1.05 .4$; control, $1243 \pm 128.5$ ) (Figure 4). In addition, the Egr-1, knock-down prevented galectin-3 induced collagen I production by cultured rat cardiac fibroblasts (densitometric units: control, $1.32 \pm 0.17$; galectin-3+Egr $/$ siRNA, $1.44 \pm 0.14$, galectin-3, $2.79 \pm 0.12$ ) (Figure 5).

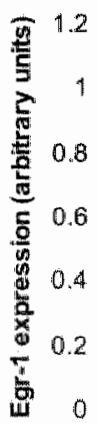

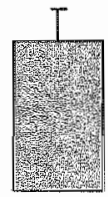

Control

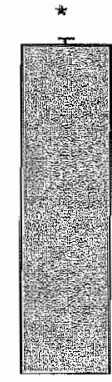

G3

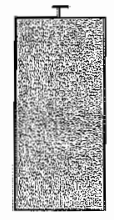

G3+Egr1-si

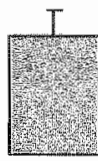

Egr1-sii

Figure 3. Western blot to quantify galectin-3-induced $E g r-I$ axpression by cardiac hibroblasts and the offect of $E g /-I$-specific siRNA to delete $E g \gamma^{\prime} I$ expression. Top pamel, nepresentative blot for Egr l expression in cultured cardinc fibroblasts. Bothom pawed, quantification in denstometric units in relation to a housekeeping protein GAPDH. G3, cardiac fibroblasts treated with recombinant galectin-3, G3+Egr 1-si, fibroblasts treated with galectin-3 and siRNA for $E g r /$, Egr 1-sil, fibroblasts treated with siRNA 


\section{Discussion}

The results of the current study show that galectin-3 mediates Ang 11 -mediated cardiac dysfunction and fibrosis. Galectin-3 can increase the expression of Egr -1 , a known transeription factor for collagen I. The targeted deletion of galectin-3 gene in a mouse model with Ang II infusion results in preserved cardiac function and prevention of Ang II-induced collagen deposition in the myocardium. Intrapericardial infusion of galectin-3 in a rat model leads to cardiac collagen deposition, Egr-I expression and functional deterioration. Deletion of Egr-l expression by siRNA prevents the galectin-3-induces cardiac fibroblast proliferation and collagen I production in cultured rat cardiac fibroblasts.
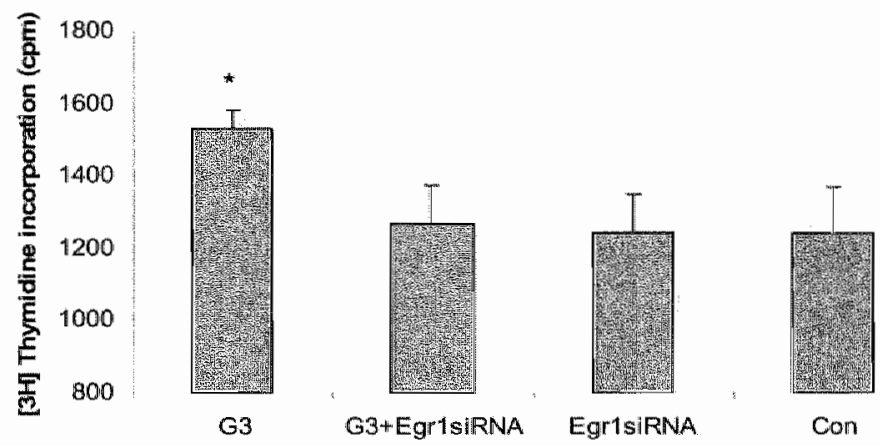

Figure 4. Effects of galectin-3 and $E g r-I$ knockdown on cardiac tibroblast proliferation. Tritiated thymidine incorporation by dividing fibroblasts after treating the cells with $30 \mu \mathrm{g} / \mathrm{mol}$ of recombinant galectin-3 (G3). galectin-3 and silk NA for Egr-1 (G3+Egr1-sil) and sikNA for Egr-1 (Egil-si )., $\mathrm{P}<0.05$ ws. rest of the comparison groups; $\mathrm{N}=8$, each group. 
Our previous finding that galectin- 3 is overexpressed well before transition to overt HF suggested the novel concept that already in the compensated phase; some hypertrophied hearts produce proinflammatory and pro-fibrotic mediators". Therefore, early recognition of failure-prone hearts and pharmacological antagonism of such agents might provide additional benefit over existing treatment strategies. In the current study, this concept has been further clarified by showing a beneficial effect of galectin-3 KO in an Ang II-infused model.

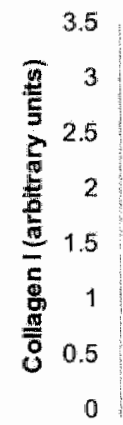

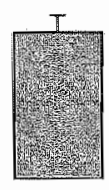

Control

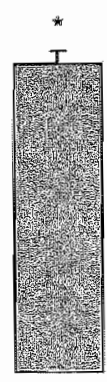

$\mathrm{G3}$

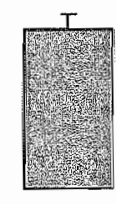

G3+Egr'1-si

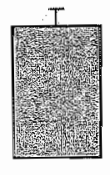

Egr|wis

Figure 5. Western blot to measure the effects of galectin-3 and Egr-I knockdown on collagen I production by cardiac fibroblasts. Top panel, representative blot for collagen I expression in cultured cardiac fibroblasts. Bothom ponel, quantification in densitometric units in relation to a housekeping protein GAPDH. G3, cardiac fibroblasts treated whth tecombinant galectin-3, G3+ldgr 1-si, fibroblasts treated with galectin-3 and siRNA for Egy-1, Egr 1-si, fibroblasts treated witit siRNA for Bgr-1.* P<0.05 vs. rest of the comparison groups. 
Galectin-3 consists of a short $\mathrm{N}$-terminal domain continuing into a unique proline-glycine-allaninetyrosine rich repeat motif and a highly conserved $\mathrm{C}$-terminus containing the carbohydrate recognition domain (CRD) ${ }^{14}$. Intracellularly, galectin-3 acts as a pre-mRNA splicing factor and regulates cell cycle, with promotion of replication and inhibition of apoptosis ${ }^{15}$. Extracellularly, galectin-3 regulates cell adhesion with bomo- and heterotypic cell-to-cell interaction ${ }^{16}$, whereas it down-regulates cell adhesion to the $\mathrm{ECM}^{17}$. Extracellular galectin-3 also binds with $\operatorname{IgE}$ receptors facilitating mast cell activation ${ }^{18}$. Galectin-3 is also involved in a hingh-affinity binding, internalization and degradation of advanced glycosylation end-products ${ }^{19}$. We have recently shown that galectin-3 ligands are located in the cytoplasmic space of the cardiac fibroblasts and these ligands migrate to perinuclear area in dividing cells. In addition, galectin-3 receptors are also located in the extracellular matrix of the myocardial tissue!. These observations, along with the previous reports of Kim et al, show that gallectin-3 regulates cell division and protein synthesis by activating nuclear cell cycle regulators and transcription factors ${ }^{20}$.

We propose a possible explanation through which $E g r-I$ could exert such effect in cardiac collagen deposition. First, the Egr-1 DNA-binding motif is present in a range of genes relevant to collagen production, and lack of $E g r-1$ can directly attenuate the expression of the respective RNA. Second, absence of $E g r^{*}-1$ can allow its co-repressors, especially the inducible molecule Nab-2, to interact with other transcription factors affecting the regulation of myocardial matrix proteins ${ }^{9,21}$. Although further studies will be required to clarify the undlerlying mechanisms, our results identify a prominent role of galectin-3-Egr-1 interaction for the deposition of fibrillar collagen in the myocardium. This can, in turn, increase myocardial stiffness, decrease viscular reserve volume leading to functional deterioration.

\section{Conclusions and Implications}

The current study, by demonstrating the role of galectin-3 for the development of cardiac dysfunction, expands on our previous publication that described the possible involvement of galectin-3 in the early stages of HF. Furthermore, this study provides the mechanistic imsights on the galectin-3 dependent collagen synthesis. The finding that targeted deletion of Egr 1 in rat cardiac fibroblasts can prevent galectin-3-induced cardiac fibroblast proliferation and collagen I synthesis suggests the novel concept that galectin-3-Egr-I axis can be a critical mediator for the Ang II-induced cardiac fibrosis and dysfunction. Galectin-3 is the only member of the galectin family with an unusually broad activity including protein-carbohydrate and protein-protein 
Chapter 7

Interactions in nuclel, cytoplasm, plasma membrane, and extracellular matrix. These results shape the concept of considering galectin-3 and its downstream mediator, EgF- $l$ as the new targets for therapeutic intervention of cardiac fibrosis and dysfunction. 


\section{References}

1. Sharma UC, Poklarel S, van Brakel TJ, van Berlo JH, Cleutjens IP, Schroen B, Andre S, Crins HI, Gabius HI, Maessen J Pinto YM. Galectin-3 marks activated macrophages in failure-prone hypertrophied hearts and contributes to cardiac dysfunction. Circulatian. 2004;110:3121-8.

2. Hughes RC. Mac-2: a versatile galactose-binding protein of mamnalian tissues, Ghoobiology, 1994;4:5-12.

3. Gabius HJ. Glycohistochernistry: the why and how of detection and localization of endogenous lectins. Anat Histol Embryol. 2001;30;3-31.

4. Sato S, Hughes RC. Regulation of secretion and surface expression of Mac-2, a gallactoside-binding protiein of macrophages. J Biol Chen". 1994:269:4424-30.

5. Sano H, Hsu DK, Apgar JR, Yu L, Sharma BB, Kuwabara II, lzuil S, Liu FT. Critical role of galectin-3i in phagocytosis by macrophages. J Clin Invest. 2003;112:389-97.

6. Ochieng J, Furtak V, Lukyanov P. Extracellular functions of galectin-3. Gbcoconj J. 2004:19:527-35.

7. Liu FT, Patterson RJ, Wang JL. Intracellular functions of galectins. Biochim Biophys Acta. 2002;1572:263-73.

8. Iwami K, Ashizawa N, Do YS, Graf K, Hsueh WA. Comparison of ANG II with other growth factors on Egr-1 and matrix gene expression in cardiac fibroblasts. Am J Physiol. 1996;270:H2100-7.

9. Yan SF, Fujita T, Lu J, Okada K, Shan Zou X, Mackman N, Pinsky DJ, Stern DM. Egr-1, a master switch coordinating upregulation of divergent gene families underlying ischemic stress. Nat Med. 2000;6:1355-61.

10. Adamson ED, Mercola D. Egr1 transcription factor: multiple roles in prostate tumor cell growth and survival. Tumour Biol. 2002;23:93-102.

11. Alexander D, Judex M, Meyringer R, Weis-KLlemm M, Gay S, Muller-Ladner U, Aicher WK. Transcription factor Egr-1 activates collagen expression in immortalized fibroblasts or fibrosarcoma cells. Biol Chem. $2002 ; 383: 1845-53$.

12. Gabius HJ. Influence of type of linkage and spacer on the interaction of beta-galactoside-binding proteins with immobilized affinity ligands. Anal Biochen. 1990;189:91-4.

13. Pokharel S, Rasoul S, Roks AJ, van Leeuwen RE, van Luyn MJ, Deelman LE, Smits JF, Carretero O, wan Gilst WH, Pinto YM. N-acetyl-Ser-Asp-Lys-Pro inhibits phosphorylation of Smad2 in cardiac fibroblasts. Hypertension. 2002;40:155-61.

14. Pricei F, Leto $G$, Amadio L, lacobini $C$, Romeo $G$, Cordone S, Gradimi R, Barsotti P, Liu FT, Di Mario U, Pugliese G. Role of galectin-3 as a receptor for advanced glycosylation end products. Kidney Int Suppl. 2000;7 :S31-9.

15. Dagher $S F$, Wang JL, Patterson RJ. Identification of galectin-3 as a factor in pre-mRNA splicing. Proc Narl AcadSci U SA. 1995;92:1213-7.

16. Inohara $\mathrm{H}, \mathrm{Raz}$ A. Functional evidence that cell surface galectim-3 mediates homotypic cell adhesion. Cancer Res. 1995;55:3267-71.

17. Ochieng J, Leite-Browning ML, Warfield P. Regulation of celiular adhesion to extracellular matrix proteins by galectin-3. Biochem Biophys Res Commun. 1998;246:788-91.

18. Frigeri LG, Zuberi RI, Liu FT. Epsilon BP, a beta-galactoside-binding animal lectin, recognizes IgẼ receptor (Fc epsilon RD) and activates mast cells. Biochemistry. 1993;32:7644-9. 
19. Vlassara H, LI YM, Imani $F_{3}$ Wojciechowicz D, Yang Z, Liu FT, Cerami A. Identification of gallectin-3 as a high-affinily binding protein for adwanced glycation end products (AGE): a new member of the AGE-receptor complex. Mol Med. 1995; 1:634-46.

20. Kim HR, Lin HM, Biliran $H_{3}$ Raz A. Cell cycle arnest and inhibition of anoikis by galectin-3 in human breast epithelial cells. Cancer Res $1999,59: 4148-54$.

21. Svaren I, Sevetson BR, Apel ED, Zimonjic DB, Popescu NC, Milbrandt J. NAB2, a corepressor of NGFI-A (Egr-1) and Krox20, is induced by proliferative and differentiative stimuli. Mol Cell Biol. 1996;16:3545-53. 


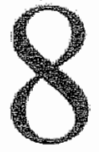

General discussion 
Hypertension can lead to cardiac hypertrophy and HF, but not every patient with hypertension suffers this outcome $e^{1-3}$. Recrutment and activation of macrophages to the heart is an important precedent of the development of HF through the production of galection-3 by activated macrophages ${ }^{4,5}$. Gallectin-3 causes fibroblast proliferation and collagen 1 production, important features of cardiac hypertrophy leading to HF, in addition to being a pro-inflammatory molecule ${ }^{5}$. To this end, in this thesis, we will discuss the growth of knowledge that has taken place in this field, with a focus on what we have learned about the early macrophage activation in failure-prone hearts and what will thappen when the hearts are deprived of the macrophages. We will also discuss the role of galectin-3, a macrophage-derived cytokine to mediate cardiac dysfunction and fibrillar collagen production in the heart. Finally, we will discuss the potential direction of future research in this area.

\section{Identification HF-related genes by microarray technique: Immunological and Matricellular profile}

We used cDNA microarrays to define comprehensive gene expression profiles in an experimental model of genetic hypertension, during the development of LVH and in transition to HF. Nearly $50 \%$ of the Ren-2 rats develop severe and rapid HF by 13-15 weeks of age therefore these rats constitute a usefull model for genomic studies of $\mathrm{HF}^{6}$. The microarray technique provides substantial advantages over other methods also aimed at identifying these genes, as it allows a functional. assessment of candidate genes without any preconceived information about their expression, and so represents an unbiased approach ${ }^{7}$. In our microarray experiment aimed at identifying the HFassociated genes in a model of angiotensin II-driven model, we compared the myocardium with compensated cardiac hypertrophy to the similarly hypertrophied hearts with functional deterioration. By a rigorous data mining strategy, marked changes in the arrays of genes predominantly associated with immune function and ECM production were observed in transithion to HF. In addition to previously identified genes in HF e.g., collagens, fibronectin and osteopontin, several novel immunological and ECM-related genes like galectin-3 (Mac-2), major histocomapatibility-III (MHC-II) antigens, immunoglobulin receptor, vimentin, cathepsin, elongation factor-1, tissue inhibitor of matrix metalloproteinase 1 (TIMP-1) and thrombospondin genes were also noticed to be overexpressed. Classic hypertrophy related genes like BNP are upregulated both in compensated and in failing hearts: therefore these genes cannot truly be seen as molecular mechanisms unique to failure ${ }^{6}$. Broadly, these genes could be classified into 2 pathologically relevant classes: 
Immunological profile: Although immune system is designed to fight against microbes, cancer cells and any foreign material that could by harmfial to the body, the hypertensive hearts suffer poor outcome because of the loss of immune regulation or tolerance " This is evident from our study that failing hypertrophied hearts showed a concerted overexpression of several genes involved in antigen recognition and processing. The most striking finding was that there was 5 -fold increase in galectin-3 expression, specifically in the failing hypertrophied hearts ${ }^{9}$. Galectins, a family of animal carbohydrate binding proteins (lectins), have been strongly implicated in inflammation and may be useful targets for development of new anti-inflammatory therapies ${ }^{10-12}$. Since potent galectin-3 inhibitors are developed by structure based drug design and combinatorial chemistry, this is a promising molecule to further investigate to design adjunctive treatment strategies for HF. The second interesting immunological gene specifically overexpressed in failing hearts was major histocompatibility protein class 2 (MHC-II). Class II MHC proteins are found only on immune cells such as phagocytes that engulf foreign particles. These cells are specially designed to present peptide antigens derived from such digested particles. The antigens are presented to helper T-cells, which have receptors for class II MHC proteins. The purpose of this surveillance system is to stop the immune system running out of control and attacking the body's own cells ${ }^{13}$.

Matricellular profile: In the heart, collagens are the major extracellular matrix (ECM) proteins. Collagens, which are present in the myocardium in relatively small amounts, are the most abundant structural protein of the connective tissue network. Its structural organization consists of a complex weave of collagen fibers that surrounds and interconnects myocytes, groups of myocyles, nuscle fibers and muscle bundles. The conformation of interstitial fibrillar collagen makes it highly resistant to degradation by all proteinases other than specific collagenases ${ }^{14}$. In hearts with myocardial inflammation or cardiomyopathy, a complex sequence of compensatory events occurs that eventually results in an adverse left ventricular remodeling. The net effect is a shift in the ballance between collagen synthesis and degradation which leads to excess fibrillar collagen matrix, progressive ventricular stiffening and eventual heart failure ${ }^{15}$.

The extracellular matrix of the heart is not merely a passive structure. In the past few years, it has emerged that the matrix is a dynamic action zone that functions to instruct cellular phenotype. Extracellular matrix proteins like thrombospondins, vimentins, fibronectin, osteopontin etc., interact directly with cell surface receptors to initiate signal transduction pathways and to modulate those 
triggered by differentiation and growth factors. The extracellular matrix proteins also control the activity and presentation of a wide range of growth factors. Thus modulation of the extracellular matrix, by remodeling its structure and activity, has profound effects on its function and the consequent behavior of tissue residing on or within it. Overall, this suggests that, in $\mathrm{HF}$, two pathological mechanisms are activated side-by-side, one affecting immune regulation and the second related to active remodeling of the diseased myocardium ${ }^{15,16}$. The apparent split of the genes into these 2 broad categories in our experiments suggested that these 2 areas can be the targets for designing new therapeutic strategies for $\mathrm{HF}$.

\section{Early identification of failure-prone hearts and role of galectin-3 for the transition to heart} failure

Heart failure is common, has a poor prognosis, and can be treated. The incidence is increasing, and the most common causes are hypertension and coronary heart disease and, and the prevention of heart failure is inextricably linked to the prevention of these disorders. Physicians have sought simple quantitative indicators based on the ejection fraction or heart size that might aid in the diagnosis of heart failure and predict the outcome. An old adage is that a big heart is a bad heart. This is not entirely true. The presence of heart failure predicts worsening heart failure, and worsening heart failure predicts death from heart failure ${ }^{17}$.

Given the emergence of newer therapeutic interventions, early diagnosis of HF has become an issue of intense investigation. We addressed the question that whether it would be possible to identify the hearts that have increased predisposition to fail early and have poorer outcome. To test the hypothesis that gene expression profiling of the hypertrophied hearts before overt HF could identify a molecular signature that would distinguish failure-prone hearts in the future, we obtained biopsy specimens from hypertensive Ren-2 rats at 10 weeks of age. Using real-time PCR, we measured the expression of galectin-3 and other genes known to be upregulated in HF e.g., brain natriuretic peptide (BNP). Measured by real-time PCR, myocardial expression of galectin-3 gene was increased only in the rats that later progressed to HF, while it was expressed at relatively lower levels in the rats that subsequently remained compensated, and in non-transgenic control rat hearts. In human myocardial biopsies, there was significantly higher myocardial galectin-3 mRNA expression in hypertrophied hearts with relatively impaired ejection fraction as compared to the compensated forms of cardiac hypertrophy ${ }^{5}$. If future studies validate this model, stratification based on pretreatment gene expression would be feasible in patients with hypertension and left 
ventricular hypertrophy, thereby allowing the patients who are destined for HF to receive additional/alternative treatment strategies:

Conceptually, myocardial failure begins with immunological damage to the heart. Compensatory changes take place in the heart that including ventricular enlargement, hypertroplyy of individual myocytes, and modification of the extracellular matrix (e.g., fibrosis). The enlargement may be progressive or immediate ${ }^{18}$. An important question is whether immunological damage to the myocardium causes compensatory ventricular enlargement in both the damaged area and the normal tissue, or whether enlargement of the heart as a consequence of the initial damage is the principal determinant of subsequent reduced function.

\section{Heart Failure: $\mathbf{A}$ disease of autoantibody clearance deficiency?}

Monocytes and macrophages are critical scavengers for the tissue proteins and have been reported to co-ordinate immune homeostasis. These cells are important for the clearance of self-reactive immunoglobulins and removal of cell debris that has potential to initiate autoimmune reaction ${ }^{19}$. Mammalian T-lymphocytes do not react against the self-proteins present in the cell surface in a healthy state. Therefore, a normal healthy heart is immune to autoimmune destruction ${ }^{13}$. However, this immune privilege is lost when there is tissue damage and exposure of internal cellular constituents to the circulating lymphocytes. The second line of defense to avert the self-damage is a prompt removal of cell-debris and apoptotic bodies from the damaged myocardium. In the absence of macrophages, this process can slow-down substantially, thus rendering the hearts susceptible to be attacked from autoantibodies and T-lymphocytes. The autoantibodies are often of immunoglobulin $\mathrm{G}(\mathrm{IgG})$ superfamily and monocytes and macrophages express high affinity $\lg \mathrm{g}$ receptors, so that the autoantibodies are constantly removed from the circulation and the process of autoimmune reaction kept to minimum ${ }^{19}$. Recently Eriksson et al. have shown that antigens released from damaged myocardium could trigger an immune response. The response resulted in myocarditis and ultimately in dilated cardiomyopathy. In a series of in wivo and in vitro studies, the authors showed that autoimmune mediated dilated cardiomyopathy results from an altered interaction between innate and adaptive immune response ${ }^{20,21}$.

Based on our previously discussed observations, excess macrophage infiltration in failing hearts suggested a possible detrimental role of macrophages in the progression of HF. In contrary, worsening of HF and increased mortality following anti- TNF- $\alpha$ treatment raised unresolved 
questions regarding the role of macrophage-derived mechanisms in $\mathrm{HF}^{22}$. We examined whether systemic depletion of macrophages in hypertensive Ren-2 rat model of hypertension-hypertrophyHF with myocardial macrophage infiltration could alter the course of cardiac adaptation and function. Interestingly, complete depletion of macrophages and their precursors led to the worsening of cardiac function in hypertensive Ren- 2 rats. In agreement to the observed cardiac dysfunction, clodronate-treated Ren-2 rat hearts also showed areas of myocyte loss with abundant inflammatory cell infiltration. Characterization of the inflammatory infiltrates showed that these cells were CD4 positive T-lymphocytes (T-helper cells). An autoantibody-based immunoscreening of the whole myocardial proteins showed that the cladronate-treated Ren-2 rats harbored a high titer of autoantibodies directed against a $47-\mathrm{kD}$ a protein. A computational prediction of antigenicity index showed the 47-kDa protein to be heat shock protein-47 (HSP47). The in silico observations were confirmed by establishing an immunoassay that could specifically quantify anti-HSP 47 autoantibodies in the sera. This led us to conclude that macrophages are critical regulators of cardiac immune homeostasis in hypertensive animalls. Macrophage depletion from these hearts leads to loss of immunological tolerance and production of $\mathrm{T}$-cells and autoantibodies directed against myocardial self-proteins leading to deterioration of cardiac function.

Under physiological conditions, neither apoptotic nor necrotic cell material is easily found in tissues. because of its quick removal by a highly efficient scavenger system comprising of circulating monocytes and macrophages. Autoantigens are found in apoptotic and necrotic material and they are recognized by autoimmune sera from failing hypertensive rats. The clearance of dying cells is finely regulated by a highly redundant system of receptors on phagocytic cells and bridging molecules, which detect molecules specific for dying cells. Changes on apoptotic and necrotic cell surfuces are extremely important for their recognition and further disposal ${ }^{2.3}$. In this context, we warrant a further investigation to rule out the possibility of macrophage anergy or inability of the macrophages to remove tissue debris in actively remodeling hypertensive hearts.

\section{Conclusions}

We investigated the mechanisms of hypertension-induced cardiac fibrosis and failure following two independent approaches. The first unbiased genomic approach identified the key susceptibility genes involved in HF. Most of the overexpressed genes were directly related to either immune function or ECM production. Next to that, we discerned the importance of immune regulatory mechanisms in cardiac decompensation. To be able to identify gene expression patterns that bear 
individual predictive properties, we obtained minute cardiac biopsies in all Ren-2 rats, and tested whether specific expression patterns could predict either the progression to failure or the propensity to stay compensated. Eventually, this program identified galectin-3 as a novel macrophage-derived mediator that could predict the propensity to transit from compensated hypertrophy to overt cardiac failure. After these interesting abservations, we designed a second hypothesis-driven approach to investigate the role of macrophages and macrophage-derived molecule, galectin-3 for cardiac fibrosis and dysfunction. Targeted deletion of galectin-3 prevented the angiotensin II -induced cardiac dysfunction and collagen I production. Further gene deletion studies in witro showed that the mitogenic and collagen producing effect of galectin-3 in cardiac fibroblasts was mediated by a zincfinger transcription factor, early growth regulator-1. However, depletion of macrophages from hypertensive Ren-2 rats led to autoimmune cardiomyopathy, the autoantibodies being directed against heat shock protein 47 , suggesting that macrophages regulate a broad spectrum of immune homeostasis, in addition to the production of several pro-inflammatory and pro-fibrotic mediators reported in HF. Taken together, an early recognition of failure-prone hearts and intervention with newer anti-galectin-3 agents might provide additional benefit over existing treatment strategies. These results shape the concept of considering galectin-3 and its downstream mediator, $E g r-l$ as the new targets for therapeutic intervention of cardiac fibrosis and dysfunction.

\section{Future directions}

In the present thesis, we have focused on the experimental evidence suggesting that macrophage activation and release of galectin-3 play a role in disease progression in HF by virtue of the direct toxic effects on the heart. Pathophysiologically, galectin-3 induces many aspects of the so-called HF phenotype in experimental animals, including collagen deposition, cell-cycle activation and cardiac dysfunction ${ }^{5,24,25}$. Given the interesting results about the role of galectin-3 in $\mathrm{HF}$ and cardiac fibrosis, further studies are on progress to pharmacologically block galectin-3. There is evidence that soluble recombinant truncated galectin-3 (galectin-3C) can act as a dominant-negative inhibitor of galectin-3 $3^{26}$. By co-administering a functional inhibitor of galectin-3 either before or after the onset of HF, we will test whether specific blockade of gallectin-3 would protect against or reverse the functional deterioration induced by high angiotensin II. This will help us to design novel treatment strategies directed against the detrimental effects of galectin-3 for cardiac function, especially in the hypertensive animals. Further studies are also in progress to elucidate the causative role of anti-HSP47 autoantibodies for the deterioration of cardiac function in a rat model. Finally, these observations can potentially be translated to predict and treat human HF. 


\section{References}

1. Savage $\mathrm{DD}_{i}$ Garrison RJ, Kannel WB, Levy $\mathrm{D}_{*}$ Anderson SJ, Stokes $\mathrm{J}$, 3rd, Feinleib M, Castelli WP. The spectrum of lefi ventricular hypertrophy in a general population sample: the Framingham Study. Circulation. $1987 ; 75: 126-33$.

2. Schroen B, Heymans S, Sharna U, Blankesteijn WM, Pokharel S, Cleutjens JP, Porter JG, Evelo CT, Duisters $\mathrm{R}_{\text {; }}$ Van Leeuwen RE, Janssen BJ, Debets JJ, Smits JF, Daemen MJ, Crijns HJ, Bornstein P, Pirto YM.

Thrombospondin-2 Is Essential for Myocardial Matrix Integrity. Increased Expression Identifies Failure-Prone Cardiac Hypertrophy. Circ Res. 2004.

3. Sharma UC, Pokharel S, Evelo CT, Maessen JG. A systematic review of large scale and heterogeneous gene array data in heart failure. J Mol Cell Cardiol. 2005;38:425-32.

4. Fiein S, Arnon E, Kostin S, Schonburg M, Elsasser A, Polyakova V, Bauer EP, Klowekorn WP, Schaper J. Progression from compensated hypertrophy to failure in the pressure-overloaded human heart: structural deterioration and compensatory mechanisms. Circulation. 2003; 107:984-91.

5. Sharma UC, Pokharel S, van Brakel TJ, van Berlo JH, Cleutjens IP, Schroen B, Andre S, Crijns HJ, Gabius HJ, Maessen J, Pinto YM. Galectin 33 marks activated macrophages in failure-prone hypertrophied hearts and contributes to cardiac dysfunction. Circulation. 2004:110:3121-8.

6. Schroen B, Heymans S, Sharma U, Blankesteijn WM, Pokharel S, Cleutjens JP, Porter JG, Evelo CT, Duisters $\mathrm{R}_{\mathrm{s}}$ wan Leeuwen RE, Janssen BJ, Debets JJ, Smits JF, Daemen MJ, Crijns HJ, Bomstein P, Pinto YM. Thrombospondin-2 is essential for myocardial matrix integrity: increased expression identifies failure-prone cardiac hypertrophy. Circ Res. 2004;95:515-22.

7. Schena M, Shalon D, Davis RW, Brown PO. Quantitative monitoring of gene expression partens with a complementary DNA microarray. Sctence. 1995;270:467-70.

8. Frantz S, Batuersachs J, Kelly RA. Innate immunity and the heart. Curr Pharm Des. 2005; 11:1279-90.

9. Sharma UC, Pokharel S, van Brakel T, van Berlo JH, Cleutjens JPM, Schroen B, André S, Crijns HJGM, Gabius HJ, Maessen JG, Pinto YM. Galectin-3 Marks Activated Macrophages in Failure Prone Hypertrophied Hearts and Contributes to Cardiac Dysfunction. Circulation (on press). 2004.

10. Nangia Makker P, Hogan V, Honjo Y, Baccarini S, Tait L, Bresalier R, Raz A. Inhibition of human cancer cell growth and metnstasis in sude mice by oral intake of modified citrus pectin. INar/ Cancer Host. 2002;94:1854. 62.

11. Lahm H, Andre S. Hoeflich A, Kaltmer H, Siebert HC, Sordat B, von der Lieth CW, Wolf E, Gabius HJ. Tumor galectinology: insights into the complex network of a family of endogenous lectins. Glycoconj $J$. $2004 ; 20: 227-38$.

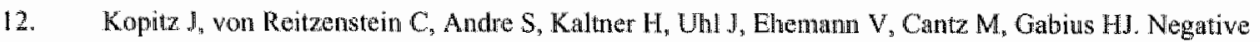
regulation of neuroblastoma cell growth by carbohydrate-dependent surface binding of galectin- $I$ and function at divergence from galectin-3. J Biol Chem. 2001;276:35917-23.

13. Lanren S. How the Inmune System Works. In. 1st ed: Blackwell Science; 1999:57-61

14. Funck RC, Wilke A, Rupp H, Brilla CO. Regulation and role of myocardial collagen matrix remodeling in hypertensive heart disease. Adv Exp Med Biol. 1997;432:35-44. 
15. Weber $\mathrm{KT}$, Sun Y, Giuarda $\mathrm{E}$ Structural remodeling in hypentensive heart disease and the rolle of homones. Typertension. 1994;23;869-77.

16. Schellings MW, Pinto YM. Heymans S. Matricellular proteins in the heart: possible role during stress and remodeling Cardionasc Res. $2004,64: 24-31$.

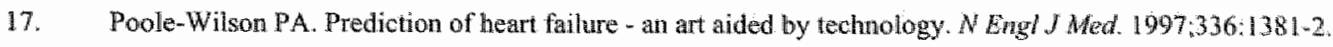

18. Singh $\mathrm{K}$, Sirokman $\mathrm{G}$, Communal $\mathrm{C}$, Robinson $\mathrm{KG}$, Conrad CH, Brooks WW, Bing OH, Colucc WS. Myocardial osteopontin expression coincides with the development of heart failure. Hypertension. $1999 ; 33: 663-70$.

19. Striker GE, Mannik M, Tung MY. Role of marrow-deriwed monocytes and mesangial cells in removal of immune complexes from reval glomenti. J Exp Med. 1979;149;127-36.

20. MacLellan WR, Lusis AJ. Dilated cardiomyopathy: leaming to live with yourself. Mat Med. 2003,9:1455-6.

21. Eriksson U, Ricci R, Hunziker L, Kurter MO, Ondit GY, Watts TH, Sonderegger I, Bachmaier K, Kopf M., Penninger $\mathrm{M}$. Dendritic cell-induced autoimmune heart failure requires cooperation between adaptive and innate immunity. Nat Med. 2003,9:1484-90.

22. Mam DL, McMurray Jj, Packer M, Swedberg K, Borer JS, Colucci WS, Djian J, Drexlar H, Feldman $A$, Kober L, Krum H, Liu P, Nreminen M, Tavazzi L, Van Veldhuisen DJ, Waldenstrom A, Warren M, Westheim A, Zannad F, Fleming T. Targeted Anticytokine Therapy in Pationts With Chronic Heart Fainure: Resuls of the Randomized Etanercept Wonldwide Evaluation (RENEWAL). Circhation, 2004.

23. Cohen PL, Carichio R, Abraham V, Camenisch TD, Jennette JC, Roubey RA, Earp HS, Matsushuma G, Reap EA. Delayed apoptotic cell clearance and hupus-like autoimmunity in mice lacking the c-mer nambrane tyrosine kinase $J$ Exp Med. 2002;196:135-40.

24. Lim FT, Patterson RJ, Wang JL. Intracellular functions of galectins. Biochim Biophys Acra. 2002;1.572:263-73.

25. Priceif F, Leto $G$, Amadio $\mathbb{L}_{\text {, }}$ lacobini $\mathrm{C}$, Romeo $\mathrm{G}$, Cordone $\mathrm{S}$, Gradini R, Barsotti P, Liu FT, Di Mario U, Pugliese $\mathrm{G}$. Role of galectin-3 as a receptor for advanced glycosylation end products. Kidney Im Suppl. $2000 ; 77: 531-9$

26. John CM, Lefter H, Kahl-Knutsson B, Svensson 1, Jarvis GA. Truncated galectim-3 inhibits tumor growith and metastasts in orthotopic nude mouse model of human breast cancer. Cha Cancer Rex. 2003;9:2374-83. 
Chapter 8 


\section{Summary}

Although hypertension leads to left ventricular hypertrophy, not all hypertrophied hearts ultimately transit to develop heart failure. Hypertensive hearts initially adapt to an increased workload by increasing the size of myocytes and altering the level of matrix composition. More impontanty, the failing myocardium shows increased expression of cell adhesion molecules, local infiltration of macrophages and local and systemic surge of various cytokines. In addition, the failing hearts show the abundant fibrillar collagen deposition. Inflammatory mediators induce progressive damage of the myocardium, adversely affect the contractile ability and finally trigger fibrosis. Excess collagen renders the ventricles stiffer and heterogeneous, thus increasing the propensity to develop rapid functional deterioration. Although macrophages are the uniform accompaniments of failing hearts, we lack a clear evidence to show whether their presence is detrimental or protective. Evidence gathers for the detrimental role of macrophages in heart failure, but at the same time, antagonizing the cytokines primarily produced by macrophages or depleting macrophages from the system, leads to worsened cardiac function and increased mortality. In this thesis we dissect the beneficial ws. detrimental effects of macrophages and suggest novel strategies to specifically target the molecules that contribute to the development of cardiac function, while sparing the immune-regulatory and homeostatic effects of macrophages.

Chapter 1 comprises the general introduction to the thesis and a short description of the Ren-2 rat model that was used to perform most of the experiments described in this thesis. This chapter also briefly discusses about the unbiased (genomic) and hypothesis-driven approaches to identify novel molecules involved in heart failure and their potential role to initiate the process of cardiac dysfunction before heart failure is clinically overt. In addition, this chapter describes the role of macrophages to scavenge the tissue debris and immune complexes.

Chapter 2 analyzes and critically discusses the database presented from 14 published studies that showed the gene expression profile in heart failure using microarray as a primary tool. After comparing the diverse database from these studies, it explains the protein transtational, matricellalar, immunological and fibrosis-related mechanisms in HF. In addition to previously annotated genes, this work analyzes two differentially expressed Expressed Sequence Tags (ESTs) (KIAA0152 and SGT1) in HF and shows how bio-informatic analysis of ESTs can lead to the identification of novel pathways active in $\mathrm{HF}$.

Chapter 3 describes the cDNA microarray strategies to identify the differentially expressed genes during the transition from compensated hypertrophy to heart failure in homozygous Ren-2 rats. 
Many of the identified genes have been reported to encode proteins with known functions whereas others correspond to genes of unknown functions, including novel genes previously not implicated in HF. Galectin-3 was identified as the most robustly owerexpressed gene in heart failure.

Chapter 4 documents that increased expression of the macrophage-derived mediator gallectin-3 is already apparent in the stage of compensated hypertroplyy of failure-prone hearts, before they progress to overt failure. This also demonstrates that galectin-3 induces HF in normal rats. These findings indicated that inflammatory and pro-fibrotic mediators can be viable therapeutic targets in HF .

Chapter 5 explains about a novel technique that can be used to visualize the apoptosis-specific membrane changes in the monocytes and macrophages. This chapter describes the clodronateinduced membrane apoptotic changes in monocytes and macrophages in wivo, in which Anx-VOregon green is used as the detection probe.

Chapter 6 is devoted to explain the findings of macrophage depletion and its impact on cardiac function in hypertension-induced cardiac hypertroplyy. Macrophage-depleted hearts show deteriorated cardiac function, excess helper T-lymphocyle infiltration and focal loss of cardiomyocytes. In addition, the sera from these animals harbor autoantibodies that are reactive against heat shock protein-47, a highly immunogenic protein expressed by cardiac fibroblasts and cardiomyocytes.

Chapter 7 demonstrates that targeted deletion of galectin-3 gene in a mouse model with Ang II infusion results in preserved cardiac function and prevention of Ang II-induced collagen deposition in the myocardium. Infusion of galectin-3 in a rat model leads to cardiac collagen deposition, $E g^{r}-1$ expression and functional deterioration. Deletion of Egr-I expression by siRNA prevents the galectin-3-induced cardiac fibroblast proliferation and collagen I production in cultured rat cardiac fibroblasts.

In conclusion, this thesis unravels how macrophages are involved in the pathogenesis of heart failure and demonstrates an unsuspected and novel mechanism of early macrophages activation in failure-prone hypertrophied hearts. Galectin-3 is a critical macrophage-derived cytokine that mediates the process of myocardial cellular growth, collagen deposition and ultimately, cardiac dysfunction. However, macrophages are physiologically important because these cells are crucial for immune homeostasis. Research is in progress to specifically block the effect of galectin-3 and check whether this strategy would protect against or reverse the cardiac functional deterioration induced by high angiotensin Il. 


\section{Samenvatting}

Hoewel hypertensie tot linker ventrikel hypertrofie leidt, wil dat niet zeggen dat alle lhypertrofische harten uiteindelijk hartfalen ont wikkenen. Bij hoge bloeddruk past het hart zich aanvankelijk aan een verhoogde werkbelasting aan, door vergroting van myocyten en door de matrixsamenstelling aan te passen. Wat nog belangrijker is dat in het falend hartwefsel, de expressie van celadhesie moleculen wordt verhoogd, lokale infiltratie van macrofagen plaats vindt en modulatie van diverse cytokines op lokal en systemisch niveau. Bovendien vertonen falende harten overvloedige vezelachtige collageendepositie. De ontstekingsmediatoren veroorzaken progressieve schade aan het myocardium, beînvloeden op een ongunstige wijze de contractiliteit en brengen tot slot verbindweefseling teweeg. Het bovenmatig collageen maakt de ventrikels stijver en heterogeen, hetgeen snelle functionele achteruitgang bevorderd. Hoewel macrofagen in falende harten altijd aanwezig zijn, ontbreekt hard bewijs dat duidelijk maakt of hun aanwezigheid een schadelijke of beschermende rol speelt. Ondanks dat bewijs voor een schadelijke rol van macrofagen in hartfalen toeneemd, blijkt depletie van macrofagen of het antagoneren van cytokines die hoofdzakelijk door macrofagen worden geproduceerd te leiden tot verslechtering van de hartfunctie en toename van de mortaliteit. In dit proefschrift ontleden wij de voordelig versus de schadelijke gevolgen van macrofagen en stellen we nieuwe strategieën voor om specifiek die moleculen die bijdragen tot ontwikkeling van hartfalen te attaqueren, terwijl de immuno-regulatoire en homeostatische effecten van macrofagen worden gespaard.

Hoofdstuk 1 bestaat uit de algemene inleiding van dit proefschrift en uit een korte beschrijving van het Ren-2 ratten model dat werd gebruikt om de meeste experimenten beschreven in dit proefschrift, uit te voeren. Dit hoofdstuk bespreekt ook kort de onbevooroordeelde (genomic) en de hypothese-gedreven benaderingen om nieuwe moleculen te identificeren betrokken bij hartfalen en bespreekt hun potentiële rol bij de initiatie van processen die lijden tot hartfalen, voor het klinisch evedent is geworden. Bovendien beschrijft dit hoofdstuk de rol van macrofagen bij het opruimen van weefselpuin en immuuncomplexen.

Hoofdstuk 2 bespreekt en analyseert kritisch het gegevensbestand samengesteld uit 14 gepubliceerde studies die allen genexpressie profielen tijdens hartfalen bestudeerden, primair met. behulp van microarray. Na het vergelijken van de diverse gegevensbestanden van deze studies, worden in dit hoofdstuk de eiwit vertalende, matricellulaire, immunologische en de fibrose gerelateerde mechanismen in hartfalen uitgelegd. Naast eerder geannoteerde genen, analyseert dit werk twee differentieel tot expressie gebrachte Uitgedrukte Markeringen van de Opeenvolging 
(ESTs) (KIAA0152 en SGT1) in HF en toont aan hoe de bio-informatic analyse van ESTs tot de identificatie van nieuwe wegen kan leiden actief in HF. Hoofdstuk 3 beschrijft cDNA microarray strategieen om de tijdens de overgang van gecompenseerde hypertrofie naar hartfalen differentieel witgedrukte genen te identificeren, in homozygote Ren-2 ratten. Van veel van de geïdentificeerde genen is beschreven dat zij coderen voor eiwitten met een bekende functie terwijl anderen corresponderen met genen met onbekende functies, inclusief nieuwe genen niet die eerder bij HF zijn beschreven. Galectin-3 werd aangewezen als het meest krachtig tot overgexpressie gebrachte gen in hartfalen. Hoofdstuk 4 documenteert dat toegenomen expressie van de macrophageafgeleide mediator galectin-3 reeds duidelijk is in het stadium van gecompenseerde hypertrofie van mislukking-naar voren gebogen harten, alvorens zij hartfalen ontwikkelen. Dit laat ook ziet dat galectin-3 hartfalen bij normale ratten veroorzaakt. Deze bevindingen wezen erop dat de ontstekingsmediatoren- en fibrotische bevorderende mediatoren reële aanknopingspunten kunnen zijn bij de behandeling van hartfalen.

Hoofdstuk 5 bespreekt een nieuwe techniek die kan worden gebruikt om apoptose-specifieke membraanveranderingen in monocyten en macrofagen te visualiseren. Dit hoofdstuk beschrijft de clodronate-geinduceerde membraan apoptotische veranderingen in monocyten en macrofagen in vivo, waarbij Annexine V Oregon Green als detectielabel wordt gebruikt.

Hoofdstuk 6 is toegewijd aan de bevindingen na macrofagen depletie en het effect hiervan op de hartfunctie in hypertensie-veroorzaakte (hart)hypertrofie. De macrophage-uitgeputte harten vertonen een verslechterde hartfunctie, bovenmatige helper T-Lymfocyten infiltratie en haardvormig verlies van cardiomyocytes. Bovendien, bevat het serums van deze proefdieren autoantilichamen tegen heat shock eiwit 47 , een hoogst immunogeen eiwit dat door cardiale fibroblasten en cardiomyocytes tot expressie wordt gebracht.

Hoofdstuk 7 toont aan dat de gerichte uitschakeling van het galectin-3 gen in een muismodel met de infusie van Angiotensine II, resulteert in behoud van de hartfunctie en preventie van Ang IIgemedieerde collageendepositie in het myocardium. De infusie van galectin-3 in een rattenmodel leidt tot cardiale collageen depositie, Egr-1 expressie en functionele verslechtering. De schrapping van egr-I expressie door middels van siRNA verhindert galectin-3-gemedieerde cardiale fibroblastenproliferatie en collageen I productie in in kweek gebrachte ratten cardiale fibroblasten. Samenvattend, ontrafelt deze thesis hoe macrofagen bij de pathogenese van hartfalen betrokken zijn en legt een onverwachte en nieuw mechanisme van wroege macrofagen activering in mislukking- 
naar voren gebogen hypertrophied harten bloot: Galectin-3 is een essentiele wan macrofagenafgeleide cytokine die het proces van de myocardiale cellulaire groei, collageendepositie en uiteindelijk, cardiale disfunctie dirigeert. Nochtans, zijn macrofagen fysiologisch belangrijk omdat deze cellen woor immuun homeostase essentieel zijin. Experimenten zijn in ingang) die de mogelijkheden tot specifieke blokkering van galectin-3 bestuderen en die onderzoeken of deze strategie het hart beschermt tegen functionele verslechtering of functieverlies veroorzaakt door hoge angiotensine II-spiegels weet te herstellen. 


\section{Acknowledgements}

The words are written, read and probably forgotten, friends are not. During these 3 years, you all have impacted my life directly or indirectly; you have helped me, facilitated me and encouraged me to move along in this profession of medical research that has no ends and no limitations.

My first words go to Dr. Yigal M Pinto, who has not only guided me with his outstanding scientific acumen and generosity of ideas, but also by his unflappable considerate attitude. Professor Maessen, I sincerely thank you for your continuous encouragement and support, no matter which side of the wall or world I was working in. You gave me the opportunity to learn how a human can be humane and how mutual trust and reliance ultimately lead to self-dependence. Professor Crijns, you always amazed me with your astute words and consistent smile. Your continuous interest on my research and your encouragement always reinforced my determinations. You always had adequate time to show concern on what $\mathbb{I}$ was doing and ask how my little family were striving in Maastricht. Professor Oscar A Carretero, despite your incredibly busy agenda, your door was always open for me. I still do have lot to learn from you but you have already taught me how the learning curve is never-ending. I always enjoyed having several ad-hoc conversations with you about T-lymphocytes and macrophages. Professor Harry Struiker-Boudier, I feel proud to be the member of your big research family, CARIM and your contributions to lighten our career are incalculable. Professor Jos Smits, your benevolence for my career in Maastricht always remained helpful.

I would like to thank Ben Janssen, Mataijs Blankesteijn, Rob Hermans, Marc van Bilsen, Jack Cleutjens, Adriaan Duivesteijn, Peter Heeringa, Menno de Winther, Mat Daamen, Martin Hofker and Leo Hofstra for keeping all the doors open for a newcomer like me, who knew very little about the Dutch System and spoke no Dutch. I would like to express my gratitude to Suzanne Janssen, Rick van Leeuwen, Wouter Verhesen and Rudy Duisters for the experimental and computer assistance, Blanche Schroen, Mark Schellings, Nard and Veronica for all your help and joyous conversation. I am thankful to Bianca, Emmy, Christal, Jacqueline and Miriam for their secretarial assistance. I also would like to thank, Alexandra Bühler, Bianca Schrans, Henny Schulten, Andris Gilde, Pascal Smeets, Peter Willemson, Paul Volders, Stephane Heymans and Steffan Vób for your help, friendly conversation and humor.

I am also grateful to the colleagues from the Department of Clinical Pharmacology where I felt always at ease to work and enjoyed sharing a moment with a cup of coffee. I am especially thankful 
to Jos Paquay for his willingness to offer help all the time; Monica Huiben, Susanne van den Borne, Geraldine Cohuet and Markus Baumann for creating friendly environment. Thank you Chris, Stan. and Rachael for all your help regarding the bio-informatics. I am also gratefull to the colleagues involved in the anmal laboratory of the Department of Pharmacology namely, Helma van Essen, Jacques Debets, Nicole Bitsch, Agniske and Peter for technical assistance.

Lysette, your contribution for the completion of my $\mathrm{PhD}$ is exemplary. Without your consistency, anity and promptness, it would not be possible for me to come this far. I always enjoyed sharing the thoughts about our family. Thomas, you are not only a tall and intelligent Dutch man, your scholarship, hard-working attitude and sense of humor are unmatchable. I still do remember your joke on "Acute Bum-out Syndrome". Thank you for staying till late to help me complete some of my critical experiments. I would also like to thank my wonderful colleagues in Cardiothoracic Surgery who always extended their friendship and good wishes while I was working there. Thank you Theo, Eric (both), Paul, Koen, Loes, Rob, Antoine, Nard, Jan, Yvonne and Chris. Thank you Professor Mochtar for all your encouragement and good wishes. I am grateful to my friends Ryan Accord and Robby Nieuwlaat who will provide moral support as "paranymphs" during the defense of my thesis. Roland, Robby, Jop, Veerle and Geert: thank you for the innumerable things you have done for me and my little family and I hope our friendship will keep growing while being on the other continent. Dr. Braat, thanks for teaching me how to play indoor football/basketball in Maastricht.

Il would like to give my special thanks to my very best friends Carl-Heinz Reinders and Mechthild Mangelmann whom I adore more than anybody else. Your continuous support, encouragement and benevolence are meagerly described by these words. I would like to thank Dr. BN Rana and Renate Rana from Germany for their continuous support during my medical education. Also, many thanks to all my friends in Nepal and my special thanks to Dr. Lok Bikram Thapa for his support when it was most needed. I an forever indebted to my parents, brothers, sisters and all other family members for their enormous love, care and endless parience, as I have become your rare guest in the last years. Finally, I an grateful to my wife Saraswati Pokharel for her continuous moral and academic support and to my little son Rosan who has made me feel "everything is possible", made me smile even when I am stressed and taught me to play and enjoy. At last, I thank everybody who is directly or indirectly related to my journey of life and whom I might have unintentionally forgotten to mention their names. 


\section{Curriculum vitae}

Umesh Chandra Sharma was born on August 28, 1972 in Okhatari, Nepal. After completing the high school education from Shantipur, Gulmi in 1989, he enrolled to Tribluwvan University, Anrit Science College for Intermediate of Science (ISc) studies. Shortly after the completion of ISc, he was chosen to start medical studies in Tribhuvan University, Central Campus Kathmandu, the only medical college existing in Nepal during that time. After completing the medical school training including one-year of compulsory rotating internship, he decided to develop his career abroad. From January to March 2000, he worked as a visiting fellow in the Department of Nephrology at Middlesex Hospital, London, United Kingdom. Subsequently, the author gained interest in the field of Immunology and completed Masters Degree in Medical Immunology from St. George's Hospital, University of London in October 2002. The same month, he joined PhD programme in the Department of Cardiothoracic Surgery and the Department of Cardiology, Academic Hospital Maastricht/ Cardiovascular Research Institute Maastricht, University of Maastricht. As a participant of Inter-institutional student exchange program, the author completed the final year of his $\mathrm{PhD}$ training in Hypertension and Vascular Research Division, Henry Ford Hospital, Detroit, USA.

As recognition of his research excellence and hard work, he received several awards and honors during his career as a student and research fellow. He received a Scholarship from Rotary International and German Nepal Help Association for completing his medical studies. He also received young investigator travel awards from European Society of Hepatology (2002), European Society of Pediatric Gastroenterology, Hepatology and Nutrition (2002), European Council of Cardiovascular Research (2003) and South of Limburg Fund (2004). The author is also a recipient of Pre-Doctoral Fellowship from American Heart Association for continuing his research on the role of galectin-3 for the development of cardiac dysfunction. 


\section{List of Publications}

1. Primary biliary cirrhosis is characterized by $\operatorname{IgG} 3$ antibodies cross-reactive with the major mitochondrial autoepitope and its Laciobacillus mirnic. Bogdanos DP, Baum H, Okamoto $M$, Montalto P, Sharma UC, Rigopoulou EI, Vlachogiannakos J, Ma Y, Burroughs AK, Vergani D. Hepatology 2005, Volume: 42, Pages: 458-65

2. Mice lacking Galectin-3 exhibit preserved cardiac function and decreased fibrosis following angiotensin II infusion. Sharma UC, Pokharel S, Gabius H, Carretero OA, Pinto YM. Manuscript Submitted

3. A systematic review of large scale and heterogeneous gene array data in heart failure. Sharma UC, Pokharel S, Evelo CT, Maessen JG. Journal of Molecular and Cellular Cardiology, 2005, Volume: 38 , Pages: 425-32

4. Real-time in vivo imaging of membrane-specific apoptotic changes in monocytes and macrophages. Sharma UC, Hofstra L, Pinto YM and JG Maessen. Apoptosis, 2005, Volume: 10, Pages: $1187-1190$

5. Immune evasion and anergy in viral infection of the myocardium. Sharma UC, Pokharel S, Maessen JG. Circulation 2005 (Letter in Press)

6. Parvovirus B 19 could have induced autoimmune reaction in the heart. Sharma UC, Pokharel S, Maessen JG. Circulation, 2005 (Letter in Press)

7. Galectin-3 marks activated macrophages in failure-prone hypertrophied hearts and contributes to cardiac dysfunction. Sharma UC, Pokharel S, wan Brakel TJ, van Berlo JH, Cleutjens JP, Schroen B, Andre S, Crijns HJ, Gabius HJ, Maessen J, Pinto YM. Circulation, 2004, Volume: 110, Pages: $3121-28$

8. Increased myocardial collagen content in transgenic rats overexpressing cardiac angiotensinconverting enzyme is related to enhanced breakdown of N-acetyl-Ser-Asp-Lys-Pro and increased phosphorylation of Smad2/3. Pokharel S, van Geel PP, Sharma UC, Cleutjens JP, Bohneneier H, 
Tian XL, Schunkert H, Crijns HJ, Paul M, Pinto YM. Circulation, 2004, Volume: 110, Pages: 3129-35

9. Thrombospondin-2 is essential for myocardial matrix integrity: increased expression identifies failure-prone cardiac hypertrophy. Schroen B*, Heymans $S^{*}$, Sharma UC* Blankesteijn WM, Pokharel S, Cleutjens JP, Porter JG, Evelo CT, Duisters R, van Leeuwen RE, Janssen BJ, Debets JJ, Smits JF, Daemen MJ, Crijns HJ, Bornstein P, Pinto YM. Circulation Research, 2004, Volume: 95, Pages: $515-22$ (* These authors contributed equally to this work)

10. Systematic review of the outcome of aortic valve replacement in patients with aortic stenosis. Sharma UC, Barenbrug P, Pokharel S, Dassen WR, Pinto YM, Maessen JG. Annals of Thoracic Surgery, 2004, Volume: 78, Pages: 90-95

11. Left ventricular hypertrophy: virtuous intentions, malign consequences. Pokharel S, Sharma UC, Pinto YM. Int J Biachem Cell Biol, 2003, Volume: 35, Pages: 802-806

12. Antibodies against homologous microbial caseinolytic proteases $P$ characterise primary biliary cirrhosis. Bogdanos DP, Baum H, Sharma UC, Grasso A, Ma Y, Burrouglas AK, Vergani D. Jonrnal of Hepatology, 2002 , Volume: 36, Pages: 14-21 


\section{Awards}

1. Best poster award (Cardiac Biology): $8^{\text {th }}$ Annual meeting of the European Council for Blood Pressure and Cardiovascular Research, 2003

2. Nepal Pediatrics Society Gold Medal (2000): Designated to the best performing medical student in Pediatrics

3. Dr Anjani Kumar Gold Medal (2000): Designated to the best performing medical student in Surgery

4. Rom Bhadra Gold Medal (2000): Designated to the best performing medical student in Anatomy

5. Siddi Mani Dixit Gold Medal (2000): Designated to the best performing medicall student in MBBS final phase examination 